\title{
Synthesis and Catalytic Applications of Non-Metal Doped Mesoporous Titania
}

\author{
Syed Z. Islam ${ }^{1}$, Suraj Nagpure ${ }^{1}$, Doo Young Kim ${ }^{2}$ and Stephen E. Rankin ${ }^{1, *}$ \\ 1 Department of Chemical and Materials Engineering, University of Kentucky, \\ Lexington, KY 40506-0046, USA; syedislam@uky.edu (S.Z.I.); suraj.nagpure@uky.edu (S.N.) \\ 2 Department of Chemistry, University of Kentucky, Lexington, KY 40506-0055, USA; dooyoung.kim@uky.edu \\ * Correspondence: srankin@engr.uky.edu; Tel.: +1-859-257-9799
}

Academic Editor: Samuel Bernard

Received: 6 January 2017; Accepted: 7 March 2017; Published: 11 March 2017

\begin{abstract}
Mesoporous titania $\left(\mathrm{mp}-\mathrm{TiO}_{2}\right)$ has drawn tremendous attention for a diverse set of applications due to its high surface area, interfacial structure, and tunable combination of pore size, pore orientation, wall thickness, and pore connectivity. Its pore structure facilitates rapid diffusion of reactants and charge carriers to the photocatalytically active interface of $\mathrm{TiO}_{2}$. However, because the large band gap of $\mathrm{TiO}_{2}$ limits its ability to utilize visible light, non-metal doping has been extensively studied to tune the energy levels of $\mathrm{TiO}_{2}$. While first-principles calculations support the efficacy of this approach, it is challenging to efficiently introduce active non-metal dopants into the lattice of $\mathrm{TiO}_{2}$. This review surveys recent advances in the preparation of $\mathrm{mp}-\mathrm{TiO}_{2}$ and their doping with non-metal atoms. Different doping strategies and dopant sources are discussed. Further, co-doping with combinations of non-metal dopants are discussed as strategies to reduce the band gap, improve photogenerated charge separation, and enhance visible light absorption. The improvements resulting from each doping strategy are discussed in light of potential changes in mesoporous architecture, dopant composition and chemical state, extent of band gap reduction, and improvement in photocatalytic activities. Finally, potential applications of non-metal-doped $\mathrm{mp}-\mathrm{TiO}_{2}$ are explored in water splitting, $\mathrm{CO}_{2}$ reduction, and environmental remediation with visible light.
\end{abstract}

Keywords: mesoporous; titania; non-metal doping; catalysis; photocatalysis; self-assembly

\section{Introduction}

$\mathrm{TiO}_{2}$ (titania) is one of the most extensively studied semiconductor photocatalysts due to its potential to help overcome the worldwide energy shortage while also counteracting issues of climate change and environmental contamination [1-3]. Since the first report of its use for hydrogen generation via the photocatalytic decomposition of water by Fujishima and Honda [4], $\mathrm{TiO}_{2}$ has attracted significant interest as a photocatalyst due to its favorable band edge positions, which are well-matched with the redox potentials of water, $\mathrm{CO}_{2}$, and a variety of organic compounds. $\mathrm{TiO}_{2}$ is also attractive for this application because of its opto-electronic properties, which can be tuned by changing lattice defects or oxygen stoichiometry, its superior chemical stability and photocorrosion resistance, and its low cost [4-8]. These unique properties have enabled $\mathrm{TiO}_{2}$ to be utilized in a wide range of applications including solar energy conversion, antimicrobial and self-cleaning surfaces, paint whiteners, ceramics, textiles, personal care products, and environmental catalysis [9-19].

Like many semiconductors, the photoactivity of $\mathrm{TiO}_{2}$ originates from its ability to absorb light with energy greater than its band gap, which generates electrons and holes as charge carriers by promoting electrons from the valence band to the conduction band [5]. This photocatalytic process involves a series of physical processes including light absorption, charge separation, charge migration, charge recombination, and surface redox reactions [20]. The photogenerated charges can recombine 
and release their energy as light and heat, or these excited charges may reach the surface of titania and participate in reactions. The excited electrons have the potential to reduce oxygen molecules to produce superoxide radicals that are very reactive and participate in different reactions. On the other hand, if they reach the electrolyte interface either at titania or a counter electrode, holes are able to oxidize water to produce reactive hydroxyl radicals [21].

Despite many attractive features of $\mathrm{TiO}_{2}$, the major challenges of its applications under natural solar light are its innate inability to absorb visible light, a high rate of photogenerated charge carrier recombination, and a low interfacial charge transfer rate of photogenerated charge carriers $[9,22]$. The first challenge results from the wide band gap of $\mathrm{TiO}_{2}$ (3.0-3.5 eV [23]), which allows the absorption of light mainly in the ultraviolet (UV) range. UV light corresponds to only $4 \%-5 \%$ of the whole solar spectrum, while visible light constitutes 40\% [24]. To reduce the intrinsic band gap of $\mathrm{TiO}_{2}$, several strategies have been tested including the incorporation of either metallic (e.g., Fe and Ni) or non-metallic (e.g., C, F, N, S, P, and B) atoms into the lattice of $\mathrm{TiO}_{2}$ host materials $[9,15,25-27]$. Metal doping has shown controversial photocatalytic activity results at both UV and visible wavelengths [28-31]. In addition, metal doping in titania can be complicated by thermal instability, an increase of carrier-recombination centers, dopant insolubility, the formation of secondary phases or surface aggregation rather than substitution, phase transformation among the titania polymorphs, the alteration of charge carrier diffusion length, narrow band bending, etc. [32-34]. From this perspective, non-metal doping is thought to be a more viable strategy to reduce the band gap and enhance the visible light driven photocatalytic activity of titania. Increased visible light photocatalytic activity has been reported in non-metal-doped titania. However, the exact chemical nature of the dopant species in titania and their roles for visible light absorption are not always clear [21].

Among non-metal dopants, nitrogen is one of the most effective elements to promote visible light photoactivity $[9,10,35-37]$. Due to its atomic size (comparable to oxygen), low ionization potential, and high stability, introducing nitrogen into the titania lattice is straightforward [21]. Effective band gap narrowing has been correlated with high amounts of dopants and strong interactions among the dopant energy states, valence, and conduction bands [38]. Nitrogen atoms are known to occupy either interstitial sites (possibly with $\mathrm{N}-\mathrm{O}$ bonding) or substitutional sites (replacement of $\mathrm{O}$ with $\mathrm{N}$ atoms) in $\mathrm{TiO}_{2}$ [36]. Though interstitial nitrogen has been shown to increase visible light absorption, it does not reduce the band gap because it forms a discrete energy state between the valence band and conduction band, often referred to as a midgap state [39]. Most of the theoretical and experimental studies have shown that the predominant active form in doped $\mathrm{TiO}_{2}$ is substitutional nitrogen which reduces the band gap and increases visible light absorption [9,36,39-42]. The reduced band gap is attributed to an upward shift of the edge of valence band due to the hybridization of the N $2 p$ with the $\mathrm{O} 2 \mathrm{p}$ orbitals [9]. As a result, doped titania is able to absorb visible light due to the electrons excited from the localized $\mathrm{N}$ orbitals to the conduction band or to surface adsorbed $\mathrm{O}_{2}$ [21]. In addition, it has been reported that nitrogen doping increases the wettability of titania, resulting in better adsorption of polar reactant molecules $[29,43]$.

Other non-metal elements such as $\mathrm{H}, \mathrm{B}, \mathrm{C}, \mathrm{F}, \mathrm{I}, \mathrm{S}$, and $\mathrm{P}$ have also been doped into $\mathrm{TiO}_{2}$ and visible light driven photocatalytic activity was observed as a result [44,45]. Valentin et al. performed density functional theory (DFT) calculations to investigate the effects on the electronic structure of replacing lattice $\mathrm{O}$ atoms with $\mathrm{B}, \mathrm{C}, \mathrm{N}$, or $\mathrm{F}$ dopants, or to include the same atoms in interstitial positions [44]. As Figure 1 shows, the energy states associated with substitutional non-metal dopants fall in between the valence and conduction bands of $\mathrm{TiO}_{2}$. Relative to the valence band, the energy level of the bands introduced by doping increases with decreasing electronegativity. $\mathrm{N}$-doping introduces an energy state just above the valence band, whereas B gives states high in the band gap. Since fluorine is very electronegative, it has introduced states below the $\mathrm{O} 2 \mathrm{p}$ valence band and leads to the formation of $\mathrm{Ti}^{3+}$ ions due to charge compensation. In contrast, interstitial doping led to a combination of energy levels above and below the valence band for B and C. Without donating any electron to the host lattice, 
$\mathrm{N}$ was predicted to form a direct bond with a lattice $\mathrm{O}$ atom to create a non-photoactive interstitial doping site.

To further improve the visible light driven photocatalytic activity of $\mathrm{TiO}_{2}$, binary and ternary co-doping of two non-metal elements such as N-B and N-C has been studied [21,46-56]. Synergistic effects of the co-doping were observed in many cases, although the complexity of the parameter space makes it difficult to draw general conclusions about doping effects. In addition to band gap reduction and visible light absorption, adding non-metal elements into $\mathrm{TiO}_{2}$ may have effects on the microstructure of the material, depending on the route of introduction. In one example, boron-doped $\mathrm{TiO}_{2}$ particles were found to have reduced size, resulting in higher surface area and suppressed phase transformation, and improved photogenerated charge separation, which significantly contributes to the photocatalytic performance of titania [57].
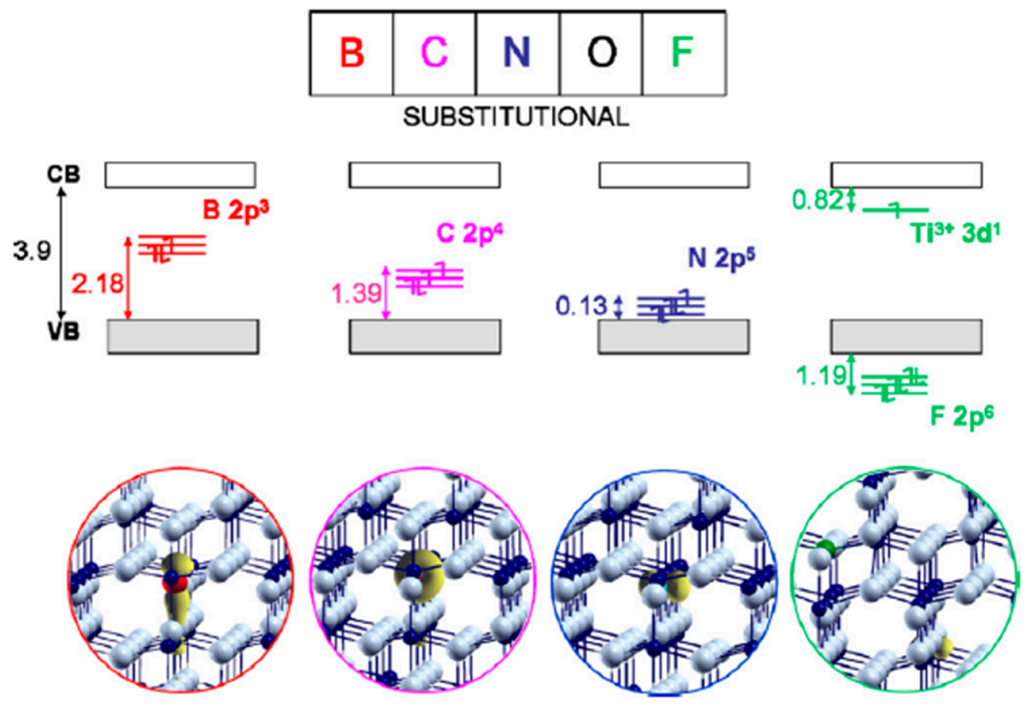

Figure 1. Schematic representation of Kohn-Sham one-electron states and spin density plot of substitutionally doped anatase $\mathrm{TiO}_{2}$. Reprinted with permission from [44]. (Reprinted from Catalysis Today vol. 206, C. Di Valentin and G. Pacchioni, “Trends in non-metal doping of anatase $\mathrm{TiO}_{2}$ : B, C, N and F", pp. 12-18, Copyright (2013), with permission from Elsevier.)

While significant positive effects of doping $\mathrm{TiO}_{2}$ have been reported, from an application and commercial point of view, the photocatalytic performance of $\mathrm{TiO}_{2}$ must be further enhanced. To address the challenges of reducing recombination and increasing interfacial transport of photogenerated charge carriers, altering the atomic and nanoscale architecture of $\mathrm{TiO}_{2}$ has become a major goal. Mesoporous $\mathrm{TiO}_{2}$ offers a promising platform to address these challenges for a number of reasons that are beneficial for efficient photocatalysis [10,58-60]. By using process variables to tune its morphology, nanostructure, and electronic properties, enhancements can be realized in the accessible surface area, light absorption, and effective charge carrier separation and transport in $\mathrm{mp}-\mathrm{TiO}_{2}$ [10,61-63]. For instance, surfactant-induced templating provides excellent control over the pore size, pore orientation, interfacial structure, and pore connectivity, which can be tuned to promote rapid diffusion of reactants to photocatalytic sites. Further, $\mathrm{mp}-\mathrm{TiO}_{2}$ films offers a high reactive surface area for photocatalysis and their thin walls provide a short distance for the transport of photogenerated charge carriers to the catalytic sites, thereby having the potential to suppress charge recombination processes $[6,58,59,64]$.

While $\mathrm{mp}-\mathrm{TiO}_{2}$ can be synthesized by different methods, it is challenging to incorporate dopants into the lattice of the material while maintaining an advantageous mesostructure and crystal phase. Normally, high-temperature heat treatment of $\mathrm{TiO}_{2}$ in the presence of a dopant source is used to incorporate new elements into the titania lattice. High temperature treatment typically causes 
a decrease in pore size, surface area, and pore accessibility by sintering and crystallization. Various strategies have been reported to introduce non-metal dopants into $\mathrm{mp}-\mathrm{TiO}_{2}$, but the properties of the doped $\mathrm{mp}-\mathrm{TiO}_{2}$ product are strongly dependent on the dopant source and strategy. For instance, we recently reported that plasma treatment of $\mathrm{mp}-\mathrm{TiO}_{2}$ introduces a high level of substitutional nitrogen into the lattice, whereas methods based on chemical precursors are more prone to generating interstitial nitrogen [65]. The photocatalytic activity of the materials is closely related to its preparation method, so understanding the relationship between synthetic strategy, structure, and performance is key to moving towards highly efficient visible-light photocatalysis using $\mathrm{mp}-\mathrm{TiO}_{2}$ based materials.

There have been a number of reviews published addressing the synthesis of $\mathrm{mp}-\mathrm{TiO}_{2}$ and its broad range of applications [66-69], so we will begin with just a brief overview of some of the most relevant strategies. In 2011, Ismail et al. published a review article on $\mathrm{mp}-\mathrm{TiO}_{2}$ photocatalysts [26] that provides an overview of the preparation and characterization of $\mathrm{mp}-\mathrm{TiO}_{2}$ and incorporation of noble metals nanoparticles, transition metal ions, and non-metal dopants. The characteristics of the mesoporous materials and their activity and mechanisms of photocatalysis are discussed. A recent short review by Zhou et al. addresses the effects of the mesoporous structure, crystallinity, surface area, and pore size of $\mathrm{TiO}_{2}$ on its photocatalytic performance [70], with a short overview of modifications of $\mathrm{mp}-\mathrm{TiO}_{2}$ using doping and composite materials. While doping has been included to some extent, the primary focus of all the reviews mentioned here was the synthesis and characterization of the $\mathrm{mp}-\mathrm{TiO}_{2}$. Considering the intense interest in visible-light photocatalysis using inexpensive materials, there is room for a review addressing primarily doping strategies and their outcomes.

This article will focus specifically on non-metal doping strategies in $\mathrm{mp}-\mathrm{TiO}_{2}$ and recent advances in understanding their effects on visible light driven photocatalytic performance for environmental and energy conversion systems. First, the general synthesis process of $\mathrm{mp}-\mathrm{TiO}_{2}$ will be presented, with an eye towards how the evolution from precursor to final mesoporous structure can be influenced by the doping strategy. Following this, a comprehensive review will be provided of non-metal dopant sources and doping strategies for $\mathrm{mp}-\mathrm{TiO}_{2}$. While fewer examples have been reported in literature, some examples of co-doping will be discussed. A summary of photocatalytic performance enhancements by non-metal doping of $\mathrm{mp}-\mathrm{TiO}_{2}$ will be provided. Finally, applications of the non-metal-doped $\mathrm{mp}-\mathrm{TiO}_{2}$ will be summarized in the fields of organic pollutant photocatalysis, hydrogen production from water splitting and $\mathrm{CO}_{2}$ reduction. Although this area of research is very broad, this review will provide a summary of key achievements and directions in the non-metal doping of $\mathrm{mp}-\mathrm{TiO}_{2}$ and the extent of applications of these materials.

\section{Synthesis of Mesoporous $\mathrm{TiO}_{2}$}

Surfactant-templated synthesis of ordered $\mathrm{mp}-\mathrm{TiO}_{2}$ was first reported by Antonelli and Ying in 1995 [71]. Since then, different mesoporous structures of $\mathrm{TiO}_{2}$ have been synthesized including 2D hexagonal, 3D cubic, and lamellar using methods including sol-gel, hydrothermal, solvothermal, microwave, and sonochemical methods [65,72-85]. A variety of morphologies have also been reported due to the interplay between mesostructure nucleation, orientation of mesophases at the surface of surfactant/precursor aggregates, and growth of organic/titania composites. Of all forms, thin $\mathrm{mp}-\mathrm{TiO}_{2}$ films are highly relevant to photoelectrocatalysis both for practical reasons (they can readily be deposited onto electrodes) and because they provide fundamental insight into the interplay of composition, processing, and surface chemistry. For instance, in our group, we have prepared $\mathrm{mp}-\mathrm{TiO}_{2}$ thin films using Pluronic triblock copolymer surfactants with cubic mesostructure [65] and orthogonally oriented 2D hexagonally close packed (o-HCP) cylindrical nanopores [82-84] using the evaporation induced self-assembly (EISA) technique by manipulating process conditions. Figure 2 shows computer-generated illustrations of typical mesoporous structures and mesophases such as Im3m cubic mesoporous material, o-HCP mesoporous film, parallel HCP mesoporous film, and lamellar mesophase where higher intensity (yellow and red) corresponds to a greater density of hydrophobic tails of the surfactant template. 


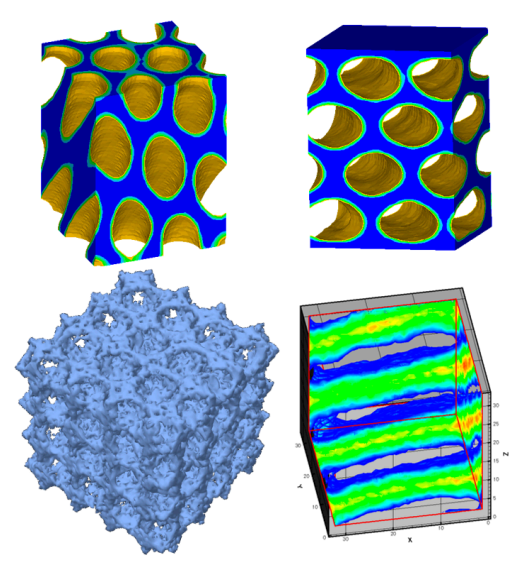

Figure 2. Computer-generated illustrations of typical mesoporous structures and mesophases. Clockwise from lower left are illustrated an Im3m cubic mesoporous material, o-HCP mesoporous film, parallel HCP mesoporous film, and lamellar mesophase where higher intensity (yellow and red) corresponds to a greater density of hydrophobic tails of the surfactant template.

\subsection{Titanium Precursor Chemistry}

Most of the doped $\mathrm{TiO}_{2}$ materials to be discussed are prepared by precipitation or sol-gel processes based on "bottom-up" growth using molecular precursors. This process proceeds by hydrolytic polycondensation of titanium precursors (most often alkoxides or chlorides) in the presence of reactivity modifiers, solvents, and organic templates. The process begins with hydrolysis, which is the formation of $\mathrm{Ti}-\mathrm{OH}$ moieties by the substitution reaction of water with Ti-Cl or Ti-OR groups (Equation (1)). After being "activated" this way, precursors undergo condensation reactions to generate $\mathrm{Ti}-\mathrm{OH}-\mathrm{Ti}$ bonds by olation (Equation (2)), or Ti-O-Ti by oxolation (Equation (3)). Livage et al. provided an excellent overview of the sol-gel chemistry of transition metal precursors [86] and described the dependence of hydrolysis reaction mechanism of metal ions on several factors including the electron affinities, sizes and the charges of metal ions and alkoxy groups, and the number of alkoxy groups. Because titanium has a high partial charge and a preferred coordination number greater than its valence, Ti precursors tend to be quite reactive towards hydrolysis. The high reactivity of transition metal oxides can be reduced by adding complexing ligands (such as acetylacetone) [87] or increasing acid concentration [88].

$$
\begin{gathered}
\text { Hydrolysis: } \equiv \mathrm{Ti}-\mathrm{X}+\mathrm{H}_{2} \mathrm{O} \rightarrow \equiv \mathrm{Ti}-\mathrm{OH}+\mathrm{XH} \text { where } \mathrm{X}=\mathrm{Cl}_{1} \mathrm{OC}_{2} \mathrm{H}_{5} \text {, etc. } \\
\text { Olation: } \equiv \mathrm{Ti}-\mathrm{OH}+\mathrm{Ti} \equiv \rightarrow \equiv \mathrm{Ti}-\mathrm{OH}-\mathrm{Ti} \equiv \\
\text { Oxolation: } \equiv \mathrm{Ti}-\mathrm{OH}+\mathrm{HO}-\mathrm{Ti} \equiv \rightarrow \equiv \mathrm{Ti}-\mathrm{O}-\mathrm{Ti} \equiv+\mathrm{H}_{2} \mathrm{O} .
\end{gathered}
$$

Kim et al. [89] proposed two kinds of mechanisms for the hydrolysis of titanium alkoxides. One is an associative mechanism, in which the entering group forms a complex with the metal first, and a detectable intermediate of expanded coordination number is then formed. The other mechanism is an interchange associative (Ia) mechanism in which the transition state is reached mostly through formation of the bond with the entering group. In this mechanism, the bond weakening of the leaving group also takes place in the course of reaching the transition state. An associative (A) mechanism is most appropriate to describe the hydrolysis of $\mathrm{Ti}(\mathrm{OEt})_{4}$, whereas the transition states for the hydrolysis for $\mathrm{Ti}\left(\mathrm{O}^{n} \mathrm{Pr}\right)_{4}$ and $\mathrm{Ti}\left(\mathrm{O}^{n} \mathrm{Bu}\right)_{4}$ are reached through the Ia mechanism. Henry et al. [90] studied the mechanistic aspects of the hydrolysis and condensation of titanium alkoxides complexed by tripodal ligands and found that bridging positions for OR groups are sites of preferential attack for substitution by $\mathrm{OH}$ and/or OX groups. Under appropriate conditions, the basic structure of the $\mathrm{Ti}_{4} \mathrm{O}_{16}$ core can be conserved upon hydrolysis and can be used as a building block for building complexes of higher nuclearity. Sanchez and coworkers [91] studied the role of water in the hydrolysis reaction in the 
presence of Pluronic surfactants and found that during anhydrous or low water conditions, there are strong Ti-polymer interactions which hinder the assembly of the template, leading to a wormlike structure. In contrast, a high water/high acid environment hinders Ti-polymer interactions, which allows the micelles to assemble into well-ordered mesostructures.

There are two main pathways for the preparation of ordered $\mathrm{mp}-\mathrm{TiO}_{2}$, soft and hard templating. The soft templating method usually proceeds by a co-assembly process of the precursors (silica, metal oxides, polymers, etc.) and surfactant templates [68]. Since the success in the synthesis of ordered mesoporous silica, this methodology has been extended to transition metal oxide analogues. Since the soft-templating method is based on the co-assembly of reacting metal oxide precursors with surfactants in a dried film, the chemistry of the precursors needs to be controlled to give the best chance of producing a desired film. As noted above, titania precursors (e.g., titanium (IV) ethoxide and titanium tetrachloride) are more reactive than silica precursors such as tetraethoxysilane, which can lead to rapid precipitation under uncontrolled conditions. Thus, titania precursors can be very difficult to work with if care is not taken in the design of the synthesis procedure.

In their synthesis, Antonelli and Ying [71] used acetylacetone to decrease the hydrolysis and condensation rate of titanates to permit assembly of well-ordered materials by interactions with the phosphate head groups of a tetradecylphosphate surfactant in aqueous solution. However, a significant amount of phosphorus remained after the surfactant template was removed leading to relatively low photocatalytic activity. In 1999, Antonelli et al. reported the synthesis of nonphosphated mp- $\mathrm{TiO}_{2}$ by using dodecylamine as the template combined with a dry aging technique [92]. However, the materials did not have high thermal stability for catalytic applications. Additionally, developing new methods of controlling the hydrolysis and polymerization of titania precursors was essential to be able to obtain high mesostructural regularity over large domains. The EISA method of Brinker and coworkers offers such an opportunity. The method was initially reported to prepare mesoporous silica thin films [93], but was almost immediately realized as the most efficient strategy to synthesize $\mathrm{mp}-\mathrm{TiO}_{2}$. Figure 3 shows schematics of the important stages of the formation of ordered nanoporous metal oxide films by EISA.
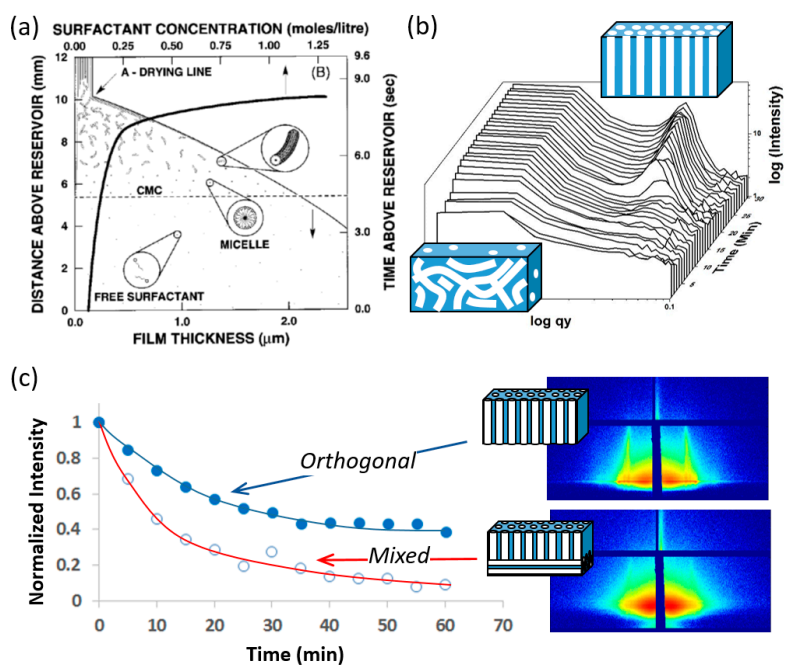

Figure 3. Schematics of the important stages of the formation of ordered nanoporous metal oxide films by EISA: (a) The dip coating process in which surfactant micelles form and may begin to assemble due to evaporation; (b) the aging process after deposition in which films organize into an ordered mesophase; and (c) high-temperature aging during which organic templates are removed by oxidation, crystallization may occur but loss of mesostructural order can happen with increasing temperature and time. Part (a) is reproduce with permission from C. J. Brinker et al. Adv. Mater. 1999 11, 579 () 1999 Wiley $\mathrm{VCH}$; (b) shows the rise of intensity from a o-HCP mesophase in a $\mathrm{TiO}_{2}$ film during aging, adapted from Nagpure et al. [82] and (c) shows the loss of intensity of the o-HCP mesophase during heating of a $\mathrm{TiO}_{2}$ film at $600{ }^{\circ} \mathrm{C}$, adapted from Das et al. [84]. 


\subsection{Surfactant-Templated Film Deposition}

Figure 3a shows the dip coating process in which surfactant micelles form and may begin to assemble due to evaporation adapted from Brinker et al. [93]. In EISA, films are prepared by dip coating of substrates from a solution containing inorganic precursors, surfactant and solvent accompanied by rapid evaporation of volatile solvents (ethanol and water) to drive the formation of an ordered mesoporous structure. One important advantage of EISA for the preparation of mesoporous transition metal based thin films is that the $\mathrm{pH}$ can initially be adjusted to stabilize the coating sol and allow gradual assembly of an ordered mesostructured after coating. In order to inhibit rapid olation and condensation of the titania precursors to allow self-assembly to occur, protons $\left(\mathrm{H}^{+}\right.$ions) have been used as inhibitors [88]. Although ligands such as acetylacetonate can also be used to reduce the reactivity of metal alkoxides, they can interfere in the interactions between titanium species and surfactants, so $\mathrm{H}^{+}$ is a more widely used inhibitor in the synthesis of surfactant templated $\mathrm{mp}-\mathrm{TiO}_{2}$ films [94-97]. Using a highly acidic sol prevents uncontrolled condensation of transition metal precursors, which allows slow formation of the inorganic network within the liquid crystal mesophase formed after coating. Gradual elimination of the acid by evaporation provides a way to control the polymerization of the inorganic components while allowing a fully cured inorganic network to form [98].

In addition to precursor chemistry, the choice of structure directing agent has a vital influence over the final mesostructure formed in surfactant-templated titania films [94,99]. For example, using titanium isopropoxide as inorganic precursor, films with an columnar 2D hexagonal close packed (HCP) mesostructure were reported using the Pluronic surfactant P123 (a triblock copolymer with average formula $\mathrm{EO}_{20} \mathrm{PO}_{70} \mathrm{EO}_{20}$, where $\mathrm{EO}$ is ethylene oxide and $\mathrm{PO}$ is propylene oxide), while cubic mesostructured films were obtained with Pluronic F127 $\left(\mathrm{EO}_{106} \mathrm{PO}_{70} \mathrm{EO}_{10}\right)$ [100]. In addition to the template itself, the molar ratio $(M)$ of structure directing agent to the titania precursor also influences the type of mesostructure formed [58,94,99]. Changing $M$ changes the amount of inorganic precursor associated with the hydrated PEO head groups and the number density of micelles formed after coating. In other words, $M$ changes the packing parameter $(P)$ of the micelles, which is defined as $P=V_{0} /\left(A_{\mathrm{e}}{ }^{*} L_{0}\right)$, where $V_{0}$ is the surfactant tail volume, $A_{\mathrm{e}}$ is the equilibrium area per molecule at the aggregate interface, and $L_{0}$ is the surfactant tail length [101]. The most direct effect of decreasing $M$ should be to increase $A_{\mathrm{e}}$ (since more polar components are present to interact with and expand the surfactant headgroups), which is expected to favor aggregates with higher curvature such as cylinders $(P=1 / 2)$ and then spheres $(P=1 / 3)$.

Films with cubic, hexagonal, and lamellar phase can be obtained by varying $M$. Crepaldi et al. [58] synthesized $\mathrm{mp}-\mathrm{TiO}_{2}$ films using $\mathrm{TiCl}_{4}$ as titania precursor using various surfactants and found that, for P123, titania films with 2D HCP mesophase are obtained for an $M$ of $0.05-0.09$ and lamellar mesophase for higher values of $M$. With F127 as template, a cubic phase is obtained for $M$ values of 0.003-0.006, and 2D HCP for M between 0.008 and 0.01 . In a slightly different but related approach, Alberius et al. [94] showed that the final mesophases in surfactant-templated materials can often be predicted based on the volume fraction of surfactant $(\Phi)$, which is defined as the ratio of the volume of surfactant in the dried film to the volume of the nonvolatile (polar) components in the final film. They predicted based on the observed phase behavior of P123 in water that, for titania films synthesized using P123 as the surfactant and titanium ethoxide $\left[\mathrm{Ti}(\mathrm{OEt})_{4}\right]$ as the titania precursor, the mesophase should be cubic, 2D HCP, or lamellar for $\Phi$ in the ranges from $29 \%$ to $36 \%, 38 \%$ to $55 \%$, and $61 \%$ to $75 \%$, respectively. Wu et al. [102] reported the synthesis of titania films using P123 and $\mathrm{Ti}(\mathrm{OEt})_{4}$ for $M$ ratios between 0.006 and 0.012 , which is expected to correspond to $\Phi$ in the range from $26 \%$ to $41 \%$ [102]. The mesostructure should vary from 2D HCP, to a cubic mesophase, to a disordered micellar solution sequentially, as the molar ratio $(M)$ decreases from 0.0122 to $0.01,0.008$ and 0.006 according to Alberius et al. [94]. However, Wu et al. [102] found for a P123 to Ti ratio as low as 0.006, a stable well-ordered mesostructure is still obtained, which is similar to the results obtained by Crepaldi et al. [58] and unlike Alberius et al. [94]. This might be because the formation mechanism of the $\mathrm{mp}-\mathrm{TiO}_{2}$-based thin films is influenced by many factors besides the templates and precursor 
volume fractions, including aging temperature, aging time, relative humidity of atmosphere [58,103], and the acidity of the solution $[58,103]$.

In addition to the type of mesophase, its orientation can be important for many applications. By analogy with surface chemistry strategies used to orient block copolymer films [104-109], the Rankin group has reported the synthesis of $\mathrm{mp}-\mathrm{TiO}_{2}$ thin films with orthogonally tilted HCP (o-HCP) cylindrical nanopores using EISA with P123 as structure directing agent and titanium(IV) ethoxide as titania precursor $[83,110]$. The hypothesis underlying this approach is that orthogonal alignment of the HCP mesophase can be achieved in EISA-derived ceramic film by modifying the substrate surface so that it interacts equally with both blocks of the P123 template, making it chemically "neutral" towards the template surfactant. Monte Carlo simulations [111,112] have shown that this is the expected outcome for mixtures of surfactants and small molecules, and not just for neat block copolymers [108]. A related epitaxial orientation procedure was demonstrated by Tolbert and coworkers, where HCP film was cast onto a cubic template film to induce orthogonal alignment [113].

\subsection{Surfactant/Titania Film Aging}

In addition to surface modification, the synthesis procedure for o- $\mathrm{HCP} \mathrm{TiO}_{2}$ films includes aging after coating in a refrigerator at $4{ }^{\circ} \mathrm{C}$ under high relative humidity (approx. 94\%). The objectives of using a low temperature are to slow titanium precursor condensation and to provide a driving force for mesophase formation, similar to the subambient temperatures used by Alberius et al. [94]. Even though this aging procedure has been found to be an essential part of o- $\mathrm{HCP} \mathrm{TiO}_{2}$ film formation, little is known about the o-HCP mesostructure formation mechanism other than what has been inferred by characterization of the films before and after calcination [83]. Grosso et al. analyzed the mechanisms involved in the formation of 2D-hexagonal templated $\mathrm{SiO}_{2}$ and $\mathrm{TiO}_{2}$ mesostructured films during dip coating using Brij-58 as surfactant and found that the self-assembly leads to the formation of organized phase at the final stage of the drying process and involves the formation of an intermediate disorganized phase [114]. The disorder to order transition takes place on the order of 2-3 min after the start of coating for $\mathrm{TiO}_{2}$ under the conditions studied. Other reports have shown that for dip-coated thin films, the mesostrucutre generally forms through a disorder-to-order transition, which may involve intermediate hybrid mesophases that are related to the concentration gradient [115-117].

Recently, Nagpure et al. [82] reported an in-situ GISAXS investigation of low-temperature aging in oriented surfactant-mesostructured titania thin films and found that the o-HCP structure is the first ordered mesophase formed, and it emerges slowly by a disorder-order transition consistent with the tunable steady state (TSS) proposed for highly acidic $\mathrm{TiO}_{2}$ sols $[118,119]$. Figure $3 \mathrm{~b}$ shows the aging process after deposition in which films organize into an ordered mesophase. [82]. The slow mesophase formation and long TSS may also be accentuated by the use of P123 as a template [120]. Other studies that showed the formation of vertically oriented cylindrical channels by transformation of a cubic phase and merging of the pores normal to the film also showed diffraction spots consistent with the cubic phase prior to thermal treatment [121-123]. However, the results obtained by Nagpure et al. [82] are consistent with the hypothesis underlying the work of Koganti et al. [110] that vertical channels simply form due to reorientation of the HCP phase in response to the modification of the surface of the substrate with a chemically neutral crosslinked P123 layer. A perfectly o-HCP structure follows a 2D growth mechanism with nucleation at the start of the process, whereas films with mixed pore orientation follow 2D growth with continuous nucleation. The effects of aging temperature on mesostructure orientation were also studied, and it was found that, for films aged at $4{ }^{\circ} \mathrm{C}$, a very well-ordered, accessible porous structure was observed everywhere, indicating orthogonal alignment of the cylindrical micelles. When films were aged at $23^{\circ} \mathrm{C}$, randomly oriented parallel stripes were observed everywhere at the top surface of the film, indicating that the cylindrical micelles were arranged parallel to the substrate but with no preferred in-plane orientation. Significant thermotropic behavior occurs in Pluronics because of changes in the hydrophilicity of the PPO blocks at around $15-20^{\circ} \mathrm{C}$. For films aged at $4{ }^{\circ} \mathrm{C}$, the "contrast" between hydrophobic PPO and hydrophilic PEO is 
expected to be small and the polymer may find hydrophilic surfaces to be "neutral" [124] even though specific interactions with titanium precursors still drive mesophase formation. This would be expected to promote orthogonal alignment of the mesophase during low temperature aging. On the other hand, at $23^{\circ} \mathrm{C}$, PPO becomes hydrophobic and the usual contrast mechanisms return.

After deposition of the sol on glass substrates, the relative humidity ( $\mathrm{RH}$ ) of the environment in which these films are aged have been shown to play a vital role in mesostructure development. A highly humid environment is important during the aging of these films to slow down the evaporation of the water from the films (to provide sufficient time for reorientation and ordering of the mesostructure) and to permit the mesoscopic ordering of the surfactant [95,97,125-127]. Crepaldi et al. [58] provided a thorough discussion of the complete synthesis and characterization procedures to obtain ordered $\mathrm{mp}-\mathrm{TiO}_{2}$ films. They discussed all important chemical and processing parameters important for reproducible construction of $\mathrm{mp}-\mathrm{TiO}_{2}$ thin films and explained that humidity during aging determines the water content in the coatings. This water content determines the fluidity of deposited coating and the possibility of occurrence of the disorder-to-order transition. The continuous exchange of water between the film and the atmosphere during the first hour of aging after deposition allows the condensation of the organic framework around micellar aggregates and controls the final mesophase. Jang et al. [103] study the effects of $\mathrm{pH}$ of the coating sol as well as the humidity of the curing environment on the mesostructure of titania films obtained. They suggest an optimum $\mathrm{pH}(\sim-0.6)$ and humidity $(\sim 80 \% \mathrm{RH})$ values to synthesize highly organized $\mathrm{mp}-\mathrm{TiO}_{2}$ films. In much of the work in the Rankin group, high humidity $(\sim 94 \%)$ has been used to slow the condensation of inorganic precursor, and it is possible that this also plays a role in promoting o-HCP mesostructured formation [82].

\subsection{Thermal Treatment}

Calcination of titania film after aging removes surfactant molecules, stabilizes the coating, causes structural contraction, and induces anatase crystallization from the initially amorphous titania structure formed during the sol-gel process [58]. These $\mathrm{mp}-\mathrm{TiO}_{2}$ films are stable up to a certain level of thermal treatment, but as the time and temperature used for calcination increase, they begin to lose mesopore order. This is because high temperatures allow diffusion and sintering of atoms in the initial amorphous structure and induce the nucleation and growth of anatase nanocrystallites, which can destroy mesopore ordering due to extensive atomic rearrangement and modification of the oxidation state of the titanium by redox reactions [96]. Kirsch et al. [95] studied the crystallization kinetics of $\mathrm{mp}-\mathrm{TiO}_{2}$ thin films using in-situ X-ray diffraction and suggested based on the measured activation energies for the two processes that short calcination times at high temperatures are better to produce crystalline films with minimal loss of mesoporous order. However, the exact time and temperature required vary for different synthesis procedures, and the effects of pore orientation on crystallization vs. mesostructured loss remain open questions.

Das et al. [83] investigated the effects of pore orientation on the mesostructural stability for HCP nanopores of titania and found that films with pores oriented orthogonal to the substrate at the top surface retain their long-range pore order at higher calcination temperatures $\left(500{ }^{\circ} \mathrm{C}\right.$ or more) compared to films with pores oriented parallel to the substrate as shown in Figure 3c. This difference was ascribed to greater resistance to anisotropic stress during heating of the orthogonally oriented pores, and titania crystallite nucleation at the top surface of the films with orthogonally oriented pores. Consequently, the activation energy and entropy for mesostructure loss of o- $\mathrm{HCP} \mathrm{TiO}_{2}$ films was found to be greater than that for films with mixed orientation (mixture of parallel and orthogonal orientation) [84]. Nearly perfect orthogonal orientation contributes to the larger activation energy by supporting the anisotropic stresses that develops orthogonal to the films during annealing.

While progress has been made at understanding the rates and mechanisms of crystallization vs. mesostructure loss in soft-templated films, the loss of the template by oxidation at relatively low temperatures $\left(<400{ }^{\circ} \mathrm{C}\right)$ presents challenges in forming a mesoporous crystalline material. Hard templating may provide an alternative by using mesoporous solids as hard templates in 
which the growth of the precursor to a new material is restricted to the surface, cages, channels, or substrate of a hard template. The three main steps in the hard templating approach consist of (i) precursor infiltration inside mesopores of the template; (ii) conversion of the precursor into the target product in the mesopores; and (iii) removal of the mesoporous template [69]. As compared with the soft-templating method, the hard-templating method is less straightforward because of the need to selectively remove the hard template. Additionally, it is not easy to completely fill up the voids of mesoporous templates with titanium precursors because of their strong tendency to precipitate and crystallize into bulk oxide phases directly in aqueous media [86]. However, this synthesis strategy avoids the need to control cooperative assembly and possible mesostructured loss during heating, thus making it attractive for the synthesis of ordered $\mathrm{mp}-\mathrm{TiO}_{2}$ with high thermal stability and crystallinity. Lee et al. [128] synthesized thermally stable $\mathrm{mp}-\mathrm{TiO}_{2}$ with a hierarchical $4-5 \mathrm{~nm}$ mesopore/50 $\mathrm{nm}$ macropore structure via replication of citric acid-templated mesoporous silica as a hard template. Yue et al. [129] fabricated mesoporous rutile $\mathrm{TiO}_{2}$ (which forms at a higher temperature than anatase $\mathrm{TiO}_{2}$ ) by using SBA-15 and KIT-6 mesoporous silica particles as hard templates and $\mathrm{Ti}\left(\mathrm{NO}_{3}\right)_{4}$ solution as a precursor. The reaction temperature and concentration of $\mathrm{HNO}_{3}$ in the used precursor had significant effects on the crystallization of $\mathrm{TiO}_{2}$. Zhang et al. [130] reported the synthesis of mesoporous crystalline anatase $\mathrm{TiO}_{2}$ with KIT- 6 as the hard template and titanium alkoxides as the precursors. It was found that the precursor/template ratios, the calcination temperatures, and the immersion time in $\mathrm{NaOH}$ solution for the removal of the hard template are the three key synthetic parameters that play important roles in the formation of crystalline porous $\mathrm{TiO}_{2}$.

\section{Nitrogen Doping}

Non-metal doping in mp- $\mathrm{TiO}_{2}$ has the potential to extend its light absorption from UV to visible wavelengths. Hydrogen, boron, carbon, nitrogen, fluorine, iodine, sulfur, and phosphorus have been used in this capacity, but nitrogen has been studied most extensively. Until now, various approaches to incorporate nitrogen atoms into titania have been reported, such as doping during film sputtering [131], annealing under ammonia gas [12], ion implantation [132,133], hydrazine treatment [134-136], urea treatment [137-139], treatment of sol-gel titania with nitrogen-containing organics [140], electrochemical processing [141], chemical vapor deposition [142], and plasma techniques $[11,13,35,143-150]$. Most of the above doping methods require high temperature treatment and complicated or expensive equipment. Therefore, those doping methods are difficult to apply in $\mathrm{mp}-\mathrm{TiO}_{2}$ due to the risk of losing mesostructure at the doping conditions. For example, nitrogen doping in $\mathrm{mp}-\mathrm{TiO}_{2}$ by heating in the presence of nitrogen sources is not feasible. Because high temperature is required to dissociate molecular nitrogen to atomic nitrogen or nitrogen radicals, the mesostructure and crystal phase of titania cannot be easily maintained. In addition, higher temperature treatment of titania forms oxygen vacancies that work as recombination centers for photogenerated charge carriers, resulting in lower photocatalytic activity [60]. It is necessary to use simple, low-temperature methods for doping nitrogen in $\mathrm{mp}-\mathrm{TiO}_{2}$. In many approaches, a nitrogen precursor is added into the titania precursor solution during sol-gel, hydrothermal, and solvothermal methods. Several nitrogen sources such as urea, thiourea, nitric acid, and hydrazine have been used for doping in mp- $\mathrm{TiO}_{2}$. While many nitrogen sources are available, not all of them can be used in all synthesis conditions. For instance, when $\mathrm{mp}-\mathrm{TiO}_{2}$ is synthesized in an acidic medium, a nitrogen source that makes the precursor solution basic cannot be used. This can be especially limiting because acidic solutions are sometime used to prepare surfactant-templated $\mathrm{mp}-\mathrm{TiO}_{2}$ thin films in order to stabilize low-molecular weight titanates [65]. In this case, hydrazine cannot be added in the precursor solution because the increase in $\mathrm{pH}$ will induce titania precipitation. In this section, we will discuss nitrogen doping of $\mathrm{mp}-\mathrm{TiO}_{2}$ using several nitrogen sources and synthesis approaches. 


\subsection{Amines}

Amines have been widely used as sources of nitrogen for doping in mp- $\mathrm{TiO}_{2}$ [151-159]. Nassoko et al. synthesized nitrogen-doped $m p-\mathrm{TiO}_{2}\left(\mathrm{~N}-\mathrm{mp}-\mathrm{TiO}_{2}\right)$ nanoparticles by a sol-gel method using ethylene-diaminetetraacetic acid as both a soft template and a source of nitrogen [153]. The resulting $\mathrm{N}-\mathrm{mp}-\mathrm{TiO}_{2}$ nanoparticles showed enhanced rhodamine $\mathrm{B}$ degradation under visible light irradiation. Cheng et al. reported the preparation of mesoporous, nitrogen-doped dual phase titanate/titania by a low-temperature one-pot process in the presence of triethylamine [154]. The N-doped titanate/titania showed efficacy in visible-light phenol degradation. Fu et al. prepared $\mathrm{N}-\mathrm{mp}-\mathrm{TiO}_{2}$ using an exfoliation-reassembly strategy where ethylamine caused delamination of layered titanate and acted as a source of nitrogen [156]. Figure 4 shows a schematic illustration of the exfoliation-reassembly technique for the synthesis of $\mathrm{N}-\mathrm{mp}-\mathrm{TiO}_{2}$. In this method, the layered protonic titanate sheets are delaminated by ethylamine followed by reassembling with positively charged titania colloid nanoparticles leading to formation of a randomly aggregated hybrid with porous structure. Nitrogen was incorporated into titania from the decomposition of ethylamine during calcination. In the photocatalytic degradation of methyl orange, the $\mathrm{N}-\mathrm{mp}-\mathrm{TiO}_{2}$ prepared this way showed much higher photocatalytic performance at visible wavelengths compared to commercial P25 or pristine titanate. This improvement in photocatalytic activity was ascribed to the porosity, visible light absorption, and especially the effective separation of photogenerated charge carriers in the modified material.

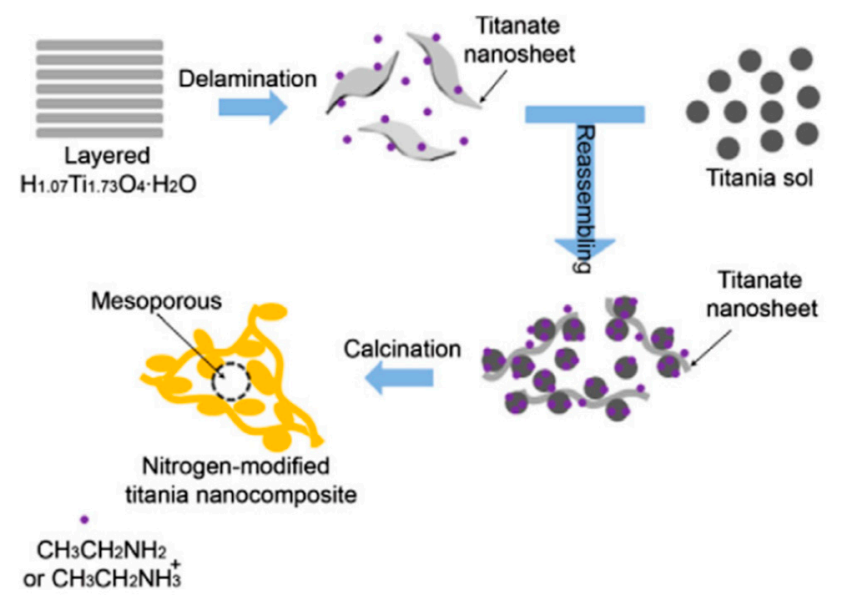

Figure 4. Schematic of procedures for preparing mesoporous nitrogen-modified titania photocatalyst. Reprinted with permission from reference [156]. (Reprinted from Chemical Engineering Journal vol. 219, J. Fu et al. "Soft-chemical synthesis of mesoporous nitrogen-modified titania with superior photocatalytic performance under visible light irradiation," pp. 155-161, Copyright (2013), with permission from Elsevier.)

Wanqin et al. reported the preparation of nanocrystalline $\mathrm{N}-\mathrm{mp}-\mathrm{TiO}_{2}$ using ultrasonic irradiation with ethylenediamine $\left(\mathrm{C}_{2} \mathrm{H}_{4}\left(\mathrm{NH}_{2}\right)_{2}\right)$ as a source of nitrogen [158]. They proposed that ethylenediamine might form $\mathrm{N}$ radicals from its decomposition under elevated temperature and pressure produced by acoustic cavitation, which are able to easily dope $\mathrm{TiO}_{2}$. The band gap was reduced from 3.3 to $2.98 \mathrm{eV}$ by this approach, and the $\mathrm{N}-\mathrm{mp}-\mathrm{TiO}_{2}$ degraded $58 \%$ of dimethyl phthalate in $5 \mathrm{~h}$, whereas undoped $\mathrm{TiO}_{2}$ did not show significant degradation. Hu et al. prepared ordered arrays of $\mathrm{N}-\mathrm{mp}-\mathrm{TiO}_{2}$ spheres using dual templating with a combination of inverse opal templating with PMMA (hard templating) and surfactant templating with P123 (soft-templating) [160]. Tetramethylammonium hydroxide was used as a source of nitrogen. The $\mathrm{N}-\mathrm{mp}-\mathrm{TiO}_{2}$ spheres showed enhanced rhodamine $\mathrm{B}$ degradation compared to nonporous $\mathrm{N}-\mathrm{TiO}_{2}$ spheres and undoped $\mathrm{mp}-\mathrm{TiO}_{2}$ spheres under visible light illumination. The high photocatalytic activity of the doped $\mathrm{mp}-\mathrm{TiO}_{2}$ spheres was attributed to $\mathrm{N}$-doping, abundant ordered mesopores and optical effects of the opal structure. 


\subsection{Ammonia}

In addition to organic amines, ammonia has been used as a source of nitrogen to prepare $\mathrm{N}-\mathrm{mp}-\mathrm{TiO}_{2}[60,160-163]$. Hou et al. reported the preparation of nanocrystalline $\mathrm{N}-\mathrm{mp}-\mathrm{TiO}_{2}$ from an alkoxide precursors and concentrated ammonia solution as a source of nitrogen [162]. Joshi et al. synthesized $\mathrm{N}-\mathrm{mp}-\mathrm{TiO}_{2}$ by templating with chitosan, which also served as nitrogen source along with ammonium hydroxide [163]. The resulting $\mathrm{N}-\mathrm{mp}-\mathrm{TiO}_{2}$ showed enhanced methyl orange degradation under visible light illumination. $\mathrm{Li}$ et al. prepared $\mathrm{N}-\mathrm{mp}-\mathrm{TiO}_{2}$ spheres by a hydrothermal method with $\mathrm{CTAB}$ and ammonia as template and nitrogen source, respectively. Varying ratios of ammonia: Ti were used to give $\mathrm{N}-\mathrm{mp}-\mathrm{TiO}_{2}$ spheres containing about $1.31 \%$ of nitrogen (vs. $0.17 \%$ for nonporous $\mathrm{N}-\mathrm{TiO}_{2}$ spheres). A higher level of doping was found in the mesoporous spheres because of homogeneous doping facilitated by ammonia uptake into the mesopores. Due to greater, more homogeneous doping, the $\mathrm{N}-\mathrm{mp}-\mathrm{TiO}_{2}$ spheres showed the greatest degree of degradation of rhodamine $\mathrm{B}$ under a $1000 \mathrm{~W}$ tungsten halogen lamp ( $>420 \mathrm{~nm}$ ). The degradation of rhodamine B was found to be $100 \%, 50 \%$, $35 \%$, and $20 \%$ for $\mathrm{N}-\mathrm{mp}-\mathrm{TiO}_{2}$, nonporous $\mathrm{N}-\mathrm{TiO}_{2}, \mathrm{mp}-\mathrm{TiO}_{2}$, and solid $\mathrm{TiO}_{2}$ spheres, respectively. The enhanced photocatalytic activity of $\mathrm{N}-\mathrm{mp}-\mathrm{TiO}_{2}$ spheres is attributed to combination of $\mathrm{N}$-doping and mesopore structure. The maximum photocatalytic activity was found with a 0.5 molar ratio of ammonia to $\mathrm{TiO}_{2}$. The surface area of the materials was reduced by the use of more ammonia, which decreased the photocatalytic activity of the samples. In addition, excessive nitrogen might cause the formation of recombination centers for photogenerated electrons and holes.

\subsection{Hydrazine}

Hydrazine has also been tested as a potential source of nitrogen in $\mathrm{N}-\mathrm{mp}-\mathrm{TiO}_{2}$. Along with nitrogen, titanium $\left(\mathrm{Ti}^{3+}\right)$ introduced into the $\mathrm{TiO}_{2}$ due to reduction by in situ hydrogen generation is expected to create an energy state below the conduction band of $\mathrm{TiO}_{2}$ which further reduces the band gap $[45,135,136,164-171]$. This $\mathrm{Ti}^{3+}$ state in $\mathrm{TiO}_{2}$ might improve not only light absorption but also charge transport. For instance, $\mathrm{Zuo}$ et al. prepared a self-doped $\left(\mathrm{Ti}^{3+}\right) \mathrm{TiO}_{2}$ photocatalyst and demonstrated its use for hydrogen production under visible light [164]. More recently, $\mathrm{Ti}^{3+}$-doped $\mathrm{TiO}_{2}$ prepared by hydrazine reduction has been reported [135]. When $\mathrm{TiO}_{2}$ is reduced by any reducing agent, $\mathrm{Ti}^{3+}$ is expected to be formed along with oxygen vacancies. However, with hydrazine $\left(\mathrm{N}_{2} \mathrm{H}_{4}\right)$, titania is expected to be co-doped with both $\mathrm{Ti}^{3+}$ and $\mathrm{N}$ and is therefore to synergistically absorb more visible light and potentially be a more effective redox catalyst than $\mathrm{TiO}_{2}$-doped with either species alone. Aman et al. explored this concept using $\mathrm{Ti}^{3+}$ and $\mathrm{N}-\mathrm{mp}-\mathrm{TiO}_{2}$ nanoparticles for enhanced photocatalytic activity under visible light [134]. The $\mathrm{Ti}^{3+} / \mathrm{N}-\mathrm{mp}-\mathrm{TiO}_{2}$ showed higher photocatalytic reduction of selenium to metallic $\mathrm{Se}^{\circ}$ under visible light illumination compared to undoped $\mathrm{TiO}_{2}$.

When hydrazine is decomposed under heat treatment, ammonia, nitrogen, and hydrogen gases are formed as by Equations (4) and (5).

$$
\begin{gathered}
3 \mathrm{~N}_{2} \mathrm{H}_{4} \rightarrow 4 \mathrm{NH}_{3}+\mathrm{N}_{2} \\
4 \mathrm{NH}_{3}+\mathrm{N}_{2} \mathrm{H}_{4} \rightarrow 3 \mathrm{~N}_{2}+8 \mathrm{H}_{2} .
\end{gathered}
$$

This in-situ formed ammonia and nitrogen (and possibly unstable radical species) act as sources of nitrogen for doping [134]. Selvam et al. prepared $\mathrm{N}-\mathrm{mp}-\mathrm{TiO}_{2}$ particles by wet impregnation with hydrazine [172]. The $\mathrm{N}-\mathrm{mp}-\mathrm{TiO}_{2}$ particles were used for the conversion of azoxybenzene to amines or 2-phynylindazoles with methanol using a $365 \mathrm{~nm}$ medium-pressure mercury lamp. In addition to introducing $\mathrm{N}$ and $\mathrm{Ti}^{3+}$, hydrazine increased the surface area from 74 to $134 \mathrm{~m}^{2} / \mathrm{g}$ due to hydrazine decomposition [134,172]. The yield of $4,4^{\prime}$-azoxyanisole by catalytic reductive cleavage on $\mathrm{N}-\mathrm{mp}-\mathrm{TiO}_{2}(95.7 \%)$ in methanol under UV $(365 \mathrm{~nm})$ light illumination is higher than that on undoped $\mathrm{mp}-\mathrm{TiO}_{2}(60.3 \%)$ and $\mathrm{P} 25(50.6 \%)$. These results show that both high surface area and nitrogen doping contributed in the higher photocatalytic activity of the N-mp- $-\mathrm{TiO}_{2}$. 


\subsection{Plasma Doping}

Plasma treatment is an efficient method to introduce nitrogen into the titania lattice [11,13,35,143-150]. Among available doping approaches, plasma-assisted doping has several critical advantages, such as (i) effectively incorporating heteroatoms into the $\mathrm{TiO}_{2}$ host by providing reactive dopant species and (ii) being conducted at relatively low temperature so that the nanostructure of $\mathrm{TiO}_{2}$ is maintained. Recently, we have reported the incorporation of nitrogen into surfactant templated cubic ordered $\mathrm{mp}-\mathrm{TiO}_{2}$ thin films by $\mathrm{N}_{2} /$ Ar plasma treatments $[65,173]$. About $2-5$ atom $\%$ substitutional nitrogen was found in the doped films, and the nitrogen was found to be uniformly distributed through the depth of the films. XPS and optical characterization results suggest that the band gap of $\mathrm{TiO}_{2}$ films was reduced from $3.5 \mathrm{eV}$ (in undoped $\mathrm{TiO}_{2}$ films) down to a minimum of $3.0 \mathrm{eV}$ after the plasma treatment. Photocatalytic degradation tests with methylene blue demonstrated a significant enhancement in photocatalytic activity of the $\mathrm{N}-\mathrm{TiO}_{2}$ films over undoped $\mathrm{TiO}_{2}$ films under visible-light illumination ( $455 \mathrm{~nm}$ LED) as shown in concentration profile in Figure 5 . The $\mathrm{N}-\mathrm{TiO}_{2}$ prepared by $150 \mathrm{~min}$ plasma treatment showed the best photocatalytic performance, with the determined rate coefficient of $0.24 \mathrm{~h}^{-1}$, roughly 6 times greater than that of undoped $\mathrm{TiO}_{2}$ films. This enhancement in photocatalytic activity is qualitatively similar to prior studies of nitrogen doping in nanostructured titania but significantly greater in magnitude than the 2-3 times enhancement reported by Liu et al. [145]. This photocatalytic improvement is attributed to the combination of the efficient $\mathrm{N}_{2}$ / Ar plasma-induced doping approach with the well-defined high surface area found in surfactant-templated $\mathrm{mp}-\mathrm{TiO}_{2}$ thin films. The present study showed that plasma-induced doping enables the efficient incorporation of heteroatoms into the $\mathrm{TiO}_{2}$ films while maintaining their mesoporous structure, thereby leading to the significant enhancement of visible-light photoactivity. The coating and plasma based process presented here has several advantages over competing synthetic strategies, as it can be scaled to continuous film production and to deposition of the films onto other substrates for photoelectrocatalytic applications.
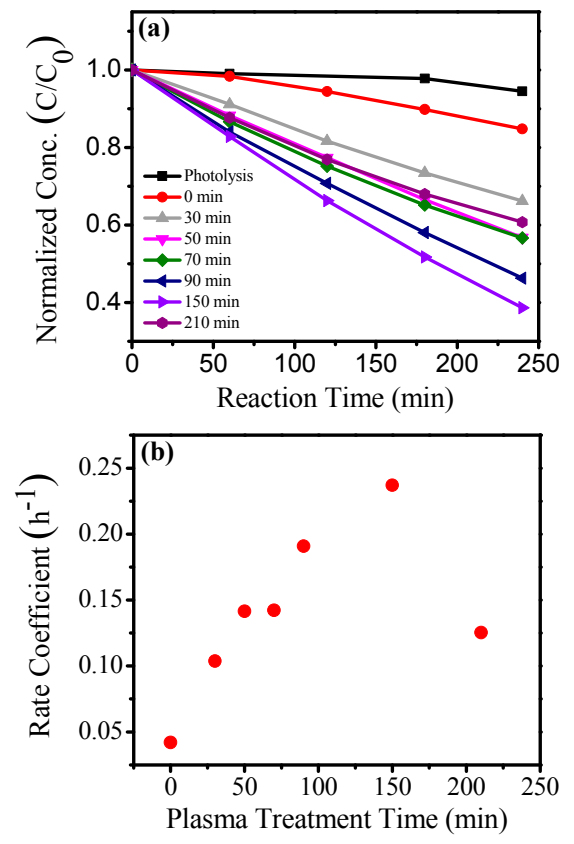

Figure 5. Methylene blue degradation reaction with undoped $\mathrm{TiO}_{2}(0 \mathrm{~min})$ film, $\mathrm{N}-\mathrm{TiO}_{2}$ films and without films (Photolysis): (a) Concentration profile (b) the plot of the first-order rate coefficient vs. plasma treatment time. Reprinted with permission from reference [65]. (Reprinted from Microporous and Mesoporous Materials vol. 220, S. Z. Islam et al. " $\mathrm{N}_{2}$ / Ar plasma induced doping of ordered mesoporous $\mathrm{TiO}_{2}$ thin films for visible light active photocatalysis", pp. 120-128, Copyright (2018), with permission from Elsevier.) 


\subsection{Thiourea}

Thiourea has also been used as a nitrogen source for the doping of $\mathrm{mp}-\mathrm{TiO}_{2}[10,174,175]$. Soni et al. reported the preparation of $\mathrm{N}-\mathrm{mp}-\mathrm{TiO}_{2}$ films via evaporation induced self-assembly using $\mathrm{P} 123$ as a template and thiourea as a source of nitrogen [10]. The films showed thicknesses of $73 \mathrm{~nm}, 211 \mathrm{~nm}$, $385 \mathrm{~nm}$, and $695 \mathrm{~nm}$ after multiple coating and contained 0.9, 1.7, 4.8, and 8.3 atom \% of interstitial nitrogen, respectively. It is not clear why nitrogen content increases with the film thickness formed by multilayer film deposition. While $73 \mathrm{~nm}$ thick $\mathrm{N}^{-\mathrm{TiO}_{2}}$ films degraded about $10 \%$ methylene blue in $18 \mathrm{~h}$, undoped $\mathrm{TiO}_{2}$ did not show any degradation in the photocatalytic degradation test under visible light of $442 \mathrm{~nm}$ illumination. $\mathrm{N}-\mathrm{TiO}_{2}$ of $695 \mathrm{~nm}$ thickness showed the best response which was complete degradation of methylene blue in $18 \mathrm{~h}$. Thus, $695 \mathrm{~nm}$ thick $\mathrm{N}-\mathrm{TiO}_{2}$ films exhibited about 10 times higher rate compared to $73 \mathrm{~nm}$ thick $\mathrm{N}-\mathrm{TiO}_{2}$ films, which is due to the increased surface area in the thicker films. The same research group used the $\mathrm{N}-\mathrm{mp}-\mathrm{TiO}_{2}$ thin films for visible light induced bactericidal activity on Gram-positive bacteria (Bacillus amyloliquifacience) [175]. An electron paramagnetic resonance study of the $\mathrm{N}-\mathrm{mp}-\mathrm{TiO}_{2}$ powders produced using thiourea by this group showed several paramagnetic species associated with oxygen radicals after calcination at $400{ }^{\circ} \mathrm{C}$, while nitrogen centers appear after calcination at temperature as high as $500^{\circ} \mathrm{C}$ [174]. Interestingly, since it contains nitrogen, carbon, and sulfur, different authors have claimed that thiourea modified $\mathrm{mp}-\mathrm{TiO}_{2}$ contains different dopants and combinations of dopants including $\mathrm{B} / \mathrm{N} / \mathrm{S}$ co-doped $\mathrm{mp}-\mathrm{TiO}_{2}[46,176-179]$. This will be discussed below.

\subsection{Urea}

Urea is a common source of nitrogen for doping in $\mathrm{mp}-\mathrm{TiO}_{2}$ since it is readily available and easy to introduce into $\mathrm{TiO}_{2}$ precursor sol or solid $\mathrm{TiO}_{2}$ using a urea solution [22,56,180-189]. In addition to being a nitrogen source, urea can contribute to forming mesopores in titania by generation of $\mathrm{CO}_{2}$ gas bubbles during its decomposition (Equation (6)) [22,183]. For instance, the surface area of $\mathrm{mp}-\mathrm{TiO}_{2}$ prepared using urea was reported in one procedure to be $154 \mathrm{~m}^{2} / \mathrm{g}$, but only $101 \mathrm{~m}^{2} / \mathrm{g}$ in $\mathrm{mp}-\mathrm{TiO}_{2}$ prepared using a similar method without urea [183].

$$
\mathrm{CO}\left(\mathrm{NH}_{2}\right)_{2}+3 \mathrm{H}_{2} \mathrm{O} \rightarrow 2 \mathrm{NH}_{3} \cdot \mathrm{H}_{2} \mathrm{O}+\mathrm{CO}_{2} \text {. }
$$

Chi et al. synthesized $\mathrm{N}-\mathrm{mp}-\mathrm{TiO}_{2}$ by a solvothermal method using urea as both a source of nitrogen and mesopore former [183]. The nitrogen content in the $\mathrm{N}-\mathrm{mp}-\mathrm{TiO}_{2}$ was 0.81 atom \%. The $\mathrm{N}-\mathrm{mp}-\mathrm{TiO}_{2}$ degraded about $38 \%$ of methylene blue, whereas undoped $\mathrm{mp}-\mathrm{TiO}_{2}$ degraded only about $20 \%$ under visible light illumination, indicating a 2.1 times increase in photoactivity upon nitrogen doping. Shao et al. reported the preparation of hierarchical mesoporous-macroporous $\mathrm{N}-\mathrm{TiO}_{2}$ by thermal treatment of the hierarchical $\mathrm{TiO}_{2}$ with urea solution [185]. The band gap was reduced from 3.14 to $2.48 \mathrm{eV}$ after $\mathrm{N}$-doping. XPS and FT-IR spectra confirmed the formation of $\mathrm{Ti}-\mathrm{N}$ bonds in the meso-macroporous $\mathrm{N}-\mathrm{TiO}_{2}$. The first-order photocatalytic degradation of rhodamine B under visible light illumination was increased from $3.7 \times 10^{-3}$ to $5.3 \times 10^{-3} \mathrm{~min}^{-1}$ due to N-doping. This enhancement in the photocatalytic performance was due to the incorporation of nitrogen into the titania lattice and the presence of the hierarchical meso/macroporous structure. Recently, N-mp- $\mathrm{TiO}_{2}$ was prepared using a urea-assisted solvothermal method at mild temperature [180]. The band gap was reduced from 3.16 to $3.02 \mathrm{eV}$ upon nitrogen doping. In photocatalytic oxidation of acetic acid in 60 min under a solar simulator, $\mathrm{N}-\mathrm{mp}-\mathrm{TiO}_{2}$ showed about a 1.55 times higher performance compared to undoped $\mathrm{TiO}_{2}$. Notably, the properties such as the band gap, the chemical state of nitrogen, and the enhancement in photocatalytic activity of $\mathrm{N}-\mathrm{mp}-\mathrm{TiO}_{2}$ were very different based on the preparation methods even when urea was used as the nitrogen source. To help to understand the reason for this variability, Sreethawong et al. prepared nanocrystalline $\mathrm{N}-\mathrm{mp}-\mathrm{TiO}_{2}$ and studied the urea decomposition process, in conjunction with XRD characterization [190]. A mechanism was proposed based on the appearance of biuret and cyanuric acid along with anatase titania as observed by XRD. Biuret and cyanuric acid formed at about $150-250^{\circ} \mathrm{C}$ and $190-350^{\circ} \mathrm{C}$, respectively. 


\subsection{Summary of Nitrogen Doped Mesoporous Titania}

A summary of synthesis methods, pore directing agents, dopant sources, $\mathrm{N}$ 1s binding energy in doped $\mathrm{TiO}_{2}$, band gaps before and after doping, specific surface area, compounds used for photocatalytic testing, and photocatalytic enhancement found in the $\mathrm{N}-\mathrm{mp}-\mathrm{TiO}_{2}$ from various literature are presented in Table 1. The photocatalytic tests were performed under visible light in all cases, although the light source varied. Typical organic compounds used for photocatalytic test are methylene blue (MB), methyl orange (MO), and rhodamine B (Rh B).

It is difficult to compare results of different studies directly due to variations in testing conditions, including the preparation method of the photocatalyst, light sources, light intensities, excitation wavelengths, organic compound chosen for photocatalytic testing, catalyst amount, and reactor geometry. For the sake of comparison, the enhancement is defined by the rate of reaction using doped $\mathrm{mp}-\mathrm{TiO}_{2}$ divided by the rate of reaction using undoped $\mathrm{mp}-\mathrm{TiO}_{2}$. When there was no photocatalytic test using undoped titania, the enhancement could not be defined. Most of the literature did not directly report the rate coefficient for degradation of the organic compounds, in which case the reaction is assumed to be pseudo-first order to determine the photocatalytic enhancement. The enhancement is the calculated ratio of the maximum photodegradation occurring over a certain reaction duration by the doped $m p-\mathrm{TiO}_{2}$ to the photodegradation by the undoped $m p-\mathrm{TiO}_{2}$. The reported specific surface area is for undoped $\mathrm{TiO}_{2}$. If the surface area of undoped titania was not given, the surface area of doped titania is reported in Table 1 . The content of dopants are in atomic percentage unless otherwise noted.

From Table 1, it is observed that, in most cases, urea gives about 1 atom $\% \mathrm{~N}$. N-mp-TiO prepared using urea showed about a $0.1-0.2 \mathrm{eV}$ bandgap reduction. Only one study was performed using nitrogen plasma-treated $\mathrm{mp}-\mathrm{TiO}_{2}$. The nitrogen content and band gap reduction in the resulting $\mathrm{N}-\mathrm{mp}-\mathrm{TiO}_{2}$ were 3.2 atom $\%$ and $0.48 \mathrm{eV}$, respectively. The $\mathrm{N}-\mathrm{mp}-\mathrm{TiO}_{2}$ prepared using ethylenediamine showed the largest band gap reduction of $2.2 \mathrm{eV}$. However, this band gap reduction is not from a primary absorption edge shift but from the formation of a new absorption edge in the visible region [151]. Typically, the binding energies of nitrogen in $\mathrm{N}-\mathrm{TiO}_{2}$ are in the range of $396-404 \mathrm{eV}[6,43,47]$. Two types of nitrogen atoms were assigned in titania: (i) substitutional nitrogen with a binding energy of $396 \mathrm{eV}$; and (ii) interstitial nitrogen with a binding energy of $400 \mathrm{eV}$. The XPS peak at $396-397 \mathrm{eV}$ is for substitutional nitrogen because it indicates Ti-N bonding [48]. The binding energy at around $400 \mathrm{eV}$ is due to the interstitial nitrogen incorporated through various $\mathrm{N}-\mathrm{O}-\mathrm{Ti}$ species. From Table 1, it is seen that most of the nitrogen is interstitial in the $\mathrm{N}-\mathrm{TiO}_{2}$, which forms mid-gap states between the valence band and conduction bands. On the other hand, very few methods produce $\mathrm{N}$-mp- $\mathrm{TiO}_{2}$ containing substitutional nitrogen which is responsible for band gap reduction. In some cases, authors deconvoluted the N 1s XPS peak and showed both interstitial and substitutional nitrogen. Only $\mathrm{N}-\mathrm{TiO}_{2}$ prepared by supercritical $\mathrm{CO}_{2}$ drying method and nitrogen plasma explicitly showed substitutional nitrogen $[65,184]$. In terms of photocatalytic enhancement, all $\mathrm{N}-\mathrm{mp}-\mathrm{TiO}_{2}$ materials showed higher visible-light activity compared to undoped titania. Of all approaches, $\mathrm{N}-\mathrm{mp}-\mathrm{TiO}_{2}$ prepared using nitrogen plasma and amines give the greatest enhancement.

Cong et al. performed an comparison of $\mathrm{N}-\mathrm{mp}-\mathrm{TiO}_{2}$ prepared using a microemulsionhydrothermal method with triethylamine, urea, thiourea, or hydrazine hydrate as nitrogen source and Triton X-100 and 1-hexanol as structure directing agents [34]. All of the $\mathrm{N}-\mathrm{mp}-\mathrm{TiO}_{2}$ catalysts exhibited higher photoactivity compared to undoped titania and P25 for rhodamine $\mathrm{B}$ degradation under visible light irradiation. The $\mathrm{N}-\mathrm{TiO}_{2}$ prepared with triethylamine showed the highest photocatalytic activity and thiourea showed the lowest. The photocatalytic activity increased with nitrogen content. That was correlated with the band gap reduction and enhancement in visible light absorption. Nitrogen doping could also inhibit charge recombination resulting in increased photocatalytic activity as found by photoluminescence measurements. The results from this study are also in agreement with the other studies that $\mathrm{N}-\mathrm{mp}-\mathrm{TiO}_{2}$ prepared with amines as a nitrogen source showed higher photocatalytic performance than those prepared with other sources, as shown in Table 1. 
Table 1. The synthesis method, dopant source, and the chemical, optical, and photocatalytic properties of nitrogen-doped mesoporous titania.

\begin{tabular}{|c|c|c|c|c|c|c|c|c|c|c|}
\hline Method & Template & N Source & $\begin{array}{l}\text { N Comp } \\
\text { (atom \%) }\end{array}$ & $\begin{array}{c}\text { Binding Energy } \\
(\mathrm{eV})\end{array}$ & $\begin{array}{c}\text { Initial } \\
\text { BG (eV) }\end{array}$ & $\begin{array}{l}\text { Final } \\
\text { BG (eV) }\end{array}$ & $\mathrm{S}_{\mathrm{BET}}\left(\mathrm{m}^{2} / \mathrm{g}\right)$ & Test Compound & Enhance-Ment & Ref. \\
\hline Solvothermal & Free & Urea & 1.43 & 400 & 3.14 & 3.09 & 121 & $\mathrm{Rh} B$ & 1.43 & [185] \\
\hline Solvothermal & Free & Urea & - & 399.5 & 3.16 & 3.02 & 23.6 & Acetic Acid & 1.54 & [180] \\
\hline EISA & F127 & Urea & 3.46 & 398.8 & - & - & 67 & Water Splitting & 2.37 & [181] \\
\hline Solvothermal & Urea & Urea & 0.8 & 399.5 & - & - & 154 & $\mathrm{MB}$ & 3.1 & [183] \\
\hline $\begin{array}{c}\text { Supercritical } \mathrm{CO}_{2} \\
\text { drying }\end{array}$ & - & Urea & - & 396 & 3.1 & 1.92 & 116 & - & - & [184] \\
\hline $\begin{array}{l}\text { Homogeneous } \\
\text { precipitation }\end{array}$ & - & Urea & 0.91 & $395.4,401.5$ & - & - & 89 & $\mathrm{MB}$ & 3 & [186] \\
\hline Sol-gel & PAM + PEG & Urea & 0.6 & $397,398.8,402.4$ & 2.9 & 2.75 & 110 & MO & 3 & [188] \\
\hline Sol-gel & $\begin{array}{l}\text { Laurylamine } \\
\text { hydrochloride }\end{array}$ & Urea & $26.2 \mathrm{wt} \%$ & 400.8 & 3.2 & 3.1 & 110.3 & Water Splitting & 1.44 & [191] \\
\hline Sol-gel & F127 & $\mathrm{N}_{2}$ plasma & 3.2 & 396 & 3.5 & 3.02 & 143 & $\mathrm{MB}$ & 6 & [65] \\
\hline $\begin{array}{l}\text { Exfoliation- } \\
\text { reassembly }\end{array}$ & - & Ethylamine & - & 399.8 & - & - & 217 & MO & 9 & [156] \\
\hline Solvothermal & F127 & Ethylenediamine & $4.1 \mathrm{wt} \%$ & 398.6 & 3.1 & 2.2 & 180.2 & MB & - & [151] \\
\hline Solvothermal & F127 & Ethylenediamine & $0.13(\mathrm{~N} / \mathrm{Ti})$ & $399.5,401.4$ & 3.32 & 2.98 & 185.4 & $\begin{array}{l}\text { Dimethyl } \\
\text { Phthalate }\end{array}$ & - & [158] \\
\hline Sol-gel & Triethylamine & Triethylamine & 4 & 401.6 & - & - & 180 & Phenol & 7.5 & [154] \\
\hline Sol-gel & - & Triethanolamine & 1.09 & $397,399.9$ & - & - & 70.5 & $\mathrm{MB}$ & & [155] \\
\hline Hydrothermal & P123 & Triethylamine & - & 399 & - & - & 150 & Rh B & 3.3 & [152] \\
\hline $\begin{array}{l}\text { Sol-gel reverse } \\
\text { micelle }\end{array}$ & TritonX100 & $\mathrm{Na}_{2}$ EDTA & $6 \mathrm{wt} \%$ & - & 3.13 & 3.06 & 58 & MB & 4 & [157] \\
\hline Sol-gel & EDTA & EDTA & - & - & 3.1 & 2.29 & 72.46 & Rh B & 1.5 & [153] \\
\hline Hydrothermal & СТAB & Ammonia solution & 1.31 & $\begin{array}{l}399.5,400.6 \\
\quad 401.5\end{array}$ & - & - & 83.1 & Rh B & 5 & [161] \\
\hline Sol-gel & P123 & $\begin{array}{c}\text { Tetramethylammonium } \\
\text { hydroxide }\end{array}$ & - & 400 & - & - & 105 & Rh B & 4 & [160] \\
\hline Sol-gel & Chitosan & Chitosan and $\mathrm{NH}_{4} \mathrm{OH}$ & $0.72 \mathrm{wt} \%$ & $394.2,400.9$ & - & 2.65 & 132.26 & MO & 2 & [163] \\
\hline EISA & F127 & $\mathrm{NH}_{3}$ gas & - & 395.9 & - & - & $173 \mathrm{~m}^{2} / \mathrm{cm}^{3}$ & MB & 1.47 & {$[60]$} \\
\hline Wet Impregnation & $\begin{array}{l}\text { Hydrazine } \\
\text { Hydrate }\end{array}$ & Hydrazine Hydrate & - & 398.1 & - & - & 74 & Azoxybenzene & - & [172] \\
\hline
\end{tabular}




\section{Other Non-Metal Doped Mesoporous Titania}

\subsection{Hydrogenation}

Hydrogen doping is a potential strategy to reduce the band gap of $\mathrm{TiO}_{2}$ by introducing electronic states below the conduction band [45]. In addition to band gap reduction, hydrogenation of $\mathrm{TiO}_{2}$ has been shown to increase its conductivity and subsequently its capacitance [192]. Upon hydrogenation, titania becomes black and can absorb light over a wide wavelength range [6,193-196]. It has been speculated that hydrogenation introduces surface functional groups which also allow for Faradaic reactions to take place [192]. Hydrogenation in titania leads to $\mathrm{Ti}^{3+}$ formation or oxygen vacancies.

Zhou et al. reported the preparation of hydrogenated $\mathrm{mp}-\mathrm{TiO}_{2}\left(\mathrm{H}-\mathrm{mp}-\mathrm{TiO}_{2}\right)$ with $5-10 \mathrm{~nm}$ pores [197]. The nanoporous titania was formed in situ on titanium flakes by electrodeposition followed by annealing in a 1:4 $\mathrm{H}_{2}$ / Ar atmosphere. Oxygen vacancies and hydroxyl groups formed on the surface of $\mathrm{TiO}_{2}$ due to the hydrogenation. The $\mathrm{H}-\mathrm{mp}-\mathrm{TiO}_{2}$ showed a capacitance of $1.05 \mathrm{mF} \cdot \mathrm{cm}-1$ at a scanning rate of $100 \mathrm{mV} \cdot \mathrm{s}^{-1}$, which is 14 -fold higher than that of pure $\mathrm{TiO}_{2}$. This capacitance enhancement was attributed to the nanoporous architecture which provides easy access of the surface to liquid electrolyte, more active sites for ion binding and charge separation, and improvement in electrical conductivity. Muhammad et al. reported reduced $\mathrm{mp}-\mathrm{TiO}_{2}$ thin films prepared by evaporation induced self-assembly using F127 as a pore template followed by heat treatment under a hydrogen environment [198]. The transparent titania thin films turned black upon heat treatment. However, no evidence of forming $\mathrm{Ti}^{3+}$ was provided. The band gap did not change after hydrogenation, but the $\mathrm{H}-\mathrm{mp}-\mathrm{TiO}_{2}$ films were used for photoelectrocatalytic water oxidation at $0.6 \mathrm{~V}$ vs. Ag/ $\mathrm{AgCl}$ in a $1 \mathrm{M} \mathrm{NaOH}$ solution under a $150 \mathrm{~W}$ Xenon lamp-based solar simulator. The hydrogenated films showed about 11 times higher photocurrent compared to pure films. This enhancement was attributed to the oxygen vacancy formation during the heat treatment under flowing hydrogen gas.

\subsection{Boron Doping}

As noted above, other non-metals than nitrogen have been used in an effort to enhance the visible light absorption of titania. Boron-doped $\mathrm{mp}-\mathrm{TiO}_{2}\left(\mathrm{~B}-\mathrm{mp}-\mathrm{TiO}_{2}\right)$ was prepared by a sol-gel process using boric acid as a boron source [57]. Different concentrations of boron ranging from 0.25 to 9.0 (wt \%) were used in the precursor solution to obtain $\mathrm{B}-\mathrm{mp}-\mathrm{TiO}_{2}$ with different loadings. The surface area of samples prepared with $2 \%$ and $5 \%$ of boron were 104 and $100 \mathrm{~m}^{2} / \mathrm{g}$, respectively, which were higher than other samples. At this concentration of boron, aggregation of particles was reduced resulting in a higher surface area. On the other hand, agglomerates were fused together to form comparatively larger irregular grains in pure $\mathrm{TiO}_{2}$ and $9 \% \mathrm{~B}-\mathrm{mp}-\mathrm{TiO}_{2}$, resulting in a lower surface area. This suggests that the presence of boron significantly affects the particle size and surface area. Despite the incorporation of boron as $\mathrm{B}-\mathrm{O}-\mathrm{Ti}$ species, the band gap of $\mathrm{TiO}_{2}$ was not reduced upon boron doping. The photocatalytic activity of the boron-doped titania were tested for the degradation of pharmaceutical contaminant metoprolol using a Xe lamp solar simulator. Among all the samples, the highest degradation $(70 \%)$ was obtained for the sample with $5 \% \mathrm{~B}$, whereas undoped $\mathrm{TiO}_{2}$ removed $48 \%$ of metoprolol after 180 min of treatment. Further increase in nominal boron loading (to $9 \%$ ) reduced the photocatalytic performance. At this percentage of $B$, a level of maximum saturation at the particle surface is reached and an excessive amount of boron occupied active sites of the catalyst, inhibiting the radiation absorption of $\mathrm{TiO}_{2}$ particles. The observed photocatalytic enhancement was attributed to the high surface area, mesoporous structure, formation of Ti(III), introduction of boron as a B-O-Ti species and uniformity in particle size with 5\% B.

\subsection{Carbon Doping}

Doping with carbon atoms has been found to increase visible light absorption and photocatalytic activity of titania. The carbon dopants can form a new energy state in between the valence band and conduction band of titania as shown in Figure 1 [44,199]. In addition, carbon doping increases the 
photocatalytic activity of titania by decreasing the recombination rate of photogenerated electron-hole pairs where carbon works as an electron scavenger [199]. Furthermore, carbon doping increases the conductivity of titania and improves the charge transfer from the bulk to the surface sites where charge carriers participate in reactions [29]. Several studies have been reported on carbon-doped $\mathrm{mp}-\mathrm{TiO}_{2}\left(\mathrm{C}-\mathrm{mp}-\mathrm{TiO}_{2}\right)$ [199-204]. C-mp-TiO ${ }_{2}$ films were synthesized by a sol-gel process combined with hydrothermal treatment using glucose as a source of carbon and a structure-directing agent [199]. In this method, titania particles prepared from $\mathrm{Ti}(\mathrm{OBu})_{4}$ and glucose were hydrothermally treated in an autoclave containing a glass substrate to make C-mp- $\mathrm{TiO}_{2}$ films. XPS showed a peak at $282.4 \mathrm{eV}$ for Ti-C along with other peaks at $284.8,286.2$, and $288.6 \mathrm{eV}$ for adventitious elemental C or residual carbon from the precursor. These results indicated that substitutional carbon was incorporated into titania lattice by replacing oxygen to form $\mathrm{O}-\mathrm{Ti}-\mathrm{C}$ bonds. Photoluminescence showed that electron-hole recombination is reduced due to carbon doping. The C-doped $\mathrm{mp}-\mathrm{TiO}_{2}$ films also exhibited higher photocatalytic degradation of Brilliant Red X-3B under both UV and visible light irradiation compared with that of the smooth $\mathrm{TiO}_{2}$ film and a P25 particle film. The degradation rate coefficients of the doped films were enhanced 2.4 times under UV light and 3.6 times under visible light irradiation compared with the undoped film. High surface area, enhanced visible light absorption, and lower charge carrier recombination due to carbon doping contributed to this higher photocatalytic activity of $\mathrm{C}-\mathrm{mp}-\mathrm{TiO}_{2}$ films. Another important feature of this study was repeated cycling, under which it was found that $\mathrm{C}-\mathrm{mp}-\mathrm{TiO}_{2}$ showed a $3 \%$ decrease in UV photocatalytic activity after 5 cycles, whereas undoped titania showed a $16 \%$ decrease. Thus, $\mathrm{C}$-doped titania is more stable than undoped titania.

Zhang et al. prepared bimodal C-mp- $\mathrm{TiO}_{2}$ in supercritical ethanol from tetrabutyl titanate and raw rice [32]. The mixed precursor solution was heated at varying temperatures (all supercritical) and treated at varying temperatures. In the carbon-doped $\mathrm{mp}-\mathrm{TiO}_{2}$, carbon was proposed to play dual roles as a dopant in the titania lattice and a photosensitizer at the surface of titania. Sensitization was proposed to come from nanosized carbon at the surface of the material, which accepts photogenerated electrons from titania to reduce charge carrier recombination. Although this phenomenon is sometimes called sensitization, it is basically a charge separator or electron sink since carbon-doped titania itself absorbs the light. The mesostructure was developed due to the ethanol supercritical treatment. The surface area of titania increased from 138 to $160 \mathrm{~m}^{2} / \mathrm{g}$ upon doping, which suggests that carbon doping prohibited the aggregation of nanoparticles. From XPS spectra, peaks for carbon were found at $284.9,285.8,288.2$, and $288.6 \mathrm{eV}$. The peak at $284.9 \mathrm{eV}$ is for adventitious elemental carbon, whereas peaks at 285.8 and $288.6 \mathrm{eV}$ are assigned to the oxygen bound species $\mathrm{C}-\mathrm{O}$ and $\mathrm{C}=\mathrm{O}$, respectively. The incorporated carbon in the titania lattice showed a peak at $288.2 \mathrm{eV}$. Phenol degradation under visible light has demonstrated that the carbon-doped $\mathrm{mp}-\mathrm{TiO}_{2}$ performed with much higher activity compared to undoped titania. The optimal sample was $\mathrm{C}-\mathrm{mp}-\mathrm{TiO}_{2}$ prepared at $260{ }^{\circ} \mathrm{C}$ giving a pseudo-first order rate coefficient for phenol degradation of $0.452 \mathrm{~min}^{-1}$. Excessive carbon was left on the $250{ }^{\circ} \mathrm{C}$ treated titania surface, which inhibited the transfer of the photo-generated electrons from the sensitizer layer (outer carbon layer) to the $\mathrm{TiO}_{2}$. On the other hand, the sample treated at $270{ }^{\circ} \mathrm{C}$ showed lower activity because of a low content of carbon, a higher band gap, and a lower surface area. In order to identify the contribution from carbon doping and sensitization, the best performing sample prepared first at $260^{\circ} \mathrm{C}$ was further heat-treated, and it was found that the sample treated at the lowest temperature $\left(300^{\circ} \mathrm{C}\right)$ showed the lowest band gap $(2.7 \mathrm{eV})$ and highest photocatalytic activity $\left(0.526 \mathrm{~min}^{-1}\right)$. Treatment at $300^{\circ} \mathrm{C}$ was proposed to enhance crystallinity and hence photoactivity. However, at $400{ }^{\circ} \mathrm{C}$ and higher, the sample might lose carbon and widen the band gap, resulting in lower photoactivity. These results suggest that the activity contribution from the carbon sensitization is about three times that coming from the promotion effect of carbon doped in the titania lattice. Such synergistic effect of the lower band gap induced by the carbon doped in the titania crystal lattice and photosensitizing resulting from the hybridized carbon grafted on the titania surface played a significant role in the photocatalytic degradation of phenol as shown in Figure 6. 


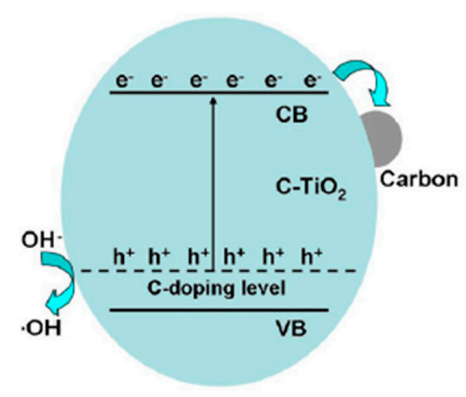

Figure 6. Proposed photocatalytic mechanism over the $\mathrm{C}-\mathrm{TiO}_{2}$ samples. Reprinted with permission from reference [32]. (Reprinted from Applied Catalysis B vol. 115, Y. Zhang et al. "Ethanol supercritical route for fabricating bimodal carbon modified mesoporous $\mathrm{TiO}_{2}$ with enhanced photocatalytic capability in degrading phenol", pp. 236-244, Copyright (2012), with permission from Elsevier.)

\subsection{Fluorine Doping}

Studies have been carried out on fluorine doping in $\mathrm{mp}-\mathrm{TiO}_{2}$ to improve its photocatalytic performance [205-209]. Pan et al. reported the preparation of fluoride-doped mp- $\mathrm{TiO}_{2}\left(\mathrm{~F}-\mathrm{mp}-\mathrm{TiO}_{2}\right)$ hollow microspherical photocatalyst for membrane-based water purification [206]. F-mp- $\mathrm{TiO}_{2}$ microspheres were synthesized by hydrothermal treatment of $\mathrm{TiF}_{4}$ in a $\mathrm{H}_{2} \mathrm{SO}_{4}$ aqueous solution, which acts as an acid source to promote HF etching. This etching governed the aggregation of hydrolyzed $\mathrm{TiO}_{2}$ primary particles and the formation of porous microspheres depending on the concentration of $\mathrm{H}_{2} \mathrm{SO}_{4}(0.1 \%$ to $1.0 \%$ by mass $) . \mathrm{H}_{2} \mathrm{SO}_{4}$ with $1.0 \%$ concentration provided monodispersed mesoporous hollow $\mathrm{F}_{-} \mathrm{TiO}_{2}$ microspheres with abundant cavities and nanopores. Figure 7 shows SEMs of mesopore structure at different $\mathrm{H}_{2} \mathrm{SO}_{4}$ concentrations and a TEM image of F-mp- $\mathrm{TiO}_{2}$ hollow microspheres. The XPS spectrum revealed only one peak for $\mathrm{F}^{-}$at $684.3 \mathrm{eV}$, which is associated with physically adsorbed anions on the surface of $\mathrm{TiO}_{2}$ microspheres. It has been reported that $\mathrm{OH}$. radicals are more mobile on the $\mathrm{F}-\mathrm{TiO}_{2}$ surface than on pure $\mathrm{TiO}_{2}$, which accelerates the photocatalytic degradation of organic pollutants [210]. F-mp- $\mathrm{TiO}_{2}$ microspheres were more efficient in the absorption of visible light compared to P25, which was attributed to light scattering inside the core and mesopores. In the methylene blue photocatalytic degradation under UV light, the F-mp- $\mathrm{TiO}_{2}$ hollow microspheres showed about 93\% degradation compared with $88 \%$ for P25 over the same time interval. This enhancement was attributed to the presence of accessible mesopore channels, improved light harvesting capabilities, and surface fluorination.

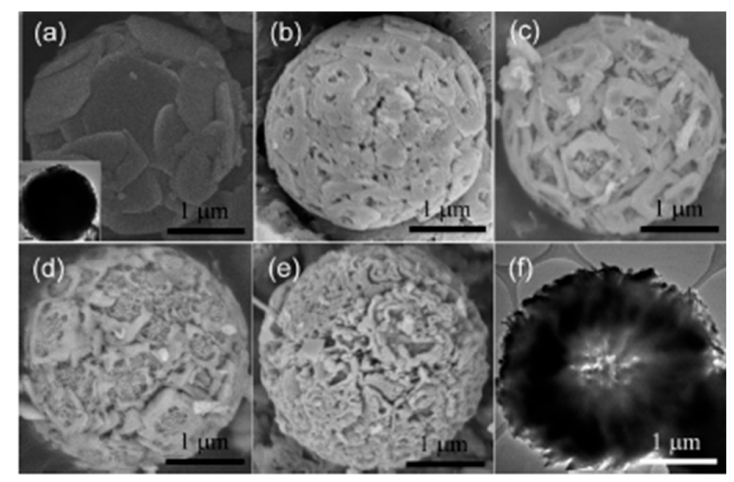

Figure 7. SEM images of F-mp- $\mathrm{TiO}_{2}$ microspheres synthesized in (a) 0.1 ; (b) 0.3 ; (c) 0.5 ; (d) 0.8 ; and (e) $1.0 \% \mathrm{H}_{2} \mathrm{SO}_{4}$ solution. Panel (f) and the insert of panel (a) are TEM images corresponding to hollow (e) and solid (a) microspheres, respectively. Reprinted with permission from reference [206]. (Reprinted with permission from Journal of the American Chemical Society vol. 130, J.H. Pan et al. "Self-etching reconstruction of hierarchically mesoporous $\mathrm{F}_{-} \mathrm{TiO}_{2}$ hollow microspherical photocatalyst for concurrent membrane water purifications", pp. 11256-11257, Copyright (2008) American Chemical Society.) 
Along with enhancing the production of free $\mathrm{OH}$. radicals and reduction of the recombination of photogenerated electrons and holes due to the strong electron-withdrawing ability of the surface fluoride, it was shown that $\mathrm{F}^{-}$ions suppress the crystallization of the brookite phase, catalyze the phase transformation of brookite to anatase, and enhance the growth of anatase crystallites [208]. F-mp- $\mathrm{TiO}_{2}$ powders were prepared by a hydrothermal method from $\mathrm{NH}_{4} \mathrm{HF}_{2}-\mathrm{H}_{2} \mathrm{O}-\mathrm{C}_{2} \mathrm{H}_{5} \mathrm{OH}$ mixed solution with tetrabutylorthotitanate $\left.\left(\mathrm{Ti}\left(\mathrm{OC}_{4} \mathrm{H}_{9}\right)_{4}, \mathrm{TBOT}\right)\right)$ as precursor. XPS showed fluorine in the form of surface adsorbed $\mathrm{F}^{-}$and the UV-vis absorption edge remained unchanged while slight visible light absorption was increased due to surface fluorination. The photocatalytic decomposition of acetone under UV illumination was used to test the activity of $\mathrm{F}-\mathrm{mp}-\mathrm{TiO}_{2}$ powders. The rate constant for F-mp- $\mathrm{TiO}_{2}$ powders is about $0.0175 \mathrm{~min}^{-1}$, which is about 2.8 times higher than pure $\mathrm{TiO}_{2}$. This enhancement in photoactivity is due to the strong electron-withdrawing ability of the surface $\equiv \mathrm{Ti}-\mathrm{F}$ groups of $\mathrm{F}-\mathrm{TiO}_{2}$ powders, which reduces the recombination of photogenerated electrons and holes, and enhances the formation of free $\mathrm{OH}$ - radicals as shown in Figure 8. All of the above studies suggest that the improvement in photocatalytic activity of $\mathrm{F}-\mathrm{mp}-\mathrm{TiO}_{2}$ tested under $\mathrm{UV}$ irradiation is due to efficient charge separation but not band gap reduction.

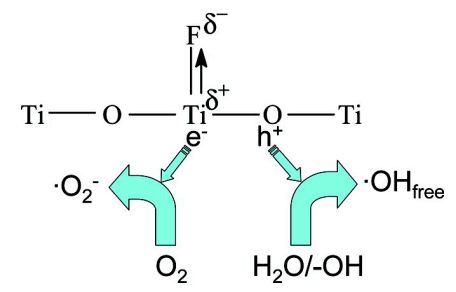

Figure 8. Schematic diagram for generation and transfer of charge carriers in $\mathrm{F}^{-\mathrm{TiO}_{2}}$ under UV irradiation. Reprinted with permission from reference [208]. (Reprinted with permission from The Journal of Physical Chemistry C vol. 113, J. Yu et al. "Enhancement of photocatalytic activity of mesoporous $\mathrm{TiO}_{2}$ powders by hydrothermal surface fluorination treatment", pp. 6743-6750, Copyright (2009) American Chemical Society.)

\subsection{Iodine Doping}

Iodine doping in titania can enhance visible light absorption, and iodine acts as an electron acceptor to reduce charge carrier recombination [211]. Liu et al. prepared visible light active iodine-doped $\mathrm{mp}-\mathrm{TiO}_{2}\left(\mathrm{I}-\mathrm{mp}-\mathrm{TiO}_{2}\right)$ with a bicrystalline framework by a hydrothermal method using Ti[OCCH$\left.\left(\mathrm{CH}_{3}\right)_{2}\right]_{4}, \mathrm{P} 123$, and iodic acid as precursor, pore directing agent, and iodine source, respectively [212]. Iodine-doped titania was also synthesized without the use of a block copolymer as a template. The resulting titania had a mix of anatase and rutile crystal structure. The photocatalytic activity of the I-mp- $\mathrm{TiO}_{2}$ was demonstrated by $\mathrm{MB}$ degradation under visible light. The degradation with $\mathrm{I}-\mathrm{mp}-\mathrm{TiO}_{2}$ was about $85 \%$ in $240 \mathrm{~min}$, whereas the $\mathrm{I}-\mathrm{TiO}_{2}$ and $\mathrm{P} 25$ showed about $55 \%$ and $15 \%$, respectively. The superiority of the $\mathrm{I}-\mathrm{mp}-\mathrm{TiO}_{2}$ is attributed to the large surface area, mesoporous structure, high crystallinity, bicrystalline framework, and higher visible light absorbance due to iodine doping. Qian et al. reported the synthesis of polyvinyl alcohol [PVA]-iodine complex-doped $\mathrm{mp}-\mathrm{TiO}_{2}$ (PIT) and iodine-doped $\mathrm{TiO}_{2}$ (IT) by a hydrothermal method using TBOT as precursor, with potassium iodate and iodine as iodine sources [211]. A smaller particle size of PIT was obtained with PVA additive because the polymer helped to disperse particles and control the size of the titania. PIT prepared with calcination at $200{ }^{\circ} \mathrm{C}$ contained the maximum observed iodine content of $0.62 \%$. Further increasing calcination temperature resulted in the reduction of both surface area and iodine content. The lowest band gap of IT and PIT were 1.93 and $1.38 \mathrm{eV}$, respectively. In MB degradation under a $100 \mathrm{~W}$ halogen lamp for $1 \mathrm{~h}$, the PIT nanoparticles showed the maximum degradation of $90.2 \%$, whereas it was only $80 \%$ and $9 \%$ with IT and P25, respectively. Photoluminescence spectra obtained using terephthalic acid as a probe molecule revealed the production of a large amount of $\mathrm{OH}$. radicals on the surface of the photocatalysts. The photocatalytic enhancement of the PIT is due to the higher visible light absorption, 
less aggregated particles, and synergy produced by carbon doped from PVA. The thermal stability of iodine in PIT was also improved due to the use of PVA.

\subsection{Phosphorus Doping}

Phosphorus has been doped in $\mathrm{mp}-\mathrm{TiO}_{2}$ to improve its photocatalytic activity [213-217]. Yu et al. prepared a surfactant-templated phosphorus-doped $\mathrm{mp}-\mathrm{TiO}_{2}\left(\mathrm{P}-\mathrm{mp}-\mathrm{TiO}_{2}\right)$ using phosphoric acid as a source of phosphorus [214]. It was found that the specific surface area of the materials decreased with increasing calcination temperature. The specific surface area of $\mathrm{P}-\mathrm{mp}-\mathrm{TiO}_{2}$ calcined at $400{ }^{\circ} \mathrm{C}$ was $301 \mathrm{~m}^{2} / \mathrm{g}$ compared with $137 \mathrm{~m}^{2} / \mathrm{g}$ for pure $\mathrm{mp}-\mathrm{TiO}_{2}$. The XRD data showed that the crystallite size increased in the pure $\mathrm{mp}-\mathrm{TiO}_{2}$, which caused the collapse of the mesoporous structure, resulting in lower surface area. In contrast, the crystallite size did not change much with calcination temperature in the $\mathrm{P}-\mathrm{mp}-\mathrm{TiO}_{2}$ indicating the inhibition of anatase grain growth. Undoped titania exhibited mesoporosity loss due to the condensation of Ti-OH from the as-prepared material, while $\mathrm{H}_{3} \mathrm{PO}_{4}$ promoted the formation of more completely condensed walls without mesopore loss by providing repulsion between grains. XPS showed a P $2 \mathrm{p}$ peak at $133.8 \mathrm{eV}$ in $\mathrm{P}-\mathrm{mp}-\mathrm{TiO}_{2}$, which indicates phosphorus pentavalent oxidation state $\left(\mathrm{P}^{5+}\right)$. This indicates the absence of Ti-P since the binding energy of Ti-P is $128.6 \mathrm{eV}$. Pentane oxidation was used to demonstrate the photocatalytic activity of $\mathrm{P}-\mathrm{mp}-\mathrm{TiO}_{2}$. The UV-vis spectroscopy measurement showed that the band gap of $\mathrm{TiO}_{2}$ increased from 3.10 to $3.17 \mathrm{eV}$ in $\mathrm{P}-\mathrm{mp}-\mathrm{TiO}_{2}$. This blue shift in light absorption upon phosphorus doping is attributed to the reduced crystallinity of the $\mathrm{P}-\mathrm{mp}-\mathrm{TiO}_{2} . \mathrm{P}-\mathrm{mp}-\mathrm{TiO}_{2}$ calcined at $500{ }^{\circ} \mathrm{C}$ showed the highest pentane oxidation rate of about $8.5 \mathrm{ppm} \cdot \mathrm{min}^{-1} \cdot \mathrm{g}^{-1}$, whereas it was only $6 \mathrm{ppm} \cdot \mathrm{min}^{-1} \cdot \mathrm{g}^{-1}$ with pure $m p-\mathrm{TiO}_{2}$. The higher photocatalytic activity of $\mathrm{P}-\mathrm{mp}-\mathrm{TiO}_{2}$ was explained by the extended band gap energy, which provided a more powerful redox ability, large surface area, and the existence of Ti ions in tetrahedral coordination.

Fan et al. studied the role of phosphorus in the synthesis of $\mathrm{P}-\mathrm{mp}-\mathrm{TiO}_{2}$ prepared by EISA [215]. As noted above, the incorporation of phosphorus is of benefit to improving the thermal stability and enhancing the surface area of $\mathrm{mp}-\mathrm{TiO}_{2}$ by constraining the growth of anatase crystallites. UV-vis spectra showed no change after phosphorus doping, and XPS revealed pentavalent phosphorous $\left(\mathrm{P}^{5+}\right)$ consistent with amorphous titanium phosphate embedded in the nanocrystalline $\mathrm{TiO}_{2}$. P-mp- $-\mathrm{TiO}_{2}$ exhibited higher photocatalytic degradation of gas phase acetaldehyde compared to pure $\mathrm{mp}-\mathrm{TiO}_{2}$ and P25 under a 300-W Xe arc lamp due to the enhanced surface area upon phosphorus doping. The optimum amount of phosphorus was obtained from the balance between the increased surface area and the formation of recombination centers for photogenerated charge carriers.

Guo et al. reported the synthesis $\mathrm{P}-\mathrm{mp}-\mathrm{TiO}_{2}$ by hydrothermal and sol-gel methods [213]. The P-mp- $\mathrm{TiO}_{2}$ showed high photocatalytic activity in $\mathrm{MB}$ degradation under Xe lamp irradiation due to the mesoporous structure and large specific surface area. The above studies suggest that phosphorus doping showed improved photocatalytic activity of $\mathrm{mp}-\mathrm{TiO}_{2}$ due to the inhibition of crystal growth and maintaining high-surface area mesostructure, but not improvement in visible light absorption. Basically, phosphorus might not be present in the lattice of $\mathrm{mp}-\mathrm{TiO}_{2}$ as a dopant, but it has a favorable mesopore structure effect.

\subsection{Summary of Nonmetal Dopants Other Than Nitrogen}

Table 2 summarizes the synthesis methods, pore directing agents, dopant sources, relevant XPS binding energies, band gaps before and after doping, specific surface areas, compounds used for photocatalytic testing, and photocatalytic enhancement found in titania doped with non-metals other than N. As discussed above, C, B, F, I, and P have been used to enhance visible light absorption and visible light driven photocatalytic activity of titania by various mechanisms. All of the non-metal-doped $\mathrm{mp}-\mathrm{TiO}_{2}$ showed higher photocatalytic performance compared to either undoped $\mathrm{mp}-\mathrm{TiO}_{2}$ or doped nonporous titania. Contributions to improved photocatalytic activity of titania include better visible light absorption due to bandgap reduction and optical effects, efficient charge separation, suppressing phase transformation, controlling crystal growth, and inhibiting photogenerated charge carrier recombination. 
Table 2. The synthesis method, dopant source, and the chemical, optical, and photocatalytic properties of non-metal-doped mesoporous titania.

\begin{tabular}{|c|c|c|c|c|c|c|c|c|c|c|}
\hline Method & Template & Dopant Source & $\begin{array}{c}\text { Dopant Composition } \\
\text { (atom \%) }\end{array}$ & $\begin{array}{c}\text { XPS Binding } \\
\text { Energy }(\mathrm{eV})\end{array}$ & $\begin{array}{c}\text { Initial } \\
\text { BG (eV) }\end{array}$ & $\begin{array}{c}\text { Final } \\
\text { BG }(\mathrm{eV})\end{array}$ & $\mathrm{S}_{\mathrm{BET}}\left(\mathrm{m}^{2} / \mathrm{g}\right)$ & $\begin{array}{c}\text { Test } \\
\text { Compounds }\end{array}$ & Enhancement & Ref. \\
\hline $\begin{array}{l}\text { Sol-gel plus } \\
\text { hydrothermal }\end{array}$ & Glucose & Glucose & $\mathrm{C}$ & $\begin{array}{l}282.4,284.8 \\
286.2,288.6\end{array}$ & - & - & 190 & $\begin{array}{c}\text { Reactive } \\
\text { Brilliant X-3B }\end{array}$ & 3.6 & [199] \\
\hline Solvothermal & Free & Rice & C & $\begin{array}{l}284.9,285.8 \\
288.2,288.6\end{array}$ & 3.1 & 2.04 & 138 & $\mathrm{MO}$ & 25.8 & [32] \\
\hline Hydrothermal & Free & $\mathrm{TiF}_{4}$ & 0.16 (atomic ratio, $\mathrm{F} / \mathrm{Ti}$ ) & 684.3 & - & - & 21.6 & $\mathrm{MB}$ & 1.06 & [206] \\
\hline Hydrothermal & - & $\begin{array}{c}\mathrm{NH}_{4} \mathrm{HF}_{2}-\mathrm{H}_{2} \mathrm{O}- \\
\mathrm{C}_{2} \mathrm{H}_{5} \mathrm{OH}\end{array}$ & 0.5 (atomic ratio, $\mathrm{F} / \mathrm{Ti}$ ) & 684 & - & - & 196.6 & Acetone & 3 & [208] \\
\hline Hydrothermal & P123 & Iodic acid & $5.2(\mathrm{I})$ & 624.5 & - & - & 157 & $\mathrm{MB}$ & 5.6 & [212] \\
\hline Hydrothermal & $\begin{array}{l}\text { Polyvinyl } \\
\text { alcohol }\end{array}$ & $\mathrm{KI}$ and $\mathrm{I}_{2}$ & $0.62(\mathrm{I})$ & - & - & 1.39 & $\begin{array}{c}190.22 \\
\text { (doped) }\end{array}$ & $\mathrm{MB}$ & 9 & [211] \\
\hline Sol-gel & - & Boric acid & $17.8(\mathrm{~B})$ & 192 & 3.05 & 3.04 & 68.11 & Metoprolol & 1.45 & [57] \\
\hline Sol-gel & P123 & Phosphoric acid & 14 (atomic ratio, $\mathrm{P} / \mathrm{Ti}$ ) & - & 3.1 & 3.17 & - & Pentane & 1.42 & [214] \\
\hline $\begin{array}{l}\text { Hydrothermal } \\
\text { and sol-gel }\end{array}$ & - & Phosphoric acid & - & $133.4,133.5$ & - & - & 106.86 & MB & 2 & [213] \\
\hline
\end{tabular}




\section{Co-Doping of Non-Metals}

Overall, non-metal doping in $\mathrm{mp}-\mathrm{TiO}_{2}$ has been shown to have a variety of effects including extending the absorption edge into the visible-light region, improving the separation efficiency of photogenerated electron-hole pairs and thus enhancing visible light driven photocatalytic activity. Further progress in the utilization of solar energy has increased in recent years. Since different dopant elements form energy states at different positions between the valence and conduction band of titania, co-doping has been hypothesized to induce synergistic enhancements in photocatalytic activity of $\mathrm{TiO}_{2}$. In addition, co-doping may help to reduce charge recombination by compensating for charge vacancies formed by nitrogen doping alone. Co-doping of $\mathrm{mp}-\mathrm{TiO}_{2}$ to improve visible light photoactivity has been accomplished with B/N [218-221], C/N [33,222], F/N [50,187,223,224], $\mathrm{P} / \mathrm{N}[56], \mathrm{S} / \mathrm{N}[176,177,179,223,225,226], \mathrm{I} / \mathrm{S}$ [227], and S/N/C [46,178].

$\mathrm{B} / \mathrm{N}$ co-doping in $\mathrm{mp}-\mathrm{TiO}_{2}$ has been shown in several reports to give enhanced visible light photoactivity [218-221]. Liu et al. showed synergistic effects of $\mathrm{B} / \mathrm{N}$ co-doping of $\mathrm{mp}-\mathrm{TiO}_{2}$ prepared using P123 as a template in visible light photocatalytic degradation of rhodamine B [47]. B dopant (with XPS binding energy of $191.5 \mathrm{eV}$ ) was incorporated by hydrothermal processing and $\mathrm{N}$ dopant by thermal treatment under ammonia. The presence of $\mathrm{O}-\mathrm{Ti}-\mathrm{B}$ bonds contributed to the visible light absorption, and a new O-Ti-B-N structure that formed on the surface of the $\mathrm{mp}-\mathrm{TiO}_{2}$ enhanced the separation and transfer of photogenerated charge carriers. In addition, the presence of boron stabilized the structure, including the crystal size and specific surface area, relative to undoped titania during the nitrogen doping process. All of these factors contributed to much higher visible light-driven photocatalytic activity of $\mathrm{B} / \mathrm{N}-\mathrm{mp}-\mathrm{TiO}_{2}$ compared to $\mathrm{B}-\mathrm{mp}-\mathrm{TiO}_{2}$ and $\mathrm{N}-\mathrm{mp}-\mathrm{TiO}_{2}$ alone. Zhou et al. studied the effect of nitrogen doping temperature of $\mathrm{B} / \mathrm{N}$-doped $\mathrm{TiO}_{2}$ by boron doping first and subsequently nitrogen doping in $\mathrm{NH}_{3}$ at variable temperatures. The $\mathrm{B} / \mathrm{N}-\mathrm{TiO}_{2}$ showed a synergistic effect in the photocatalytic activity demonstrated by methyl orange degradation under visible light irradiation. Boron and nitrogen can both be incorporated either interstitially or substitutionally, and the Ti-O-B-N structure plays a vital role in visible-wavelength photocatalytic activity. Figure 9 shows a schematic of the transformation of surface structures of $\mathrm{B} / \mathrm{N}-\mathrm{TiO}_{2}$ at different calcination temperatures. At low temperature, the main dopants are $\mathrm{Ti}-\mathrm{O}-\mathrm{N}$ or $\mathrm{Ti}-\mathrm{O}-\mathrm{N}$ and $\mathrm{Ti}-\mathrm{O}-\mathrm{B}$ bonds, whereas the Ti-O-B-N structure becomes unstable at higher temperatures and $\mathrm{Ti}-\mathrm{B}$ and $\mathrm{Ti}-\mathrm{N}$ bonds are formed. The optimal nitrogen doping temperature was $550{ }^{\circ} \mathrm{C}$ while further increasing the calcination temperature formed oxygen vacancies and $\mathrm{Ti}^{3+}$ species, resulting in the decrease of photocatalytic activity in visible light.

$\mathrm{N} / \mathrm{F}$ co-doped $\mathrm{mp}-\mathrm{TiO}_{2}$ has been shown to exhibit enhanced visible light adsorption and photoactivity $[50,187,223,224]$. Nitrogen and fluorine co-doping provides synergistic effects compared with single element doping. Preparation of N/F-mp- $-\mathrm{TiO}_{2}$ microsphere by a solvothermal method has been reported using urea as a nitrogen source and ammonium fluoride as a fluorine source [187]. The band gaps of $\mathrm{TiO}_{2}, \mathrm{~F}-\mathrm{TiO}_{2}, \mathrm{~N}-\mathrm{TiO}_{2}$, and N/F- $-\mathrm{TiO}_{2}$ were 3.02, 2.95, 2.8, and $2.74 \mathrm{eV}$, respectively. The contents of $\mathrm{F}$ and $\mathrm{N}$ were 1.9 atom $\%$ and 0.57 atom \%, respectively. The photocatalytic activity of the doped titania was evaluated by the acid orange 7 dye degradation under visible light. The percentages of degradation after $5 \mathrm{~h}$ were $10 \%, 15 \%, 20 \%, 48 \%$, and $55 \%$ for P25, $\mathrm{TiO}_{2}, \mathrm{~N}-\mathrm{mp}-\mathrm{TiO}_{2}, \mathrm{~F}-\mathrm{mp}-\mathrm{TiO}_{2}$, and N/F-mp-TiO 2 , respectively. Fluorine doping contributed to the photocatalytic performance enhancement in different ways such as band gap narrowing, inhibition of the transformation from anatase to rutile and increasing the concentration of $\mathrm{OH}$ - radicals in the solution, which reduces the charge carrier recombination. In addition, fluorine doping formed surface acid sites that enhance the adsorption of reactant molecules and act as electron acceptors. High surface area, mesostructure, and a synergistic effect of $\mathrm{N}$ and $\mathrm{F}$ co-doping improved photocatalytic activity of $\mathrm{N} / \mathrm{F}-\mathrm{mp}-\mathrm{TiO}_{2}$ microspheres.

$\mathrm{P} / \mathrm{N}$ doping can also enhance visible light driven photocatalytic activity and thermal stability of $\mathrm{mp}-\mathrm{TiO}_{2}$ [56]. Shao et al. synthesized $\mathrm{P} / \mathrm{N}-\mathrm{mp}-\mathrm{TiO}_{2}$ by direct phosphorylation from phosphoric acid followed by nitridation with urea solution [56]. The band gap of the $\mathrm{P} / \mathrm{N}-\mathrm{mp}-\mathrm{TiO}_{2}$ is narrower than 
either N- or P-doped titania. Rhodamine B degradation was carried out using the co-doped titania under visible light illumination with a 40-W tungsten bulb. The pseudo-first order degradation rate coefficient of rhodamine $\mathrm{B}$ for $\mathrm{P} / \mathrm{N}-\mathrm{mp}-\mathrm{TiO}_{2}$ is $4.9 \times 10^{-3} \mathrm{~min}^{-1}$, which is much higher than that of P-mp- $\mathrm{TiO}_{2}, \mathrm{~N}-\mathrm{mp}-\mathrm{TiO}_{2}$, or mp- $\mathrm{TiO}_{2}$.
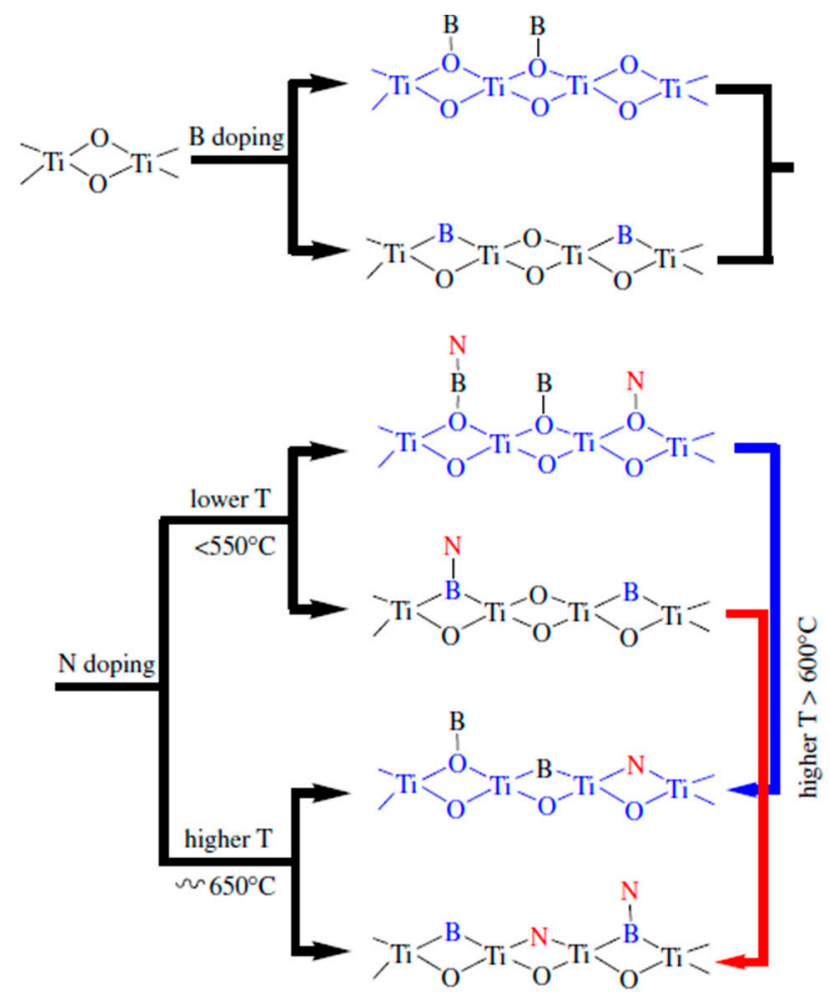

Figure 9. The transformation of surface structures of $\mathrm{B} / \mathrm{N}-\mathrm{TiO}_{2}$. Reprinted with permission from reference [221]. (Reprinted from Journal of Solid State Chemistry vol. 184, X. Zhou et al. "Effect of nitrogen-doping temperature on the structure and photocatalytic activity of the $\mathrm{B}, \mathrm{N}$-doped $\mathrm{TiO}_{2}$ ", $\mathrm{pp}$. 134-140, Copyright (2011) with permission from Elsevier.)

Tri-element co-doping of $\mathrm{mp}-\mathrm{TiO}_{2}$ provides even more opportunities to enhance visible light driven photocatalytic activity but has been studied less frequently due to the complexities of such systems $[46,178]$. The band gap is proposed to be narrowed by mixing the $\mathrm{O} 2 \mathrm{p}$ with $\mathrm{C} 2 \mathrm{p}, \mathrm{N} 2 \mathrm{p}$ and $\mathrm{S} 3 \mathrm{p}$ orbitals. El-Sheikh et al. reported the preparation of $\mathrm{S} / \mathrm{N} / \mathrm{C}-\mathrm{mp}-\mathrm{TiO}_{2}$ by sol-gel process using P123 as a template and thiourea as a precursor [46]. The titania is comprised of both anatase and brookite phases. The prepared photocatalysts were applied for the degradation of microcystin-LR under a $15 \mathrm{~W}$ fluorescent lamp. The $\mathrm{S} / \mathrm{N} / \mathrm{C}-\mathrm{mp}-\mathrm{TiO}_{2}$ performed $100 \%$ degradation with a pseudo first order rate coefficient of $0.0095 \mathrm{~min}^{-1}$, which is about 11.5 times higher compared to pure $\mathrm{TiO}_{2}$. This higher activity of the $\mathrm{S} / \mathrm{N} / \mathrm{C}-\mathrm{mp}-\mathrm{TiO}_{2}$ is attributed to the mesostructure, trielement co-doping, the crystallinity of titania, and the conductivity obtained due to carbon doping.

Table 3 summarizes the synthesis methods, pore directing agents, dopant sources, XPS binding energy of relevant dopants, band gaps before and after doping, specific surface area, compounds used for photocatalytic testing, and photocatalytic enhancement found in the non-metal co-doped $\mathrm{mp}-\mathrm{TiO}_{2}$. All reported co-doped $\mathrm{TiO}_{2}$ materials had band gaps below $3.0 \mathrm{eV}$. Visible-light photocatalytic activity was achieved using both single non-metal dopants and co-doping of $\mathrm{mp}-\mathrm{TiO}_{2}$. However, it appears that the enhancement in photocatalytic activity of the co-doped $\mathrm{mp}-\mathrm{TiO}_{2}$ is consistently higher compared to single-element doping, as shown in Tables 1 and 2, due to the synergistic effects of co-doping. 
Table 3. The synthesis method, dopant source, and chemical, optical, and photocatalytic properties of non-metal co-doped mp-TiO .

\begin{tabular}{|c|c|c|c|c|c|c|c|c|c|c|}
\hline Method & Template & Dopant Source & $\begin{array}{c}\begin{array}{c}\text { Dopant } \\
\text { Composition } \\
(\text { atom \%) }\end{array} \\
\end{array}$ & $\begin{array}{l}\text { XPS Binding } \\
\text { Energy }(e V)\end{array}$ & $\begin{array}{c}\text { Initial } \\
\text { BG (eV) }\end{array}$ & $\begin{array}{c}\text { Final } \\
\text { BG (eV) }\end{array}$ & $\mathrm{S}_{\mathrm{BET}}\left(\mathrm{m}^{2} / \mathrm{g}\right)$ & $\begin{array}{c}\text { Test } \\
\text { Compounds }\end{array}$ & Enhancement & Ref. \\
\hline Sol-gel & P123 & Thiourea & $\begin{array}{c}1.41(\mathrm{~N}), 2.33(\mathrm{~S}) \\
\mathrm{C}\end{array}$ & $399.7,401.8$ & 3.1 & 2.9 & 85.1 & $\begin{array}{l}\text { Cyanotoxin } \\
\text { microcystin-LR }\end{array}$ & 11.5 & [46] \\
\hline Sol-gel & CTAB & Thiourea & - & $\begin{array}{c}396,399.2,284.6 \\
288.2,165,169\end{array}$ & - & - & 123.8 & $\begin{array}{c}\text { Reactive } \\
\text { Brilliant Red } \\
\text { X-3B }\end{array}$ & 5 & [178] \\
\hline EISA & F127 & Thiourea & $\begin{array}{l}0.044(\mathrm{~N} / \mathrm{O}) \\
0.048(\mathrm{~S} / \mathrm{O})\end{array}$ & $400.2,396,168.5$ & - & 2.38 & 105 & $\mathrm{MO}$ & 18 & [179] \\
\hline Solvothermal & Thiourea & Thiourea & $0.62(\mathrm{~N}), 0.35(\mathrm{~S})$ & $\begin{array}{c}168.6,169.7,395.9 \\
399.7\end{array}$ & - & - & 29.11 & $\mathrm{MB}$ & 1.23 & [176] \\
\hline Hydrothermal & - & Thiourea & $1.1(\mathrm{~N}), 1.1(\mathrm{~S})$ & $\begin{array}{c}395.2,396.9,400.1 \\
168.9,170.3\end{array}$ & - & - & 22.8 (doped) & $\begin{array}{l}\text { Potassium ethyl } \\
\text { xanthate }\end{array}$ & - & [177] \\
\hline Solvothermal & - & $\begin{array}{c}\text { Urea, } \\
\text { Ammonium } \\
\text { Fluoride }\end{array}$ & $0.57(\mathrm{~N}), 1.9(\mathrm{~F})$ & $\begin{array}{c}683.7-684.6 \\
688-688.6,399.1 \\
400.1\end{array}$ & 3.02 & 2.74 & 36 & Acid Orange 7 & 5.5 & [187] \\
\hline Sol-gel & PAM and PEG & $\begin{array}{c}\text { Urea }(\mathrm{N}) \\
\text { Boric acid (B) }\end{array}$ & $1.78(\mathrm{~N}), 1.23(\mathrm{~B})$ & $400.5,192.1$ & 3.18 & 2.78 & 121.6 & MB & 3 & [219] \\
\hline EISA & $\begin{array}{c}{[\mathrm{C} 2 \mathrm{mim}][\mathrm{Cl}]} \\
\text { doped/F127 } \\
\text { undoped }\end{array}$ & {$[\mathrm{C} 2 \mathrm{mim}][\mathrm{Cl}]$} & $1.75(\mathrm{~N}), \mathrm{C}$ & $398.2,400.2$ & 3.1 & 2.98 & 54 & Water splitting & 10.5 & [33] \\
\hline
\end{tabular}




\section{Applications}

Due to its combination of optoelectronic activity, high surface area, mesostructure, and controllable morphology, $\mathrm{mp}-\mathrm{TiO}_{2}$ has many potential applications, including sensors, photocatalytic decomposition of organic compounds, solar hydrogen production by water splitting, photovoltaics, photocatalytic $\mathrm{CO}_{2}$ reduction, lithium ion batteries, and supercapacitors. Non-metal doping of $\mathrm{mp}-\mathrm{TiO}_{2}$ further can have benefits for all of these applications. As reviewed so far in this article, extensive studies have been performed on making visible light active titania materials and testing their photocatalytic performance by the decoloration and degradation of organic compounds such as methylene blue, methyl orange, and rhodamine B. However, fewer studies were carried out to apply the developed materials in energy conversion and storage. The following sections review what has been reported regarding the application of non-metal-doped $\mathrm{mp}-\mathrm{TiO}_{2}$ in photocatalytic water splitting and $\mathrm{CO}_{2}$ reduction. The benefits of non-metal doping for sensors, batteries, and capacitor applications are most likely related to conductivity changes rather than optical and surface chemical changes, and are beyond the scope of this review.

\subsection{Water Splitting}

Molecular hydrogen is considered to be one of the best alternative green energy sources to renewably fulfill increasing global energy demands [228]. Hydrogen can be produced with solar energy by water splitting using a semiconductor photocatalyst. There are two primary requirements for the semiconductor to be a water-splitting photocatalyst. First, the band gap of the semiconductor must be higher than the energy needed to split water. Second, band alignment is needed; the conduction band potential of the semiconductor must be more negative than the water reduction potential $\left(\mathrm{H}^{+} / \mathrm{H}_{2}\right.$, $0 \mathrm{~V}$ vs. NHE) and the highest level of valence band potential must be more positive than the water oxidation potential $\left(\mathrm{O}_{2} / \mathrm{H}_{2} \mathrm{O}, 1.23 \mathrm{~V}\right.$ vs. NHE). Titania fulfills these requirements and thus has the potential to be a photocatalyst for solar $\mathrm{H}_{2}$ production. Figure 10 summarizes how titania has the capability of both oxidizing water to $\mathrm{O}_{2}$ by holes generated during photoexcitation, and reducing water by excited electrons to produce $\mathrm{H}_{2}$.

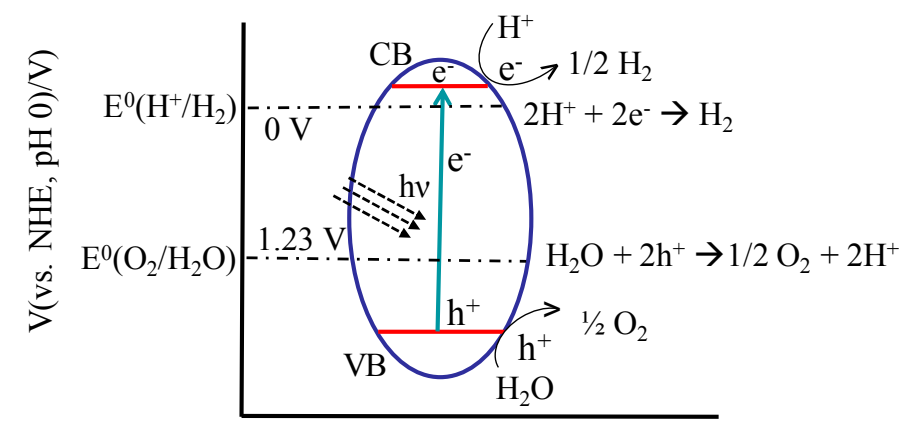

Figure 10. Basic principle of the overall water-splitting reaction on a semiconductor photocatalyst. Adapted from reference [1].

Hartmann et al. showed the effectiveness of sol-gel derived $\mathrm{mp}-\mathrm{TiO}_{2}$ in the water splitting reaction, but its large bandgap limits visible light absorption [229]. To improve hydrogen production from water splitting using visible light, non-metal elements have been doped into mp-TiO2 $[33,152,181,190,191,230]$. First, Sreethawong et al. prepared $\mathrm{N}-\mathrm{mp}-\mathrm{TiO}_{2}$ and assemblies of $\mathrm{TiO}_{2}$ nanocrystals [190]. $\mathrm{Mp}-\mathrm{TiO}_{2}$ was synthesized by a sol-gel method using laurylamine hydrochloride as a structure-directing agent, and nitrogen was doped in titania by calcination using urea. The activity of the materials were tested by photocatalytic $\mathrm{H}_{2}$ production from aqueous methanol solution under a $300 \mathrm{~W}$ Xe arc lamp with a wavelength longer than $400 \mathrm{~nm}$ using a UV cut-off glass filter. The N-mp-TiO ${ }_{2}$ showed a maximum hydrogen production rate of about $6.5 \mu \mathrm{L} \cdot \mathrm{h}^{-1}$ whereas it is 
at most about $4.5 \mu \mathrm{L} \cdot \mathrm{h}^{-1}$ for $\mathrm{N}$-doped commercial titania, which demonstrated the importance of the mesoporous structure of the photocatalyst. In 2009, the same research group investigated the effect of $\mathrm{Pt}$ loading in $\mathrm{N}-\mathrm{mp}-\mathrm{TiO}_{2}$ on the photocatalytic hydrogen production from water splitting under visible light irradiation [191]. Various amounts of $\mathrm{Pt}$ were loaded onto the $\mathrm{N}-\mathrm{mp}-\mathrm{TiO}_{2}$ from hydrogen hexachlorophatinate (IV) hexahydrate aqueous solution via the incipient wetness impregnation method. Hydrogen was produced from water splitting in an aqueous methanol solution in a closed system under a $300 \mathrm{~W}$ Xe arc lamp with a wavelength longer than $400 \mathrm{~nm}$ using a UV cut-off glass filter, where methanol was used as a sacrificial electron donor. The Pt loaded $\mathrm{N}-\mathrm{mp}-\mathrm{TiO}_{2}$ produced more hydrogen compared to only $\mathrm{N}-\mathrm{mp}-\mathrm{TiO}_{2}$. The hydrogen production increases with the Pt loading. The maximum production of hydrogen was about $27 \mu \mathrm{L} \cdot \mathrm{h}^{-1}$ using $1.3 \mathrm{wt} \% \mathrm{Pt}$ loaded nitrogen-doped titania, which is about 4.5 times higher than that of $\mathrm{N}-\mathrm{mp}-\mathrm{TiO}_{2}$. The improvement of hydrogen production upon Pt loading is due to the effect of electron trapping by Pt metal on the surface of titania. The excited electrons on the conduction band of titania are moved to the Pt metal surface, which locally traps the electrons and increases the charge carrier lifetime, and then they participate in water reduction to produce hydrogen [231]. In the meantime, the methanol consumes the photogenerated holes in the valence band of titania, which inhibits the undesired photogenerated charge recombination. This efficient charge separation by Pt resulted in improved hydrogen production from water splitting. An increase in Pt loading of more than $1.3 \mathrm{wt} \%$ decreased the hydrogen production due to increased $\mathrm{Pt}$ agglomeration, excessive coverage of the titania surface by the Pt nanoparticles, and an increased probability of charge recombination by the excess electrons on the Pt surface. Fang et al. also showed the efficacy of Pt loading in N/S-mp- $\mathrm{TiO}_{2}$ in water splitting [230]. The co-doped samples were prepared by controlled thermal decomposition of a single source, ammonium titanyl sulfate $\left(\left(\mathrm{NH}_{4}\right)_{2} \mathrm{TiO}\left(\mathrm{SO}_{4}\right)_{2}\right)$. Following preparation, $\mathrm{Pt}$ was loaded into the $\mathrm{TiO}_{2}$ mesopores via incipient wetness. The doped titania showed high photocatalytic methyl orange degradation, whereas P25 did not show any detectable degradation under visible light irradiation. The UV-vis spectroscopy data showed that the band gap of the N/S-mp- $-\mathrm{TiO}_{2}$ is $3.2 \mathrm{eV}$, which indicates that the doping did not reduce the band gap significantly but instead formed isolated energy states in the band gap of titania. The $\mathrm{N}-\mathrm{mp}-\mathrm{TiO}_{2}$ contained Brønsted acid sites arising from covalently bound sulfate groups from the precursor, which also helped with $\mathrm{MO}$ degradation. The optimum amounts of $\mathrm{Pt}$ were $1 \mathrm{wt} \%$ and $0.1 \mathrm{wt} \%$ for broad spectrum and visible light, respectively. The Pt loaded $\mathrm{N}-\mathrm{mp}-\mathrm{TiO}_{2}$ produced 740 and $3.49 \mu \mathrm{mol} \cdot \mathrm{h}^{-1} \cdot \mathrm{g}^{-1}$ hydrogen from aqueous solution of methanol under broad spectrum and visible $(\lambda>400 \mathrm{~nm})$ illumination, respectively. The hydrogen production rates without Pt loading were 20.4 and $1.82 \mu \mathrm{mol} \cdot \mathrm{h}^{-1} \cdot \mathrm{g}^{-1}$ under broad spectrum and visible $(\lambda>400 \mathrm{~nm})$ illumination, respectively.

Recently, Liu et al. prepared N-mp-TiO ${ }_{2}$ nanoparticles by an EISA method [181]. The mp- $\mathrm{TiO}_{2}$ was doped with nitrogen using urea to introduce 3.46 atom $\%$ nitrogen. In the photocatalytic water splitting from an aqueous solution containing methanol under visible light illumination (450 W Xe lamp with cutoff filter $\geq 450 \mathrm{~nm}$ ), they found that $\mathrm{N}-\mathrm{mp}-\mathrm{TiO}_{2}$ showed about seven times higher hydrogen generation rate $\left(14.9 \mu \mathrm{mol} \cdot \mathrm{g}^{-1} \cdot \mathrm{h}^{-1}\right)$ compared to undoped titania. This enhancement was attributed to the high surface area of $\mathrm{mp}-\mathrm{TiO}_{2}$ as well as $\mathrm{N}$-doping.

Liu et al. reported the preparation of $\mathrm{C} / \mathrm{N}-\mathrm{mp}-\mathrm{TiO}_{2}$ nanoparticles via an EISA method using an ionic liquid [33]. The ionic liquid (1-ethyl-3-methylimidazolium chloride, $\left.\left[\mathrm{C}_{2} \mathrm{~min}\right][\mathrm{Cl}]\right)$ provided a source of carbon and nitrogen and served as a template for pore formation. Figure 11 shows a schematic illustration of the synthesis of $\mathrm{C} / \mathrm{N}-\mathrm{mp}-\mathrm{TiO}_{2}$. The positively charged titania prepared from Ti isopropoxide co-assemble with $\left[\mathrm{C}_{2} \mathrm{mim}\right][\mathrm{Cl}]$ aggregates followed by calcination to generate

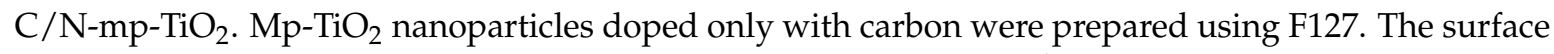
areas obtained from $\left[\mathrm{C}_{2} \mathrm{mim}\right][\mathrm{Cl}]$ and $\mathrm{F} 127$ were 101 and $54 \mathrm{~m}^{2} / \mathrm{g}$, respectively. The nitrogen content and band gap of the $\mathrm{C} / \mathrm{N}-\mathrm{mp}-\mathrm{TiO}_{2}$ nanoparticles were 1.75 atom $\%$ and $2.92 \mathrm{eV}$, respectively. Both doped and undoped titania showed carbon peaks in XPS spectra. No peak for Ti-C at $281 \mathrm{eV}$ was observed, indicating that substitutional $\mathrm{C}$ atoms may not have been incorporated. Photocatalytic hydrogen generation rates from water with methanol as a sacrificial reagent under $450 \mathrm{~W}$ Xe lamp for 
P25, C-mp- $\mathrm{TiO}_{2}$ and best performing C/N-mp- $\mathrm{TiO}_{2}$ nanoparticles were $2.2,7.8$, and $81.8 \mu \mathrm{mol} \cdot \mathrm{g}^{-1} \cdot \mathrm{h}^{-1}$, respectively. This superior photocatalytic activity is attributed to the high surface area, and synergistic effects of carbon and nitrogen co-doping. In addition, the small particle size found in $\mathrm{mp}-\mathrm{TiO}_{2}$ helped reduce charge recombination, which contributed to the improved water splitting performance.

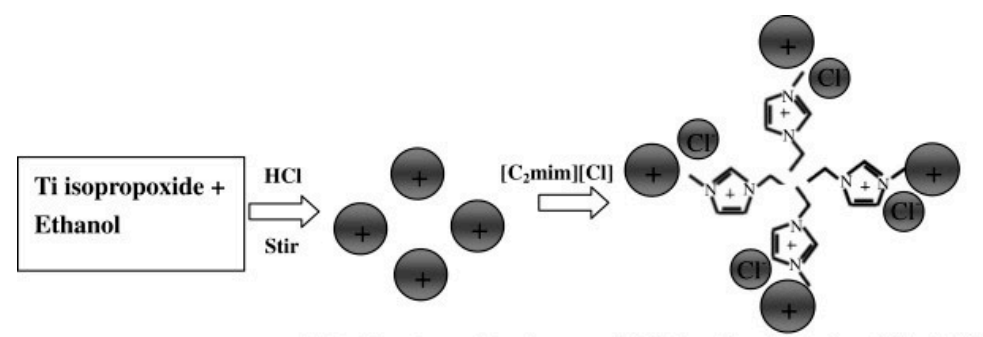

(a) Positive charged titania

(b) Interaction of titania and $\left[\mathrm{C}_{2}\right.$ mim] $[\mathrm{Cl}]$

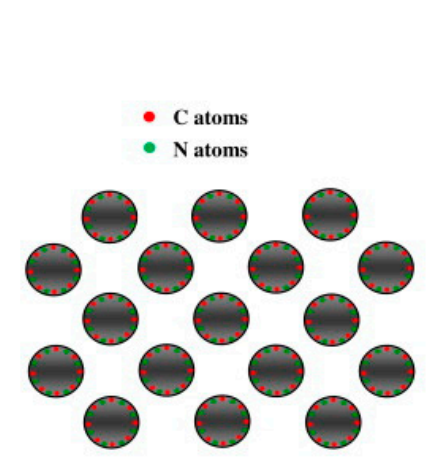

(d) CNMT- $x$

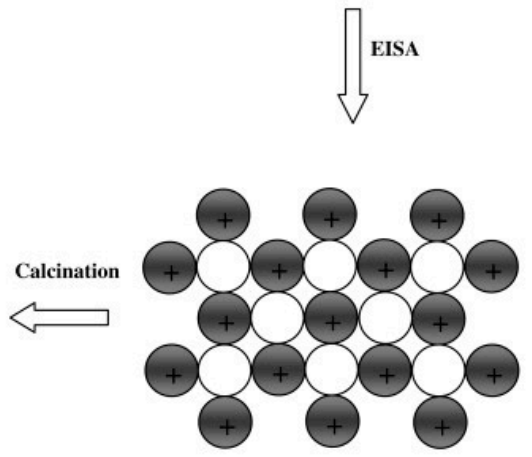

(c) Ethanol induced self-assembly

Figure 11. Schematic illustrations of synthesis procedure for CNMT- $x$ samples. Reprinted with permission from reference [33]. (Reprinted from International Journal of Hydrogen Energy vol. 38, S.-H. Liu and H.-R. Syu, "High visible-light photocatalytic hydrogen evolution of C,N-co-doped mesoporous $\mathrm{TiO}_{2}$ nanoparticles prepared via an ionic-liquid-template approach," pp. 13856-13865, Copyright (2013) with permission from Elsevier.)

Recently, our group has reported surfactant templated $\mathrm{mp}-\mathrm{TiO}_{2}$ films treated with $\mathrm{N}_{2}$ /argon plasma studied for ultraviolet and visible light induced photocatalytic water splitting activity [173]. The effect of light sources on PEC performance was explored using UV (365 nm), blue (455 nm), and green $(530 \mathrm{~nm}) \mathrm{LEDs}$. N-TiO 2 films showed $242 \times$ and $240 \times$ enhancement of photocurrent, compared to undoped $\mathrm{TiO}_{2}$ films under UV $(365 \mathrm{~nm})$ and blue LED $(455 \mathrm{~nm})$ irradiation, respectively. The N-doped films also showed overall enhancement of up to $70 \times$ and $92 \times$ with a broad spectrum Xe arc lamp and halogen bulb, respectively, and photocatalytic activity even with green LED illumination, compared to no measurable activity without doping. This study showed that plasma-induced doping of sol-gel materials enables the efficient incorporation of heteroatoms into disordered metal oxide nanostructures, thereby leading to remarkable enhancement in visible-light driven photoelectrochemical water splitting.

\section{2. $\mathrm{CO}_{2}$ Reduction}

Recently, depletion of fossil fuels and climate change due to $\mathrm{CO}_{2}$ emission have become profound concerns [232]. To tackle these global concerns, intensive research is ongoing to find clean and renewable energy sources and reduce $\mathrm{CO}_{2}$ emissions. $\mathrm{TiO}_{2}$ can address these concerns through its use for $\mathrm{CO}_{2}$ conversion to fuel since its conduction band potential is more negative than the reduction potential of $\mathrm{CO}_{2}$. Fuels such as formic acid, formaldehyde, methyl alcohol, and methane can be formed 
by the reduction of $\mathrm{CO}_{2}[233,234]$. A multistep reaction (Equations (7)-(11)) process for $\mathrm{CO}_{2}$ reduction has been suggested based on the products $\left(\mathrm{HCOOH}, \mathrm{HCHO}, \mathrm{CH}_{3} \mathrm{OH}\right.$ and $\left.\mathrm{CH}_{4}\right)$ [234].

$$
\begin{gathered}
\mathrm{H}_{2} \mathrm{O}+2 \mathrm{~h}^{+} \rightarrow 1 / 2 \mathrm{O}_{2}+2 \mathrm{H}^{+} \\
\mathrm{CO}_{2} \text { (aq.) }+2 \mathrm{H}^{+}+2 \mathrm{e}^{-} \rightarrow \mathrm{HCOOH} \\
\mathrm{HCOOH}+2 \mathrm{H}^{+}+2 \mathrm{e}^{-} \rightarrow \mathrm{HCHO}+\mathrm{H}_{2} \mathrm{O} \\
\mathrm{HCHO}+2 \mathrm{H}^{+}+2 \mathrm{e}^{-} \rightarrow \mathrm{CH}_{3} \mathrm{OH} \\
\mathrm{CH}_{3} \mathrm{OH}+2 \mathrm{H}^{+}+2 \mathrm{e}^{-} \rightarrow \mathrm{CH}_{4}+\mathrm{H}_{2} \mathrm{O} .
\end{gathered}
$$

In this mechanism, consumption of $\mathrm{CO}_{2}$ leads to formation of several different products depending on the photocatalyst and co-catalyst used. Only one article reports the application of non-metal-doped $\mathrm{mp}-\mathrm{TiO}_{2}$ in $\mathrm{CO}_{2}$ reduction [235]. Mengyu et al. reported the synthesis of silver-loaded, nitrogen-doped $\mathrm{TiO}_{2} / \mathrm{SBA}-15$ mesoporous catalysts through a solvothermal method using titanium n-butoxide, carboxylate-modified SBA-15, urea, and silver nitrate as $\mathrm{TiO}_{2}$ precursor, support, and nitrogen and Ag sources, respectively [235]. The mesoporous SBA-15 support was loaded with anatase $\mathrm{N}-\mathrm{TiO}_{2}$ and $\mathrm{Ag}$. Ag served as an effective electron trap to prevent fast recombination of photogenerated charge carriers, and at the same time, visible light absorption was enhanced by silver nanoparticles due to a surface plasmon resonance effect. Both substitutional and interstitial nitrogen were found in the doped titania. In the $\mathrm{CO}_{2}$ reduction reaction, the catalyst produced $45.7 \mu \mathrm{mol} \cdot \mathrm{g}^{-1} \cdot \mathrm{h}^{-1}$ methanol. The improvement of methanol production upon Ag loading is due to the effect electron trapping by Ag metal on the surface of titania as illustrated in Figure 12. The excited electrons formed in the conduction band of titania are injected to Ag nanoparticles where they participate in $\mathrm{CO}_{2}$ reduction to produce carbon radicals. In the meantime, water is oxidized by photogenerated holes to form $\mathrm{OH}$ - radicals. These radicals ultimately form methanol. The enhanced visible light driven activity was attributed to the synergistic effect of $\mathrm{N}$-doping and $\mathrm{Ag}$ nanoparticle loading over $\mathrm{TiO}_{2}$. Though many publications have reported the synthesis of non-metal doped $\mathrm{mp}-\mathrm{TiO}_{2}$ and demonstrated its photocatalytic activity by degrading different compounds, a significant opportunity still exists to explore and develop these materials for $\mathrm{CO}_{2}$ reduction to produce fuels.

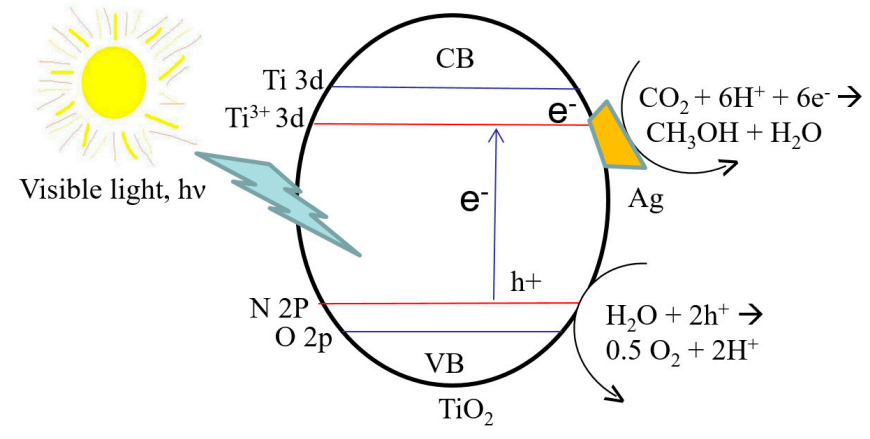

Figure 12. The mechanism of photocatalytic reduction of $\mathrm{CO}_{2}$ under visible light irradiation. Adapted from reference [235].

\section{Future Directions}

Intensive studies have been carried out on the synthesis of $\mathrm{mp}-\mathrm{TiO}_{2}$ and its non-metal doping for environment and energy applications. Although significant progress has been made in band gap reduction, visible light absorption, and increasing the surface area of titania by various treatments, there is still significant room for development of these materials for photocatalysis and photovoltaics. Some of the remaining questions to be addressed are whether the mesopores are fully accessible, 
whether the dopants are distributed uniformly, whether the dopants are only on the surface of titania incorporated into the bulk of the material, and how the crystal structure of the matrix affects performance. The performance of the materials can be improved by better designing its mesostructure. For instance, charge carrier lifetimes can be increased by making materials with thin pore walls and increasing the surface/volume (bulk) ratio of titania, which will help to inhibit photogenerated charge recombination. Since the mesopores of titania particles may not be fully accessible due to aggregation of the particles, well-ordered $\mathrm{mp}-\mathrm{TiO}_{2}$ films might be promising materials to enhance pore accessibility for the separation of products and reactants. The activity can be further improved by making thick multilayer films to optimize light absorption vs. reactant and charge carrier diffusion in the materials. It is essential to understand the charge transfer dynamics among dopants, $\mathrm{mp}-\mathrm{TiO}_{2}$, and reactants molecule to further improve the photocatalytic performance of non-metal-doped $\mathrm{mp}-\mathrm{TiO}_{2}$.

In addition to non-metal dopants themselves, there is room to better understand metal co-catalysts. Noble metals act as passive sinks for electrons to promote the interfacial charge transfer process and enhance the quantum efficiency of photocatalytic system [29,236-238]. In addition, metal nanoparticles show plasmonic effects and provide hot electrons into the conduction band of titania. Incorporation of noble metal nanoparticles such as $\mathrm{Pt}, \mathrm{Au}, \mathrm{Ag}$, and $\mathrm{Cu}$ onto non-metal-doped $\mathrm{mp}-\mathrm{TiO}_{2}$ would benefit from further exploration. Furthermore, the fabrication of non-metal-doped $\mathrm{mp}-\mathrm{TiO}_{2}$ composites with other narrow band gap semiconductor materials or quantum dots that act as sensitizers will open the door to understanding the synergistic effect of doping and sensitization for further improving photocatalytic activity. Although great progress has been made in the development of materials in terms of functionality and visible light absorption for applications in the degradation of organic pollutants, few reports are available regarding their application in $\mathrm{H}_{2} \mathrm{O}$ splitting, $\mathrm{CO}_{2}$ reduction, and energy storage applications such as in lithium ion batteries. Finally, study on long-term stability and deactivation of the non-metal-doped $\mathrm{mp}-\mathrm{TiO}_{2}$ are necessary for their development for commercial use.

\section{Conclusions}

Mesoporous $\mathrm{TiO}_{2}$ presents opportunities for use in a number of applications due to combining a favorable morphology (accessible pores, high surface area, well-defined mesostructure, tunable pore size and shape, and thin pore walls) with innate optoelectronic activity. It is of particular interest for high-volume applications because of its low cost and environmentally benign nature. These unique properties make it highly promising in environmental, energy conversion, and storage applications. To overcome its limitation in visible light absorption due to its wide band gap, $\mathrm{mp}-\mathrm{TiO}_{2}$ has been doped with several non-metal elements in an effort to enhance the visible light driven photocatalytic activity. Although significant progress has been made in the last few years, incorporation of non-metal dopants into the $\mathrm{mp}-\mathrm{TiO}_{2}$ lattice while controlling its phase and mesostructure remains a challenge.

In this review, we have discussed the synthesis of $\mathrm{mp}-\mathrm{TiO}_{2}$, different doping methods, and dopant sources. Its applications in environmental pollutant degradation, $\mathrm{H}_{2} \mathrm{O}$ splitting to produce hydrogen gas, and $\mathrm{CO}_{2}$ reduction to fuel were discussed. Among several non-metal dopants and modifiers that have been investigated $(\mathrm{H}, \mathrm{C}, \mathrm{B}, \mathrm{N}, \mathrm{F}, \mathrm{I}, \mathrm{S}$, and $\mathrm{P})$, the most promising and most studied one is nitrogen. The most common approaches to materials synthesis for this purpose are based on liquid-phase methods (hydrothermal or solvothermal) where the buildup of the material from molecular precursors provides opportunities to introduce dopants during its formation (in solution or during heat treatment steps). Typical nitrogen sources are ammonia, urea, thiourea, amine, hydrazine, and nitrogen plasma. Successfully producing doped titania for photocatalytic applications involves a tradeoff between maintaining the favorable morphology of the material (high specific surface area, controlled pore morphology, crystalline phase, etc.) while selecting a doping source and method that effectively introduces dopants at a high enough level and in the appropriate chemical state for band gap reduction, visible light absorption, control of charge carrier recombination, and ultimately, enhancement in photocatalytic activity. Because of the tradeoff between loss of mesostructure 
due to harsh temperature/chemical conditions and the introduction of dopants, there is usually an optimum calcination temperature and dopant composition to yield a favorable combination of titania phase, mesostructure, doping level, surface area, and physical and chemical state to slow charge carrier recombination.

While the major contribution of nitrogen doping was to enhance visible light absorption, the other non-metal dopants mostly contribute to photocatalytic activity in other ways such as inhibiting crystal growth and phase transformations, retaining mesostructure, increasing surface area, and providing sites for efficient charge separation. Although the mechanisms vary with dopant, the literature contains many examples in which the visible light activity of $\mathrm{mp}-\mathrm{TiO}_{2}$ has been increased by on the order of several times by incorporating all of the non-metal dopants included in this review. Despite these improvements, there is still significant opportunity to continue to increase the photocatalytic activity of titania by orders of magnitude by judiciously selecting the synthesis method and doping strategy. For example, our group recently showed that two orders of magnitude increases in photocatalytic activity can be achieved by combining a sol-gel approach to forming disordered $m p-\mathrm{TiO}_{2}$ and by using $\mathrm{N}_{2}$ / Ar plasms to introduce a high level of substitutional nitrogen under mild conditions. Preventing rapid crystallization into anatase $\mathrm{TiO}_{2}$ seems to be important to accomplishing this high level of enhancement. Other groups have also begun to explore combining multiple mechanisms of visible light enhancement by co-doping $\mathrm{mp}-\mathrm{TiO}_{2}$ with more than one non-metal dopant. In many reported examples, co-doped materials exhibit greater enhancement in visible light photocatalytic activity than titania doped with single elements due to the synergistic effects of the co-doping.

Most of the investigations of photocatalytic activity of non-metal-doped $\mathrm{mp}-\mathrm{TiO}_{2}$ employ colored organic dyes such as methylene blue, methyl orange, and rhodamine B. These are useful for establishing baseline levels of enhancement and are of direct interest for the use of titania in environmental remediation and water treatment. Fewer studies have been performed on the application of non-metal-doped $\mathrm{mp}-\mathrm{TiO}_{2}$ in $\mathrm{H}_{2} \mathrm{O}$ splitting, and $\mathrm{CO}_{2}$ reduction, but these are potentially important areas for the application of titania due to the alignment of its valence and conduction bands with the relevant electrochemical potentials required for these reactions. Significant enhancements in these reactions have been made through non-metal doping of titania, including a recent report of $240 \times$ enhancement in the rate of photoelectrochemical water oxidation in $\mathrm{N}_{2}$ / Ar plasma-doped $\mathrm{mp}-\mathrm{TiO}_{2}$ films [173]. Although this review summarizes significant enhancements in visible-light photoactivity, further improvements in visible light absorption, separation of photogenerated charge carriers, and charge transfer to reactants will be necessary for widespread use of titania in practical photocatalytic applications. Future directions to improve the efficiency of the non-metal-doped $\mathrm{mp}-\mathrm{TiO}_{2}$ will include designing stable mesostructures with highly accessible pores, making composites with noble metal electron sinks and semiconductor sensitizers, and providing a better understanding of the bottlenecks in energy conversion and storage systems that limit the commercialization of these materials.

Acknowledgments: The authors acknowledge financial support from National Science Foundation EPSCoR Research Infrastructure Initiative award supported by grant No. IIA-1355438.

Author Contributions: Syed Z. Islam performed the majority of the outlining and writing of the review regarding doping and applications of doped titania materials. Suraj Nagpure contributed the discussion of mesoporous titania synthesis. Doo Young Kim and Stephen E. Rankin managed the writing process and performed detailed editing of the manuscript.

Conflicts of Interest: The authors declare no conflict of interest.

\section{References}

1. Leung, D.Y.C.; Fu, X.; Wang, C.; Ni, M.; Leung, M.K.H.; Wang, X.; Fu, X. Hydrogen production over titania-based photocatalysts. ChemSusChem 2010, 3, 681-694. [CrossRef] [PubMed] 
2. Xiang, Q.; Yu, J.; Jaroniec, M. Synergetic effect of $\mathrm{MoS}_{2}$ and graphene as cocatalysts for enhanced photocatalytic $\mathrm{H}_{2}$ production activity of $\mathrm{TiO}_{2}$ nanoparticles. J. Am. Chem. Soc. 2012, 134, 6575-6578. [CrossRef] [PubMed]

3. Tong, H.; Ouyang, S.; Bi, Y.; Umezawa, N.; Oshikiri, M.; Ye, J. Nano-photocatalytic materials: Possibilities and challenges. Adv. Mater. 2012, 24, 229-251. [CrossRef] [PubMed]

4. Fujishima, A.; Honda, K. Electrochemical photolysis of water at a semiconductor electrode. Nature 1972, 238, 37-38. [CrossRef] [PubMed]

5. Grätzel, M. Photoelectrochemical cells. Nature 2001, 414, 338-344. [CrossRef] [PubMed]

6. Wang, G.; Wang, H.; Ling, Y.; Tang, Y.; Yang, X.; Fitzmorris, R.C.; Wang, C.; Zhang, J.Z.; Li, Y. Hydrogen-treated $\mathrm{TiO}_{2}$ nanowire arrays for photoelectrochemical water splitting. Nano Lett. 2011, 11, 3026-3033. [CrossRef] [PubMed]

7. Dholam, R.; Patel, N.; Adami, M.; Miotello, A. Hydrogen production by photocatalytic water-splitting using $\mathrm{Cr}$ - or Fe-doped $\mathrm{TiO}_{2}$ composite thin films photocatalyst. Int. J. Hydrogen Energy 2009, 34, 5337-5346. [CrossRef]

8. Aurora, P.; Rhee, P.; Thompson, L. Titania nanotube supported gold photoanodes for photoelectrochemical cells. J. Electrochem. Soc. 2010, 157, K152-K155. [CrossRef]

9. Asahi, R.; Morikawa, T.; Ohwaki, T.; Aoki, K.; Taga, Y. Visible-light photocatalysis in nitrogen-doped titanium oxides. Science 2001, 293, 269-271. [CrossRef] [PubMed]

10. Soni, S.S.; Henderson, M.J.; Bardeau, J.-F.; Gibaud, A. Visible-light photocatalysis in titania-based mesoporous thin films. Adv. Mater. 2008, 20, 1493-1498. [CrossRef]

11. Shaozheng, H.; Fayun, L.; Zhiping, F.; Jianzhou, G. Improved photocatalytic hydrogen production property over $\mathrm{Ni} / \mathrm{NiO} / \mathrm{N}^{-\mathrm{TiO}_{2-x}}$ heterojunction nanocomposite prepared by $\mathrm{NH}_{3}$ plasma treatment. J. Power Sources 2014, 250, 30-39.

12. Lan, M.; Peng, X.; Pei-Nan, W. Experimental study on the band gap narrowings of $\mathrm{TiO}_{2}$ films calcined under $\mathrm{N}_{2}$ or $\mathrm{NH}_{3}$ atmosphere. Appl. Surf. Sci. 2008, 255, 2574-2580.

13. Hidetaka, I.; Bock, J.P.; Sharma, R.; Hardcastle, F.; Kannarpady, G.K.; Mazumder, M.K.; Biris, A.S. Electrochemical synthesis of titania nanostructural arrays and their surface modification for enhanced photoelectrochemical hydrogen production. Chem. Phys. Lett. 2010, 489, 81-85.

14. Lewis, N.S. Toward cost-effective solar energy use. Science 2007, 315, 798-801. [CrossRef] [PubMed]

15. Cao, X.P.; Li, D.; Jing, W.H.; Xing, W.H.; Fan, Y.Q. Synthesis of visible-light responsive C, N and Ce co-doped $\mathrm{TiO}_{2}$ mesoporous membranes via weak alkaline sol-gel process. J. Mater. Chem. 2012, 22, 15309-15315. [CrossRef]

16. Zhang, H.; Chen, G.; Bahnemann, D.W. Photoelectrocatalytic materials for environmental applications. J. Mater. Chem. 2009, 19, 5089-5121. [CrossRef]

17. Liu, G.; Wang, L.; Yang, H.G.; Cheng, H.M.; Lu, G.Q. Titania-based photocatalysts-Crystal growth, doping and heterostructuring. J. Mater. Chem. 2010, 20, 831-843. [CrossRef]

18. Zhang, L.; Du, L.; Yu, X.; Tan, S.; Cai, X.; Yang, P.; Gu, Y.; Mai, W. Significantly enhanced photocatalytic activities and charge separation mechanism of Pd-decorated ZnO-graphene oxide Nanocomposites. ACS Appl. Mater. Interfaces 2014, 6, 3623-3629. [CrossRef] [PubMed]

19. Zhang, L.; Du, L.; Cai, X.; Yu, X.; Zhang, D.; Liang, L.; Yang, P.; Xing, X.; Mai, W.; Tan, S.; et al. Role of graphene in great enhancement of photocatalytic activity of $\mathrm{ZnO}$ nanoparticle-graphene hybrids. Physica $E$ 2013, 47, 279-284. [CrossRef]

20. $\mathrm{Li}, \mathrm{J} . ; \mathrm{Wu}, \mathrm{N}$. Semiconductor-based photocatalysts and photoelectrochemical cells for solar fuel generation: A review. Catal. Sci. Technol. 2015, 5, 1360-1384. [CrossRef]

21. Banerjee, S.; Pillai, S.C.; Falaras, P.; O'Shea, K.E.; Byrne, J.A.; Dionysiou, D.D. New insights into the mechanism of visible light photocatalysis. J. Phy. Chem. Lett. 2014, 5, 2543-2554. [CrossRef] [PubMed]

22. Shi, J.W.; Cui, H.J.; Zong, X.; Chen, S.H.; Chen, J.S.; Xu, B.; Yang, W.Y.; Wang, L.Z.; Fu, M.L. Facile one-pot synthesis of $\mathrm{Eu}, \mathrm{N}$-codoped mesoporous titania microspheres with yolk-shell structure and high visible-light induced photocatalytic performance. Appl. Catal. A 2012, 435, 86-92. [CrossRef]

23. Landmann, M.; Köhler, T.; Köppen, S.; Rauls, E.; Frauenheim, T.; Schmidt, W.G. Fingerprints of order and disorder in the electronic and optical properties of crystalline and amorphous $\mathrm{TiO}_{2}$. Phys. Rev. B 2012, 86, 064201. [CrossRef] 
24. Pelaez, M.; Nolan, N.T.; Pillai, S.C.; Seery, M.K.; Falaras, P.; Kontos, A.G.; Dunlop, P.S.M.; Hamilton, J.W.J.; Byrne, J.A.; O'Shea, K.; et al. A review on the visible light active titanium dioxide photocatalysts for environmental applications. Appl. Catal. B 2012, 125, 331-349. [CrossRef]

25. Burda, C.; Lou, Y.; Chen, X.; Samia, A.C.S.; Stout, J.; Gole, J.L. Enhanced nitrogen doping in $\mathrm{TiO}_{2}$ nanoparticles. Nano Lett. 2003, 3, 1049-1051. [CrossRef]

26. Ismail, A.A.; Bahnemann, D.W. Mesoporous titania photocatalysts: Preparation, characterization and reaction mechanisms. J. Mater. Chem. 2011, 21, 11686-11707. [CrossRef]

27. Bingham, S.; Daoud, W.A. Recent advances in making nano-sized $\mathrm{TiO}_{2}$ visible-light active through rare-earth metal doping. J. Mater. Chem. 2011, 21, 2041-2050. [CrossRef]

28. Nagaveni, K.; Hegde, M.S.; Madras, G. Structure and photocatalytic activity of $\mathrm{Ti}_{1-x} \mathrm{M}_{x} \mathrm{O}_{2 \pm \delta}(\mathrm{M}=\mathrm{W}, \mathrm{V}$, $\mathrm{Ce}, \mathrm{Zr}, \mathrm{Fe}$, and $\mathrm{Cu}$ ) synthesized by solution combustion method. J. Phys. Chem. B 2004, 108, 20204-20212. [CrossRef]

29. Devi, L.G.; Kavitha, R. A review on non metal ion doped titania for the photocatalytic degradation of organic pollutants under UV/solar light: Role of photogenerated charge carrier dynamics in enhancing the activity. Appl. Catal. B 2013, 140, 559-587. [CrossRef]

30. Choi, W.; Termin, A.; Hoffmann, M.R. The role of metal ion dopants in quantum-sized $\mathrm{TiO}_{2}$ : Correlation between photoreactivity and charge carrier recombination dynamics. J. Phys. Chem. 1994, 98, 13669-13679. [CrossRef]

31. Choi, J.; Park, H.; Hoffmann, M.R. Effects of single metal-ion doping on the visible-light photoreactivity of $\mathrm{TiO}_{2}$. J. Phys. Chem. C 2010, 114, 783-792. [CrossRef]

32. Zhang, Y.; Zhang, P.; Huo, Y.N.; Zhang, D.Q.; Li, G.S.; Li, H.X. Ethanol supercritical route for fabricating bimodal carbon modified mesoporous $\mathrm{TiO}_{2}$ with enhanced photocatalytic capability in degrading phenol. Appl. Catal. B 2012, 115, 236-244. [CrossRef]

33. Liu, S.-H.; Syu, H.-R. High visible-light photocatalytic hydrogen evolution of $\mathrm{C}, \mathrm{N}$-codoped mesoporous $\mathrm{TiO}_{2}$ nanoparticles prepared via an ionic-liquid-template approach. Int. J. Hydrogen Energy 2013, 38, 13856-13865. [CrossRef]

34. Cong, Y.; Zhang, J.; Chen, F.; Anpo, M. Synthesis and characterization of nitrogen-doped $\mathrm{TiO}_{2}$ nanophotocatalyst with high visible light activity. J. Phys. Chem. C 2007, 111, 6976-6982. [CrossRef]

35. Jinlong, L.; Xinxin, M.; Mingren, S.; Li, X.; Zhenlun, S. Fabrication of nitrogen-doped mesoporous $\mathrm{TiO}_{2}$ layer with higher visible photocatalytic activity by plasma-based ion implantation. Thin Solid Films 2010, 519, 101-105. [CrossRef]

36. Varley, J.B.; Janotti, A.; van de Walle, C.G. Mechanism of visible-light photocatalysis in nitrogen-doped $\mathrm{TiO}_{2}$. Adv. Mater. 2011, 23, 2343-2347. [CrossRef] [PubMed]

37. Asahi, R.; Morikawa, T.; Irie, H.; Ohwaki, T. Nitrogen-doped titanium dioxide as visible-light-sensitive photocatalyst: Designs, developments, and prospects. Chem. Rev. 2014, 114, 9824-9852. [CrossRef] [PubMed]

38. Serpone, N. Is the band gap of pristine $\mathrm{TiO}_{2}$ narrowed by anion- and cation-doping of titanium dioxide in second-generation photocatalysts. J. Phys. Chem. B 2006, 110, 24287-24293. [CrossRef] [PubMed]

39. Pan, H.; Zhang, Y.W.; Shenoy, V.B.; Gao, H. Effects of H-, N-, and (H, N)-doping on the photocatalytic activity of $\mathrm{TiO}_{2}$. J. Phys. Chem. C 2011, 115, 12224-12231. [CrossRef]

40. Lynch, J.; Giannini, C.; Cooper, J.K.; Loiudice, A.; Sharp, I.D.; Buonsanti, R. Substitutional or interstitial site-selective nitrogen doping in $\mathrm{TiO}_{2}$ nanostructures. J. Phys. Chem. C 2015, 119, 7443-7452. [CrossRef]

41. Wang, G.; Xiao, X.; Li, W.; Lin, Z.; Zhao, Z.; Chen, C.; Wang, C.; Li, Y.; Huang, X.; Miao, L.; et al. Significantly enhanced visible light photoelectrochemical activity in $\mathrm{TiO}_{2}$ nanowire arrays by nitrogen implantation. Nano Lett. 2015, 15, 4692-4698. [CrossRef] [PubMed]

42. Chen, X.B.; Lou, Y.B.; Samia, A.C.S.; Burda, C.; Gole, J.L. Formation of oxynitride as the photocatalytic enhancing site in nitrogen-doped titania nanocatalysts: Comparison to a commercial nanopowder. Adv. Funct. Mater. 2005, 15, 41-49. [CrossRef]

43. Wang, J.; Mao, B.; Gole, J.L.; Burda, C. Visible-light-driven reversible and switchable hydrophobic to hydrophilic nitrogen-doped titania surfaces: Correlation with photocatalysis. Nanoscale 2010, 2, 2257-2261. [CrossRef] [PubMed]

44. Di Valentin, C.; Pacchioni, G. Trends in non-metal doping of anatase $\mathrm{TiO}_{2}$ : B, C, N and F. Catal. Today 2013, 206, 12-18. [CrossRef] 
45. Chen, X.; Liu, L.; Yu, P.Y.; Mao, S.S. Increasing solar absorption for photocatalysis with black hydrogenated titanium dioxide nanocrystals. Science 2011, 331, 746-750. [CrossRef] [PubMed]

46. El-Sheikh, S.M.; Zhang, G.S.; El-Hosainy, H.M.; Ismail, A.A.; O'Shea, K.E.; Falaras, P.; Kontos, A.G.; Dionysiou, D.D. High performance sulfur, nitrogen and carbon doped mesoporous anatase-brookite $\mathrm{TiO}_{2}$ photocatalyst for the removal of microcystin-LR under visible light irradiation. J. Hazard. Mater. 2014, 280, 723-733. [CrossRef] [PubMed]

47. Liu, G.; Zhao, Y.; Sun, C.; Li, F.; Lu, G.Q.; Cheng, H.M. Synergistic effects of B/N doping on the visible-light photocatalytic activity of mesoporous $\mathrm{TiO}_{2}$. Angew. Chem. Int. Ed. 2008, 47, 5277. [CrossRef]

48. Xu, J.-H.; Li, J.; Dai, W.-L.; Cao, Y.; Li, H.; Fan, K. Simple fabrication of twist-like helix N,S-codoped titania photocatalyst with visible-light response. Appl. Catal. B 2008, 79, 72-80. [CrossRef]

49. Liu, G.; Han, C.; Pelaez, M.; Zhu, D.; Liao, S.; Likodimos, V.; Kontos, A.G.; Falaras, P.; Dionysiou, D.D. Enhanced visible light photocatalytic activity of $\mathrm{CN}$-codoped $\mathrm{TiO}_{2}$ films for the degradation of microcystin-LR. J. Mol. Catal. A Chem. 2013, 372, 58-65. [CrossRef]

50. Katsanaki, A.V.; Kontos, A.G.; Maggos, T.; Pelaez, M.; Likodimos, V.; Pavlatou, E.A.; Dionysiou, D.D.; Falaras, P. Photocatalytic oxidation of nitrogen oxides on N-F-doped titania thin films. Appl. Catal. B 2013, 140-141, 619-625. [CrossRef]

51. Periyat, P.; McCormack, D.E.; Hinder, S.J.; Pillai, S.C. One-pot synthesis of anionic (nitrogen) and cationic (sulfur) codoped high-temperature stable, visible light active, anatase photocatalysts. J. Phys. Chem. C 2009, 113, 3246-3253. [CrossRef]

52. Pelaez, M.; Falaras, P.; Kontos, A.G.; de la Cruz, A.A.; O'Shea, K.; Dunlop, P.S.M.; Byrne, J.A.; Dionysiou, D.D. A comparative study on the removal of cylindrospermopsin and microcystins from water with $\mathrm{NF}_{-} \mathrm{TiO}_{2}-\mathrm{P} 25$ composite films with visible and UV-vis light photocatalytic activity. Appl. Catal. B 2012, 121-122, 30-39. [CrossRef]

53. Kontos, A.G.; Pelaez, M.; Likodimos, V.; Vaenas, N.; Dionysiou, D.D.; Falaras, P. Visible light induced wetting of nanostructured N-F co-doped titania films. Photochem. Photobiol. Sci. 2011, 10, 350-354. [CrossRef] [PubMed]

54. Pelaez, M.; de la Cruz, A.A.; Stathatos, E.; Falaras, P.; Dionysiou, D.D. Visible light-activated N-F-codoped $\mathrm{TiO}_{2}$ nanoparticles for the photocatalytic degradation of microcystin-LR in water. Catal. Today 2009, 144, 19-25. [CrossRef]

55. Zhao, C.; Pelaez, M.; Dionysiou, D.D.; Pillai, S.C.; Byrne, J.A.; O'Shea, K.E. UV and visible light activated $\mathrm{TiO}_{2}$ photocatalysis of 6-hydroxymethyl uracil, a model compound for the potent cyanotoxin cylindrospermopsin. Catal. Today 2014, 224, 70-76. [CrossRef]

56. Shao, G.S.; Wang, F.Y.; Ren, T.Z.; Liu, Y.P.; Yuan, Z.Y. Hierarchical mesoporous phosphorus and nitrogen doped titania materials: Synthesis, characterization and visible-light photocatalytic activity. Appl. Catal. B 2009, 92, 61-67. [CrossRef]

57. Cavalcante, R.P.; Dantas, R.F.; Bayarri, B.; González, O.; Giménez, J.; Esplugas, S.; Machulek Junior, A. Synthesis and characterization of $\mathrm{B}$-doped $\mathrm{TiO}_{2}$ and their performance for the degradation of metoprolol. Catal. Today 2015, 252, 27-34. [CrossRef]

58. Crepaldi, E.L.; Soler-lllia, G.J.D.A.A.; Grosso, D.; Cagnol, G.; Ribot, F.; Sanchez, C. Controlled formation of highly organized mesoporous titania thin films: From mesostructured hybrids to mesoporous nanoanatase $\mathrm{TiO}_{2}$. J. Am. Chem. Soc. 2003, 125, 9770-9786. [CrossRef] [PubMed]

59. Feng, D.; Luo, W.; Zhang, J.; Xu, M.; Zhang, R.; Wu, H.; Lv, Y.; Asiri, A.M.; Khan, S.B.; Rahman, M.M.; et al. Multi-layered mesoporous $\mathrm{TiO}_{2}$ thin films with large pores and highly crystalline frameworks for efficient photoelectrochemical conversion. J. Mater. Chem. A 2013, 1, 1591-1599. [CrossRef]

60. Martinez-Ferrero, E.; Sakatani, Y.; Boissiere, C.; Grosso, D.; Fuertes, A.; Fraxedas, J.; Sanchez, C. Nanostructured titanium oxynitride porous thin films as efficient visible-active photocatalysts. Adv. Funct. Mater. 2007, 17, 3348-3354. [CrossRef]

61. Liao, Y.T.; Huang, C.W.; Liao, C.H.; Wu, J.C.S.; Wu, K.C.W. Synthesis of mesoporous titania thin films (MTTFs) with two different structures as photocatalysts for generating hydrogen from water splitting. Appl. Energy 2012, 100, 75-80. [CrossRef]

62. Li, L.; Yan, J.; Wang, T.; Zhao, Z.J.; Zhang, J.; Gong, J.; Guan, N. Sub-10 nm rutile titanium dioxide nanoparticles for efficient visible-light-driven photocatalytic hydrogen production. Nat. Commun. 2015, 6, 5881. [CrossRef] [PubMed] 
63. Salari, M.; Aboutalebi, S.H.; Aghassi, A.; Wagner, P.; Mozera, A.J.; Wallace, G.G. Disorder engineering of undoped $\mathrm{TiO}_{2}$ nanotube arrays for highly efficient solar-driven oxygen evolution. Phys. Chem. Chem. Phys. 2015, 17, 5642-5649. [CrossRef] [PubMed]

64. Varghese, O.K.; Paulose, M.; LaTempa, T.J.; Grimes, C.A. High-rate solar photocatalytic conversion of $\mathrm{CO}_{2}$ and water vapor to hydrocarbon fuels. Nano Lett. 2009, 9, 731-737. [CrossRef] [PubMed]

65. Islam, S.Z.; Reed, A.; Kim, D.Y.; Rankin, S.E. $\mathrm{N}_{2}$ / Ar plasma induced doping of ordered mesoporous $\mathrm{TiO}_{2}$ thin films for visible light active photocatalysis. Microporous Mesoporous Mater. 2016, 220, 120-128. [CrossRef]

66. Bagheri, S.; Mohd Hir, Z.A.; Yousefi, A.T.; Abdul Hamid, S.B. Progress on mesoporous titanium dioxide: Synthesis, modification and applications. Microporous Mesoporous Mater. 2015, 218, 206-222. [CrossRef]

67. Mahoney, L.; Koodali, R. Versatility of evaporation-induced self-assembly (EISA) method for preparation of mesoporous $\mathrm{TiO}_{2}$ for energy and environmental applications. Materials 2014, 7, 2697. [CrossRef]

68. Zhang, R.; Elzatahry, A.A.; Al-Deyab, S.S.; Zhao, D. Mesoporous titania: From synthesis to application. Nano Today 2012, 7, 344-366. [CrossRef]

69. Li, W.; Wu, Z.X.; Wang, J.X.; Elzatahry, A.A.; Zhao, D.Y. A perspective on mesoporous $\mathrm{TiO}_{2}$ materials. Chem. Mater. 2014, 26, 287-298. [CrossRef]

70. Zhou, W.; Fu, H. Mesoporous $\mathrm{TiO}_{2}$ : Preparation, doping, and as a composite for photocatalysis. ChemCatChem 2013, 5, 885-894. [CrossRef]

71. Antonelli, D.M.; Ying, J.Y. Synthesis of hexagonally packed mesoporous $\mathrm{TiO}_{2}$ by a modified sol-gel method. Angew. Chem. Int. Ed. 1995, 34, 2014-2017. [CrossRef]

72. Yu, J.; Zhang, L.; Cheng, B.; Su, Y. Hydrothermal preparation and photocatalytic activity of hierarchically sponge-like macro-/mesoporous titania. J. Phys. Chem. C 2007, 111, 10582-10589. [CrossRef]

73. Wang, H.; Miao, J.J.; Zhu, J.M.; Ma, H.M.; Zhu, J.J.; Chen, H.Y. Mesoporous spherical aggregates of anatase nanocrystals with wormhole-like framework structures: Their chemical fabrication, characterization, and photocatalytic performance. Langmuir 2004, 20, 11738-11747. [CrossRef] [PubMed]

74. Liu, X.; Gao, Y.; Cao, C.; Luo, H.; Wang, W. Highly crystalline spindle-shaped mesoporous anatase titania particles: Solution-phase synthesis, characterization, and photocatalytic properties. Langmuir 2010, 26, 7671-7674. [CrossRef] [PubMed]

75. Joo, J.B.; Zhang, Q.; Lee, I.; Dahl, M.; Zaera, F.; Yin, Y. Mesoporous anatase titania hollow nanostructures though silica-protected calcination. Adv. Funct. Mater. 2012, 22, 166-174. [CrossRef]

76. Da Silva, R.O.; Goncalves, R.H.; Stroppa, D.G.; Ramirez, A.J.; Leite, E.R. Synthesis of recrystallized anatase $\mathrm{TiO}_{2}$ mesocrystals with Wulff shape assisted by oriented attachment. Nanoscale 2011, 3, 1910-1916. [CrossRef] [PubMed]

77. Bleta, R.; Alphonse, P.; Lorenzato, L. Nanoparticle route for the preparation in aqueous medium of mesoporous $\mathrm{TiO}_{2}$ with controlled porosity and crystalline framework. J. Phys. Chem. C 2010, 114, 2039-2048. [CrossRef]

78. Moonoosawmy, K.R.; Katzke, H.; Es-Souni, M.; Dietze, M.; Es-Souni, M. Mesoporous and macroporous brookite thin films having a large thermal stability range. Langmuir 2012, 28, 6706-6713. [CrossRef] [PubMed]

79. Wang, J.; Li, H.; Li, H.; Zuo, C.; Wang, H. Thermal stability and optimal photoinduced hydrophilicity of mesoporous $\mathrm{TiO}_{2}$ thin films. J. Phys. Chem. C 2012, 116, 9517-9525. [CrossRef]

80. Yin, J.B.; Zhao, X.P. Enhanced electrorheological activity of mesoporous $\mathrm{Cr}$-doped $\mathrm{TiO}_{2}$ from activated pore wall and high surface area. J. Phys. Chem. B 2006, 110, 12916-12925. [CrossRef] [PubMed]

81. Guo, C.; $\mathrm{Xu}$, J.; Zhang, Y.; He, Y. Hierarchical mesoporous $\mathrm{TiO}_{2}$ microspheres for the enhanced photocatalytic oxidation of sulfonamides and their mechanism. RSC Adv. 2012, 2, 4720-4727. [CrossRef]

82. Nagpure, S.; Das, S.; Garlapalli, R.K.; Strzalka, J.; Rankin, S.E. In situ GISAXS investigation of low-temperature aging in oriented surfactant-mesostructured titania thin films. J. Phys. Chem. C 2015, 119, 22970-22984. [CrossRef]

83. Das, S.; Wu, Q.; Garlapalli, R.K.; Nagpure, S.; Strzalka, J.; Jiang, Z.; Rankin, S.E. In-situ GISAXS investigation of pore orientation effects on the thermal transformation mechanism in mesoporous titania thin films. J. Phys. Chem. C 2014, 118, 968-976. [CrossRef]

84. Das, S.; Nagpure, S.; Garlapalli, R.K.; Wu, Q.; Islam, S.Z.; Strzalka, J.; Rankin, S.E. Pore orientation effects on the kinetics of mesostructure loss in surfactant templated titania thin films. Phys. Chem. Chem. Phys. 2016, 18, 2896-2905. [CrossRef] [PubMed] 
85. Han, O.H.; Paik, Y.; Moon, Y.S.; Lee, S.K.; Kim, T.Y.; Lee, Y.H.; Lee, W.I. Selective synthesis of lamellar titania with carboxylate precursor and characterization by solid-state NMR. Chem. Mater. 2007, 19, 3615-3623. [CrossRef]

86. Livage, J.; Henry, M.; Sanchez, C. Sol-gel chemistry of transition metal oxides. Prog. Solid State Chem. 1988, 18, 259-341. [CrossRef]

87. Schubert, U. Chemical modification of titanium alkoxides for sol-gel processing. J. Mater. Chem. 2005, 15, 3701-3715. [CrossRef]

88. Kallala, M.; Sanchez, C.; Cabane, B. Structures of inorganic polymers in sol-gel processes based on titanium oxide. Phys. Rev. E 1993, 48, 3692-3704. [CrossRef]

89. Park, J.K.; Myoung, J.J.; Kyong, J.B.; Kim, H.K. Reaction mechanism for the hydrolysis of titanium alkoxides. Bull. Korean Chem. Soc. 2003, 24, 671-673.

90. Weymann-Schildknetch, S.; Henry, M. Mechanistic aspects of the hydrolysis and condensation of titanium alkoxides complexed by tripodal ligands. J. Chem. Soc. Dalton Trans. 2001, 2425-2428. [CrossRef]

91. Soler-Illia, G.J.D.A.A.; Sanchez, C. Interactions between poly(ethylene oxide)-based surfactants and transition metal alkoxides: Their role in the templated construction of mesostructured hybrid organic-inorganic composites. New J. Chem. 2000, 24, 493-499. [CrossRef]

92. Antonelli, D.M. Synthesis of phosphorus-free mesoporous titania via templating with amine surfactants. Microporous Mesoporous Mater. 1999, 30, 315-319. [CrossRef]

93. Brinker, C.J.; Lu, Y.; Sellinger, A.; Fan, H. Evaporation-induced self-assembly: Nanostructures made easy. Adv. Mater. 1999, 11, 579-585. [CrossRef]

94. Alberius, P.C.A.; Frindell, K.L.; Hayward, R.C.; Kramer, E.J.; Stucky, G.D.; Chmelka, B.F. General predictive syntheses of cubic, hexagonal, and lamellar silica and titania mesostructured thin films. Chem. Mater. 2002, 14, 3284-3294. [CrossRef]

95. Kirsch, B.L.; Richman, E.K.; Riley, A.E.; Tolbert, S.H. In-situ X-ray diffraction study of the crystallization kinetics of mesoporous titania films. J. Phys. Chem. B 2004, 108, 12698-12706. [CrossRef]

96. Choi, S.Y.; Mamak, M.; Coombs, N.; Chopra, N.; Ozin, G.A. Thermally stable two-dimensional hexagonal mesoporous nanocrystalline anatase, meso-nc- $\mathrm{TiO}_{2}$ : Bulk and crack-free thin film morphologies. Adv. Funct. Mater. 2004, 14, 335-344. [CrossRef]

97. Haseloh, S.; Choi, S.Y.; Mamak, M.; Coombs, N.; Petrov, S.; Chopra, N.; Ozin, G.A. Towards flexible inorganic "mesomaterials": One-pot low temperature synthesis of mesostructured nanocrystalline titania. Chem. Commun. 2004, 13, 1460-1461. [CrossRef] [PubMed]

98. Sanchez, C.; Boissière, C.; Grosso, D.; Laberty, C.; Nicole, L. Design, synthesis, and properties of inorganic and hybrid thin films having periodically organized nanoporosity. Chem. Mater. 2008, 20, 682-737. [CrossRef]

99. Huo, Q.; Margolese, D.I.; Stucky, G.D. Surfactant control of phases in the synthesis of mesoporous silica-based materials. Chem. Mater. 1996, 8, 1147-1160. [CrossRef]

100. Bosc, F.; Ayral, A.; Albouy, P.A.; Datas, L.; Guizard, C. Mesostructure of anatase thin films prepared by mesophase templating. Chem. Mater. 2004, 16, 2208-2214. [CrossRef]

101. Israelachvili, J.N. Intermolecular and Surface Forces, 2nd ed.; Academic Press: New York, NY, USA, 1992; pp. 366-394.

102. Wu, Q.; Rankin, S.E. Tuning the wall thickness and pore orientation in mesoporous titania films prepared with low-temperature aging. J. Solgel Sci. Technol. 2011, 60, 81-90. [CrossRef]

103. Jang, K.S.; Song, M.G.; Cho, S.H.; Kim, J.D. Using the effects of $\mathrm{pH}$ and moisture to synthesize highly organized mesoporous titania thin films. Chem. Commun. 2004, 13, 1514-1515. [CrossRef] [PubMed]

104. Kellogg, G.; Walton, D.; Mayes, A.; Lambooy, P.; Russell, T.; Gallagher, P.; Satija, S. Observed surface energy effects in confined diblock copolymers. Phys. Rev. Lett. 1996, 76, 2503. [CrossRef] [PubMed]

105. Huang, E.; Pruzinsky, S.; Russell, T.; Mays, J.; Hawker, C. Neutrality conditions for block copolymer systems on random copolymer brush surfaces. Macromolecules 1999, 32, 5299-5303. [CrossRef]

106. Huang, E.; Russell, T.; Harrison, C.; Chaikin, P.; Register, R.; Hawker, C.; Mays, J. Using surface active random copolymers to control the domain orientation in diblock copolymer thin films. Macromolecules 1998, 31, 7641-7650. [CrossRef]

107. Thurn-Albrecht, T.; Steiner, R.; DeRouchey, J.; Stafford, C.M.; Huang, E.; Bal, M.; Tuominen, M.; Hawker, C.J.; Russell, T.P. Nanoscopic templates from oriented block copolymer films. Adv. Mater. 2000, 12, 787-791. [CrossRef] 
108. Huinink, H.; Brokken-Zijp, J.; van Dijk, M.; Sevink, G. Asymmetric block copolymers confined in a thin film. J. Chem. Phys. 2000, 112, 2452-2462. [CrossRef]

109. Pickett, G.T.; Balazs, A.C. Equilibrium orientation of confined diblock copolymer films. Macromolecules 1997, 30, 3097-3103. [CrossRef]

110. Koganti, V.R.; Dunphy, D.; Gowrishankar, V.; McGehee, M.D.; Li, X.; Wang, J.; Rankin, S.E. Generalized coating route to silica and titania films with orthogonally tilted cylindrical nanopore arrays. Nano Lett. 2006, 6, 2567-2570. [CrossRef] [PubMed]

111. Tasinkevych, M.; Ciach, A. Structural transformations in confined lamellar phases in oil-water-surfactant mixtures. J. Chem. Phys. 2001, 115, 8705-8713. [CrossRef]

112. Rankin, S.E.; Malanoski, A.P.; van Swol, F. Monte Carlo simulation of amphiphile self-assembly during dip coating. In Proceedings of the Nonlithigraphic and Lithographic Methods of Nanofabrication-From Ultralarge-Scale Integration to Photonics to Molecular Electronics, Boston, MA, USA, 26 November-1 December 2000; Materials Research Society: Boston, MA, USA, 2001; pp. D121-D126.

113. Richman, E.K.; Brezesinski, T.; Tolbert, S.H. Vertically oriented hexagonal mesoporous films formed through nanometre-scale epitaxy. Nat. Mater. 2008, 7, 712-717. [CrossRef] [PubMed]

114. Grosso, D.; Babonneau, F.; Sanchez, C.; Soler-Illia, G.J.D.A.A.; Crepaldi, E.L.; Albouy, P.A.; Amenitsch, H.; Balkenende, A.R.; Brunet-Bruneau, A. A first insight in the mechanisms involved in the self-assembly of 2D-hexagonal templated $\mathrm{SiO}_{2}$ and $\mathrm{TiO}_{2}$ mesostructured films during dip-coating. J. Solgel Sci. Technol. 2003, 26, 561-565. [CrossRef]

115. Grosso, D.; Babonneau, F.; Albouy, P.A.; Amenitsch, H.; Balkenende, A.R.; Brunet-Bruneau, A.; Rivory, J. An in situ study of mesostructured CTAB-silica film formation during dip coating using time-resolved SAXS and interferometry measurements. Chem. Mater. 2002, 14, 931-939. [CrossRef]

116. Grosso, D.; Balkenende, A.R.; Albouy, P.A.; Ayral, A.; Amenitsch, H.; Babonneau, F. Two-dimensional hexagonal mesoporous silica thin films prepared from block copolymers: Detailed characterization and formation mechanism. Chem. Mater. 2001, 13, 1848-1856. [CrossRef]

117. Grosso, D.; Babonneau, F.; Soler-Illia, G.J.D.A.A.; Albouy, P.A.; Amenitsch, H. Phase transformation during cubic mesostructured silica film formation. Chem. Commun. 2002, 748-749. [CrossRef]

118. Grosso, D.; Cagnol, F.; Soler-Illia, G.J.D.A.A.; Crepaldi, E.L.; Amenitsch, H.; Brunet-Bruneau, A.; Bourgeois, A.; Sanchez, C. Fundamentals of mesostructuring through evaporation-induced self-assembly. Adv. Funct. Mater. 2004, 14, 309-322. [CrossRef]

119. Faustini, M.; Boissière, C.; Nicole, L.; Grosso, D. From chemical solutions to inorganic nanostructured materials: A journey into evaporation-driven processes. Chem. Mater. 2014, 26, 709-723. [CrossRef]

120. Koganti, V.R.; Das, S.; Rankin, S.E. In situ FTIR investigation of the kinetics of silica polycondensation in surfactant templated, mesostructured thin films. J. Phys. Chem. C 2014, 118, 19450-19461. [CrossRef]

121. Ko, Y.-S.; Koh, C.-W.; Lee, U.-H.; Kwon, Y.-U. Synthesis of mesoporous titania thin films with vertical pore channels and thick and crystalline walls. Microporous Mesoporous Mater. 2011, 145, 141-145. [CrossRef]

122. Koh, C.-W.; Lee, U.-H.; Song, J.-K.; Lee, H.-R.; Kim, M.-H.; Suh, M.; Kwon, Y.-U. Mesoporous titania thin film with highly ordered and fully accessible vertical pores and crystalline walls. Chem. Asian J. 2008, 3, 862-867. [CrossRef] [PubMed]

123. Grosso, D.; Soler-Illia, G.J.D.A.A.; Crepaldi, E.L.; Cagnol, F.; Sinturel, C.; Bourgeois, A.; Brunet-Bruneau, A.; Amenitsch, H.; Albouy, P.A.; Sanchez, C. Highly porous $\mathrm{TiO}_{2}$ anatase optical thin films with cubic mesostructure stabilized at $700{ }^{\circ} \mathrm{C}$. Chem. Mater. 2003, 15, 4562-4570. [CrossRef]

124. Wanka, G.; Hoffmann, H.; Ulbricht, W. Phase diagrams and aggregation behavior of poly(oxyethylene)poly(oxypropylene)-poly(oxyethylene) triblock copolymers in aqueous solutions. Macromolecules 1994, 27, 4145-4159. [CrossRef]

125. Lee, U.H.; Lee, H.; Wen, S.; Mho, S.-I.; Kwon, Y.-U. Mesoporous titania thin films with pseudo-cubic structure: Synthetic studies and applications to nanomembranes and nanotemplates. Microporous Mesoporous Mater. 2006, 88, 48-55. [CrossRef]

126. Liu, K.; Fu, H.; Shi, K.; Xiao, F.; Jing, L.; Xin, B. Preparation of large-pore mesoporous nanocrystalline $\mathrm{TiO}_{2}$ thin films with tailored pore diameters. J. Phys. Chem. B 2005, 109, 18719-18722. [CrossRef] [PubMed]

127. Li, X.S.; Fryxell, G.E.; Birnbaum, J.C.; Wang, C. Effects of template and precursor chemistry on structure and properties of mesoporous $\mathrm{TiO}_{2}$ thin films. Langmuir 2004, 20, 9095-9102. [CrossRef] [PubMed] 
128. Lee, D.W.; Park, S.J.; Ihm, S.K.; Lee, K.H. Synthesis of bimodal mesoporous titania with high thermal stability via replication of citric acid-templated mesoporous silica. Chem. Mater. 2007, 19, 937-941. [CrossRef]

129. Yue, W.; Xu, X.; Irvine, J.T.S.; Attidekou, P.S.; Liu, C.; He, H.; Zhao, D.; Zhou, W. Mesoporous monocrystalline $\mathrm{TiO}_{2}$ and its solid-state electrochemical properties. Chem. Mater. 2009, 21, 2540-2546. [CrossRef]

130. Zhang, Z.; Zuo, F.; Feng, P. Hard template synthesis of crystalline mesoporous anatase $\mathrm{TiO}_{2}$ for photocatalytic hydrogen evolution. J. Mater. Chem. 2010, 20, 2206-2212. [CrossRef]

131. McDonnell, K.A.; English, N.J.; Rahman, M.; Dowling, D.P. Influence of doping on the photoactive properties of magnetron-sputtered titania coatings: Experimental and theoretical study. Phys. Rev. B Condens. Matter 2012, 86, 115306. [CrossRef]

132. Ghicov, A.; Macak, J.M.; Tsuchiya, H.; Kunze, J.; Haeublein, V.; Kleber, S.; Schmuki, P. TiO 2 nanotube layers: Dose effects during nitrogen doping by ion implantation. Chem. Phys. Lett. 2006, 419, 426-429. [CrossRef]

133. Ghicov, A.; Macak, J.M.; Tsuchiya, H.; Kunze, J.; Haeublein, V.; Frey, L.; Schmuki, P. Ion implantation and annealing for an efficient $\mathrm{N}$-doping of $\mathrm{TiO}_{2}$ nanotubes. Nano Lett. 2006, 6, 1080-1082. [CrossRef]

134. Aman, N.; Mishra, T.; Sahu, R.K.; Tiwari, J.P. Facile synthesis of mesoporous N doped zirconium titanium mixed oxide nanomaterial with enhanced photocatalytic activity under visible light. J. Mater. Chem. 2010, 20, 10876-10882. [CrossRef]

135. Mao, C.; Zuo, F.; Hou, Y.; Bu, X.; Feng, P. In situ preparation of a $\mathrm{Ti}^{3+}$ self-doped $\mathrm{TiO}_{2}$ film with enhanced activity as photoanode by $\mathrm{N}_{2} \mathrm{H}_{4}$ reduction. Angew. Chem. Int. Ed. 2014, 53, 10485-10489. [CrossRef] [PubMed]

136. Islam, S.Z.; Rankin, S.E. Hydrazine-based synergistic $\mathrm{Ti}(\mathrm{III}) / \mathrm{N}$ doping of surfactant-templated $\mathrm{TiO}_{2}$ thin films for enhanced visible light photocatalysis. Mater. Chem. Phys. 2016, 182, 382-393. [CrossRef]

137. Liu, Z.; Wang, Y.; Chu, W.; Li, Z.; Ge, C. Characteristics of doped $\mathrm{TiO}_{2}$ photocatalysts for the degradation of methylene blue waste water under visible light. J. Alloys Compd. 2010, 501, 54-59. [CrossRef]

138. Gohin, M.; Maurin, I.; Gacoin, T.; Boilot, J.P. Photocatalytic activity of mesoporous films based on N-doped $\mathrm{TiO}_{2}$ nanoparticles. J. Mater. Chem. 2010, 20, 8070-8077. [CrossRef]

139. Sivaranjani, K.; Gopinath, C.S. Porosity driven photocatalytic activity of wormhole mesoporous $\mathrm{TiO}_{2-x} \mathrm{~N}_{x}$ in direct sunlight. J. Mater. Chem. 2011, 21, 2639-2647. [CrossRef]

140. Ananpattarachai, J.; Kajitvichyanukul, P.; Seraphin, S. Visible light absorption ability and photocatalytic oxidation activity of various interstitial N-doped $\mathrm{TiO}_{2}$ prepared from different nitrogen dopants. J. Hazard. Mater. 2009, 168, 253-261. [CrossRef] [PubMed]

141. Liu, H.; Liu, G.; Shi, X. N/Zr-codoped $\mathrm{TiO}_{2}$ nanotube arrays: Fabrication, characterization, and enhanced photocatalytic cctivity. Colloids Surf. A 2010, 363, 35-40. [CrossRef]

142. Kafizas, A.; Parkin, I.P. The combinatorial atmospheric pressure chemical vapour deposition (cAPCVD) of a gradating N-doped mixed phase titania thin film. J. Mater. Chem. 2010, 20, 2157-2169. [CrossRef]

143. Miao, L.; Tanemura, S.; Watanabe, H.; Toh, S.; Kaneko, K. Structural and compositional characterization of $\mathrm{N}_{2}-\mathrm{H}_{2}$ plasma surface-treated $\mathrm{TiO}_{2}$ thin films. Appl. Surf. Sci. 2005, 244, 412-417. [CrossRef]

144. Sharma, R.; Das, P.P.; Misra, M.; Mahajan, V.; Bock, J.P.; Trigwell, S.; Biris, A.S.; Mazumder, M.K. Enhancement of the photoelectrochemical conversion efficiency of nanotubular $\mathrm{TiO}_{2}$ photoanodes using nitrogen plasma assisted surface modification. Nanotechnology 2009, 20, 075704. [CrossRef] [PubMed]

145. Liu, X.; Liu, Z.; Zheng, J.; Yan, X.; Li, D.; Chen, S.; Chu, W. Characteristics of N-Doped $\mathrm{TiO}_{2}$ nanotube arrays by $\mathrm{N}_{2}$-plasma for visible light-driven photocatalysis. J. Alloys Compd. 2011, 509, 9970-9976. [CrossRef]

146. Lee, H.U.; Lee, Y.; Lee, S.C.; Park, S.Y.; Son, B.; Lee, J.W.; Lim, C.; Choi, C.; Choi, M.; Lee, S.Y.; et al. Visible-light-responsive bicrystalline (anatase/brookite) nanoporous nitrogen-doped $\mathrm{TiO}_{2}$ photocatalysts by plasma treatment. Chem. Eng. J. 2014, 254, 268-275. [CrossRef]

147. Pulsipher, D.J.; Martin, I.T.; Fisher, E.R. Controlled nitrogen doping and film colorimetrics in porous $\mathrm{TiO}_{2}$ materials using plasma processing. ACS Appl. Mater. Interfaces 2010, 2, 1743-1753. [CrossRef] [PubMed]

148. Huang, C.M.; Chen, L.C.; Cheng, K.W.; Pan, G.T. Effect of nitrogen-plasma surface treatment to the enhancement of $\mathrm{TiO}_{2}$ photocatalytic activity under visible light irradiation. J. Mol. Catal. A Chem. 2007, 261, 218-224. [CrossRef]

149. Chen, C.; Bai, H.; Chang, C. Effect of plasma processing gas composition on the nitrogen-doping status and visible light photocatalysis of $\mathrm{TiO}_{2}$. J. Phys. Chem. C 2007, 111, 15228-15235. [CrossRef] 
150. Napoli, F.; Chiesa, M.; Livraghi, S.; Giamello, E.; Agnoli, S.; Granozzi, G.; Pacchioni, G.; Di Valentin, C. The Nitrogen photoactive centre in $\mathrm{N}$-doped titanium dioxide formed via interaction of $\mathrm{N}$ atoms with the solid. nature and energy level of the species. Chem. Phys. Lett. 2009, 477, 135-138. [CrossRef]

151. Li, G.S.; Yu, J.C.; Zhang, D.Q.; Hu, X.L.; Lau, W.M. A mesoporous $\mathrm{TiO}_{2-x} \mathrm{~N}_{x}$ photocatalyst prepared by sonication pretreatment and in situ pyrolysis. Sep. Purif. Technol. 2009, 67, 152-157. [CrossRef]

152. Liu, G.; Wang, X.; Wang, L.; Chen, Z.; Li, F.; Lu, G.Q.; Cheng, H.M. Drastically enhanced photocatalytic activity in nitrogen doped mesoporous $\mathrm{TiO}_{2}$ with abundant surface states. J. Colloid Interface Sci. 2009, 334, 171-175. [CrossRef]

153. Nassoko, D.; Li, Y.-F.; Wang, H.; Li, J.-L.; Li, Y.-Z.; Yu, Y. Nitrogen-doped $\mathrm{TiO}_{2}$ nanoparticles by using EDTA as nitrogen source and soft template: Simple preparation, mesoporous structure, and photocatalytic activity under visible light. J. Alloys Compd. 2012, 540, 228-235. [CrossRef]

154. Cheng, Y.H.; Subramaniam, V.P.; Gong, D.G.; Tang, Y.X.; Highfield, J.; Pehkonen, S.O.; Pichat, P.; Schreyer, M.K.; Chen, Z. Nitrogen-sensitized dual phase titanate/titania for visible-light driven phenol degradation. J. Solid State Chem. 2012, 196, 518-527. [CrossRef]

155. Qiao, M.; Chen, Q.A.; Wu, S.S.; Shen, J.A. Novel sol-gel synthesis of N-doped $\mathrm{TiO}_{2}$ hollow spheres with high photocatalytic activity under visible light. J. Solgel Sci. Technol. 2010, 55, 377-384. [CrossRef]

156. Fu, J.; Tian, Y.L.; Chang, B.B.; Xi, F.N.; Dong, X.P. Soft-chemical synthesis of mesoporous nitrogen-modified titania with superior photocatalytic performance under visible light irradiation. Chem. Eng. J. 2013, 219, 155-161. [CrossRef]

157. Elghniji, K.; Ksibi, M.; Elaloui, E. Sol-gel reverse micelle preparation and characterization of N-doped $\mathrm{TiO}_{2}$ : Efficient photocatalytic degradation of methylene blue in water under visible light. J. Ind. Eng. Chem. 2012, 18, 178-182. [CrossRef]

158. Zhou, W.; Yu, C.; Fan, Q.; Wei, L.; Chen, J.; Yu, J.C. Ultrasonic fabrication of $\mathrm{N}$-doped $\mathrm{TiO}_{2}$ nanocrystals with mesoporous structure and enhanced visible light photocatalytic activity. Chin. J. Catal. 2013, 34, 1250-1255. [CrossRef]

159. Nolan, N.T.; Synnott, D.W.; Seery, M.K.; Hinder, S.J.; Wassenhoven, A.V.; Pillai, S.C. Effect of N-doping on the photocatalytic activity of sol-gel $\mathrm{TiO}_{2}$. J. Hazard. Mater. 2012, 211-212, 88-94. [CrossRef] [PubMed]

160. Hu, Z.; Xu, L.; Chen, J. Ordered arrays of $\mathrm{N}$-doped mesoporous titania spheres with high visible light photocatalytic activity. Mater. Lett. 2013, 106, 421-424. [CrossRef]

161. Li, X.; Liu, P.W.; Mao, Y.; Xing, M.Y.; Zhang, J.L. Preparation of homogeneous nitrogen-doped mesoporous $\mathrm{TiO}_{2}$ spheres with enhanced visible-Light photocatalysis. Appl. Catal. B 2015, 164, 352-359. [CrossRef]

162. Hou, Y.D.; Wang, X.C.; Wu, L.; Chen, X.F.; Ding, Z.X.; Wang, X.X.; Fu, X.Z. N-doped $\mathrm{SiO}_{2} / \mathrm{TiO}_{2}$ mesoporous nanoparticles with enhanced photocatalytic activity under visible-light irradiation. Chemosphere 2008, 72, 414-421. [CrossRef] [PubMed]

163. Joshi, M.M.; Labhsetwar, N.K.; Mangrulkar, P.A.; Tijare, S.N.; Kamble, S.P.; Rayalu, S.S. Visible light induced photoreduction of methyl orange by N-doped mesoporous titania. Appl. Catal. A 2009, 357, 26-33. [CrossRef]

164. Zuo, F.; Wang, L.; Wu, T.; Zhang, Z.; Borchardt, D.; Feng, P. Self-doped Ti ${ }^{3+}$ enhanced photocatalyst for hydrogen production under visible light. J. Am. Chem. Soc. 2010, 132, 11856-11857. [CrossRef] [PubMed]

165. Zuo, F.; Bozhilov, K.; Dillon, R.J.; Wang, L.; Smith, P.; Zhao, X.; Bardeen, C.; Feng, P. Active facets on titanium(III)-doped $\mathrm{TiO}_{2}$ : An effective strategy to improve the visible-light photocatalytic activity. Angew. Chem. Int. Ed. 2012, 51, 6223-6226. [CrossRef] [PubMed]

166. Sun, H.; Bai, Y.; Jin, W.; Xu, N. Visible-light-driven $\mathrm{TiO}_{2}$ catalysts doped with low-concentration nitrogen species. Sol. Energy Mater. Sol. Cells 2008, 92, 76-83. [CrossRef]

167. Xu, J.; Ao, Y.; Chen, M.; Fu, D. Photoelectrochemical property and photocatalytic activity of N-doped $\mathrm{TiO}_{2}$ nanotube arrays. Appl. Surf. Sci. 2010, 256, 4397-4401. [CrossRef]

168. Ao, Y.; Xu, J.; Fu, D.; Yuan, C. Visible-light responsive C,N-codoped titania hollow spheres for X-3B dye photodegradation. Microporous Mesoporous Mater. 2009, 118, 382-386. [CrossRef]

169. Yang, G.; Jiang, Z.; Shi, H.; Xiao, T.; Yan, Z. Preparation of highly visible-light active N-doped $\mathrm{TiO}_{2}$ photocatalyst. J. Mater. Chem. 2010, 20, 5301-5309. [CrossRef]

170. Su, J.; Zou, X.; Chen, J.S. Self-modification of titanium dioxide materials by $\mathrm{Ti}^{3+}$ and/or oxygen vacancies: New insights into defect chemistry of metal oxides. RSC Adv. 2014, 4, 13979-13988. [CrossRef] 
171. Wang, J.; Zhang, P.; Li, X.; Zhu, J.; Li, H. Synchronical pollutant degradation and $\mathrm{H}_{2}$ production on a $\mathrm{Ti}^{3+}$-doped $\mathrm{TiO}_{2}$ visible photocatalyst with dominant (001) facets. Appl. Catal. B 2013, 134-135, 198-204. [CrossRef]

172. Selvam, K.; Balachandran, S.; Velmurugan, R.; Swaminathan, M. Mesoporous nitrogen doped nano titania-A green photocatalyst for the effective reductive cleavage of azoxybenzenes to amines or 2-phenyl indazoles in methanol. Appl. Catal. A 2012, 413-414, 213-222. [CrossRef]

173. Islam, S.Z.; Reed, A.; Wanninayake, N.; Kim, D.Y.; Rankin, S.E. Remarkable enhancement of photocatalytic water oxidation in $\mathrm{N}_{2}$ / Ar plasma treated, mesoporous $\mathrm{TiO}_{2}$ films. J. Phys. Chem. C 2016, 120, 14069-14081. [CrossRef]

174. Mei, P.; Henderson, M.; Kassiba, A.; Gibaud, A. EPR study of nitrogen-doped mesoporous $\mathrm{TiO}_{2}$ powders. J. Phys. Chem. Solids 2010, 71, 1-6. [CrossRef]

175. Soni, S.S.; Dave, G.S.; Henderson, M.J.; Gibaud, A. Visible light induced cell damage of Gram positive bacteria by $\mathrm{N}$-doped $\mathrm{TiO}_{2}$ mesoporous thin films. Thin Solid Films 2013, 531, 559-565. [CrossRef]

176. Yao, N.; Wu, C.; Jia, L.; Han, S.; Chi, B.; Pu, J.; Jian, L. Simple synthesis and characterization of mesoporous (N, S)-codoped $\mathrm{TiO}_{2}$ with enhanced visible-light photocatalytic activity. Ceram. Int. 2012, 38, 1671-1675. [CrossRef]

177. Xiao, Q.; Ouyang, L.; Gao, L.; Yao, C. Preparation and visible light photocatalytic activity of mesoporous N, S-codoped $\mathrm{TiO}_{2}$ (B) nanobelts. Appl. Surf. Sci. 2011, 257, 3652-3656. [CrossRef]

178. Ao, Y.; Xu, J.; Fu, D.; Yuan, C. Synthesis of C,N,S-tridoped mesoporous titania with enhanced visible light-induced photocatalytic activity. Microporous Mesoporous Mater. 2009, 122, 1-6. [CrossRef]

179. Wang, J.; Li, H.; Li, H.; Zou, C. Mesoporous $\mathrm{TiO}_{2-x} \mathrm{~A}_{y}(\mathrm{~A}=\mathrm{N}, \mathrm{S})$ as a visible-light-response photocatalyst. Solid State Sci. 2010, 12, 490-497. [CrossRef]

180. Zalas, M. Synthesis of N-doped template-free mesoporous titania for visible light photocatalytic applications. Catal. Today 2014, 230, 91-96. [CrossRef]

181. Liu, S.H.; Syu, H.R. One-step fabrication of $\mathrm{N}$-doped mesoporous $\mathrm{TiO}_{2}$ nanoparticles by self-assembly for photocatalytic water splitting under visible light. Appl. Energy 2012, 100, 148-154. [CrossRef]

182. Gandhe, A.R.; Naik, S.P.; Fernandes, J.B. Selective synthesis of N-doped mesoporous $\mathrm{TiO}_{2}$ phases having enhanced photocatalytic activity. Microporous Mesoporous Mater. 2005, 87, 103-109. [CrossRef]

183. Chi, B.; Zhao, L.; Jin, T. One-step template-free route for synthesis of mesoporous N-doped titania spheres. J. Phys. Chem. C 2007, 111, 6189-6193. [CrossRef]

184. Horikawa, T.; Katoh, M.; Tomida, T. Preparation and characterization of nitrogen-doped mesoporous titania with high specific surface area. Microporous Mesoporous Mater. 2008, 110, 397-404. [CrossRef]

185. Shao, G.S.; Zhang, X.J.; Yuan, Z.Y. Preparation and photocatalytic activity of hierarchically mesoporous-macroporous $\mathrm{TiO}_{2-x} \mathrm{~N}_{x}$. Appl. Catal. B 2008, 82, 208-218. [CrossRef]

186. Parida, K.M.; Naik, B. Synthesis of mesoporous $\mathrm{TiO}_{2-x} \mathrm{~N}_{x}$ spheres by template free homogeneous co-precipitation method and their photo-catalytic activity under visible light illumination. J. Colloid Interface Sci. 2009, 333, 269-276. [CrossRef] [PubMed]

187. Wu, Y.M.; Xing, M.Y.; Tian, B.Z.; Zhang, J.L.; Chen, F. Preparation of nitrogen and fluorine co-doped mesoporous $\mathrm{TiO}_{2}$ microsphere and photodegradation of acid orange 7 under visible light. Chem. Eng. J. 2010, 162, 710-717. [CrossRef]

188. Liu, E.; Guo, X.; Qin, L.; Shen, G.; Wang, X. Fabrication and photocatalytic activity of highly crystalline nitrogen doped mesoporous $\mathrm{TiO}_{2}$. Chin. J. Catal. 2012, 33, 1665-1671. [CrossRef]

189. Jia, T.; Fu, F.; Zhao, J.; Chen, J.; Wang, X.; Fan, Z.; Cui, L.; Meng, F. Sonochemical synthesis, characterization, and photocatalytic activity of $\mathrm{N}$-doped $\mathrm{TiO}_{2}$ nanocrystals with mesoporous structure. Int. J. Photoenergy 2014, 2014, 516806.

190. Sreethawong, T.; Laehsalee, S.; Chavadej, S. Comparative investigation of mesoporous- and non-mesoporousassembled $\mathrm{TiO}_{2}$ nanocrystals for photocatalytic $\mathrm{H}_{2}$ production over $\mathrm{N}$-doped $\mathrm{TiO}_{2}$ under visible light irradiation. Int. J. Hydrogen Energy 2008, 33, 5947-5957. [CrossRef]

191. Sreethawong, T.; Laehsalee, S.; Chavadej, S. Use of Pt/N-doped mesoporous-assembled nanocrystalline $\mathrm{TiO}_{2}$ for photocatalytic $\mathrm{H}_{2}$ production under visible light irradiation. Catal. Commun. 2009, 10, 538-543. [CrossRef]

192. Lu, X.H.; Wang, G.M.; Zhai, T.; Yu, M.H.; Gan, J.Y.; Tong, Y.X.; Li, Y. Hydrogenated $\mathrm{TiO}_{2}$ nanotube arrays for supercapacitors. Nano Lett. 2012, 12, 1690-1696. [CrossRef] [PubMed] 
193. Naldoni, A.; Allieta, M.; Santangelo, S.; Marelli, M.; Fabbri, F.; Cappelli, S.; Bianchi, C.L.; Psaro, R.; Dal Santo, V. Effect of nature and location of defects on bandgap narrowing in black $\mathrm{TiO}_{2}$ nanoparticles. J. Am. Chem. Soc. 2012, 134, 7600-7603. [CrossRef] [PubMed]

194. $\mathrm{Hu}, \mathrm{Y} . \mathrm{H}$. A highly efficient photocatalyst-Hydrogenated black $\mathrm{TiO}_{2}$ for the photocatalytic splitting of water. Angew. Chem. Int. Ed. 2012, 51, 12410-12412. [CrossRef] [PubMed]

195. Wang, Z.; Yang, C.Y.; Lin, T.Q.; Yin, H.; Chen, P.; Wan, D.Y.; Xu, F.F.; Huang, F.Q.; Lin, J.H.; Xie, X.M.; et al. $\mathrm{H}$-doped black titania with very high solar absorption and excellent photocatalysis enhanced by localized surface plasmon resonance. Adv. Funct. Mater. 2013, 23, 5444-5450. [CrossRef]

196. Yang, C.; Wang, Z.; Lin, T.; Yin, H.; Lu, X.; Wan, D.; Xu, T.; Zheng, C.; Lin, J.; Huang, F.; et al. Core-shell nanostructured "black" rutile titania as excellent catalyst for hydrogen production enhanced by sulfur doping. J. Am. Chem. Soc. 2013, 135, 17831-17838. [CrossRef] [PubMed]

197. Zhou, H.; Zhong, Y.; He, Z.; Zhang, L.; Wang, J.; Zhang, J.; Cao, C.-N. Three-dimensional nanoporous $\mathrm{TiO}_{2}$ network films with excellent electrochemical capacitance performance. J. Alloys Compd. 2014, 597, 1-7. [CrossRef]

198. Shahid, M.; Choi, S.-Y.; Liu, J.; Kwon, Y.-U. Reduced titania films with ordered nanopores and their application to visible light water splitting. Bull. Korean Chem. Soc. 2013, 34, 2271-2275. [CrossRef]

199. Lin, X.; Rong, F.; Ji, X.; Fu, D. Carbon-doped mesoporous $\mathrm{TiO}_{2}$ film and its photocatalytic activity. Microporous Mesoporous Mater. 2011, 142, 276-281. [CrossRef]

200. Chang, P.-Y.; Huang, C.-H.; Doong, R.-A. Ordered mesoporous carbon- $\mathrm{TiO}_{2}$ materials for improved electrochemical performance of lithium ion battery. Carbon 2012, 50, 4259-4268. [CrossRef]

201. Wang, T.; He, J.; Zhou, J.; Tang, J.; Guo, Y.; Ding, X.; Wu, S.; Zhao, J. Microwave absorption properties and infrared emissivities of ordered mesoporous $\mathrm{C}-\mathrm{TiO}_{2}$ nanocomposites with crystalline framework. J. Solid State Chem. 2010, 183, 2797-2804. [CrossRef]

202. Ren, W.; Ai, Z.; Jia, F.; Zhang, L.; Fan, X.; Zou, Z. Low temperature preparation and visible light photocatalytic activity of mesoporous carbon-doped crystalline $\mathrm{TiO}_{2}$. Appl. Catal. B 2007, 69, 138-144. [CrossRef]

203. Lin, X.X.; Fu, D.G. Synthesis of nitrogen-doped mesoporous $\mathrm{TiO}_{2}$ film and its visible light photocatalytic activity. In Sustainable Development of Urban Environment and Building Material, Pts 1-4; Li, H., Liu, Y.F., Guo, M., Zhang, R., Du, J., Eds.; Trans Tech Publications Ltd.: Zurich, Switzerland, 2012; Volume 374-377, pp. 895-898.

204. Huang, Y.; Ho, W.; Lee, S.; Zhang, L.; Li, G.; Yu, J.C. Effect of carbon doping on the mesoporous structure of nanocrystalline titanium dioxide and its solar-light-driven photocatalytic degradation of $\mathrm{NO}_{x}$. Langmuir 2008, 24, 3510-3516. [CrossRef] [PubMed]

205. Yu, C.; Yu, J.C.; Chan, M. Sonochemical fabrication of fluorinated mesoporous titanium dioxide microspheres. J. Solid State Chem. 2009, 182, 1061-1069. [CrossRef]

206. Pan, J.H.; Zhang, X.; Du, A.J.; Sun, D.D.; Leckie, J.O. Self-etching reconstruction of hierarchically mesoporous $\mathrm{F}_{-} \mathrm{TiO}_{2}$ hollow microspherical photocatalyst for concurrent membrane water Purifications. J. Am. Chem. Soc. 2008, 130, 11256-11257. [CrossRef] [PubMed]

207. Yu, J.C.; Ho, W.K.; Yu, J.G.; Hark, S.K.; Iu, K. Effects of trifluoroacetic acid modification on the surface microstructures and photocatalytic activity of mesoporous $\mathrm{TiO}_{2}$ thin films. Langmuir 2003, 19, 3889-3896. [CrossRef]

208. Yu, J.; Wang, W.; Cheng, B.; Su, B.-L. Enhancement of photocatalytic activity of mesporous $\mathrm{TiO}_{2}$ powders by hydrothermal surface fluorination treatment. J. Phys. Chem. C 2009, 113, 6743-6750. [CrossRef]

209. Yu, J.C.; Yu, J.; Ho, W.; Jiang, Z.; Zhang, L. Effects of F-doping on the photocatalytic activity and microstructures of nanocrystalline $\mathrm{TiO}_{2}$ powders. Chem. Mater. 2002, 14, 3808-3816. [CrossRef]

210. Park, H.; Choi, W. Effects of $\mathrm{TiO}_{2}$ surface fluorination on photocatalytic reactions and photoelectrochemical behaviors. J. Phys. Chem. B 2004, 108, 4086-4093. [CrossRef]

211. Shi, Q.; Jiang, C.; Wang, Y.; Yang, W.; Yang, C. Preparation and characterization of PVA-I complex doped mesoporous $\mathrm{TiO}_{2}$ by hydrothermal method. Appl. Surf. Sci. 2013, 273, 769-775. [CrossRef]

212. Liu, G.; Chen, Z.G.; Dong, C.L.; Zhao, Y.N.; Li, F.; Lu, G.Q.; Cheng, H.M. Visible light photocatalyst: Iodine-doped mesoporous titania with a bicrystalline framework. J. Phys. Chem. B 2006, 110, 20823-20828.

[CrossRef] [PubMed] 
213. Guo, S.Y.; Han, S.; Mao, H.F.; Zeng, C.H.; Sun, Y.; Chi, B.; Pu, J.; Li, J. Synthesis of phosphorus-doped titania with mesoporous structure and excellent photocatalytic activity. Mater. Res. Bull. 2013, 48, 3032-3036. [CrossRef]

214. Yu, J.C.; Zhang, L.; Zheng, Z.; Zhao, J. Synthesis and characterization of phosphated mesoporous titanium dioxide with high photocatalytic activity. Chem. Mater. 2003, 15, 2280-2286. [CrossRef]

215. Fan, X.; Yu, T.; Wang, Y.; Zheng, J.; Gao, L.; Li, Z.; Ye, J.; Zou, Z. Role of phosphorus in synthesis of phosphated mesoporous $\mathrm{TiO}_{2}$ photocatalytic materials by EISA method. Appl. Surf. Sci. 2008, 254, 5191-5198. [CrossRef]

216. Feng, H.J.; Zhang, M.H.; Yu, L.E. Phosphorus-Doped $\mathrm{TiO}_{2}$ Catalysts with Stable Anatase-Brookite Biphase Structure: Synthesis and Photocatalytic Performance. J. Nanosci. Nanotechnol. 2013, 13, 4981-4989. [CrossRef] [PubMed]

217. Yu, C.L.; Yu, J.C.; Zhou, W.Q.; Yang, $\mathrm{K} . \mathrm{WO}_{3}$ coupled $\mathrm{P}-\mathrm{TiO}_{2}$ photocatalysts with mesoporous structure. Catal. Lett. 2010, 140, 172-183. [CrossRef]

218. Zhang, K.; Wang, X.D.; He, T.N.; Guo, X.L.; Feng, Y.N. Preparation and photocatalytic activity of B-N co-doped mesoporous $\mathrm{TiO}_{2}$. Powder Technol. 2014, 253, 608-613. [CrossRef]

219. He, T.N.; Guo, X.L.; Zhang, K.; Feng, Y.M.; Wang, X.D. Synthesis and characterization of B-N co-doped mesoporous $\mathrm{TiO}_{2}$ with enhanced photocatalytic activity. Rsc Adv. 2014, 4, 5880-5886. [CrossRef]

220. Lee, J.H.; Youn, I.; Kim, Y.J.; Kim, I.K.; Jang, K.W.; Oh, H.J. Photocatalytic characteristics of boron and nitrogen doped titania film synthesized by micro-arc oxidation. Ceram. Int. 2015, 41, 11899-11907. [CrossRef]

221. Zhou, X.; Peng, F.; Wang, H.; Yu, H.; Yang, J. Effect of nitrogen-doping temperature on the structure and photocatalytic activity of the B,N-doped $\mathrm{TiO}_{2}$. J. Solid State Chem. 2011, 184, 134-140. [CrossRef]

222. Abdollahi Kakroudi, M.; Kazemi, F.; Kaboudin, B. Highly efficient photodeoximation under green and blue LEDs catalyzed by mesoporous $\mathrm{CN}$ codoped nano $\mathrm{TiO}_{2}$. J. Mol. Catal. A Chem. 2014, 392, 112-119. [CrossRef]

223. Pan, L.; Zou, J.-J.; Wang, S.; Huang, Z.-F.; Zhang, X.; Wang, L. Enhancement of visible-light-induced photodegradation over hierarchical porous $\mathrm{TiO}_{2}$ by nonmetal doping and water-mediated dye sensitization. Appl. Surf. Sci. 2013, 268, 252-258. [CrossRef]

224. Xu, J.; Yang, B.; Wu, M.; Fu, Z.; Lv, Y.; Zhao, Y. Novel N-F-codoped $\mathrm{TiO}_{2}$ inverse opal with a hierarchical meso-/macroporous structure: Synthesis, characterization, and photocatalysis. J. Phys. Chem. C 2010, 114, 15251-15259. [CrossRef]

225. Li, Y.; Jia, L.; Wu, C.; Han, S.; Gong, Y.; Chi, B.; Pu, J.; Jian, L. Mesoporous (N,S)-codoped TiO 2 nanoparticles as effective photoanode for dye-sensitized solar cells. J. Alloys Compd. 2012, 512, 23-26. [CrossRef]

226. Li, H.; Wang, J.; Li, H.; Yin, S.; Sato, T. Photocatalytic activity of (sulfur, nitrogen)-codoped mesoporous $\mathrm{TiO}_{2}$ thin films. Res. Chem. Intermed. 2010, 36, 27-37. [CrossRef]

227. Yu, C.; Cai, D.; Yang, K.; Yu, J.C.; Zhou, Y.; Fan, C. Sol-gel derived S,I-codoped mesoporous $\mathrm{TiO}_{2}$ photocatalyst with high visible-light photocatalytic activity. J. Phys. Chem. Solids 2010, 71, 1337-1343. [CrossRef]

228. Islam, S.Z.; Deshmane, V.G.; Ilias, S. Thermal stability study of Pd-composite membrane fabricated by surfactant induced electroless plating (SIEP). Sep. Sci. Technol. 2016, 51, 1176-1188. [CrossRef]

229. Hartmann, P.; Lee, D.-K.; Smarsly, B.M.; Janek, J. Mesoporous $\mathrm{TiO}_{2}$ : Comparison of classical sol-gel and nanoparticle based photoelectrodes for the water splitting reaction. ACS Nano 2010, 4, 3147-3154. [CrossRef] [PubMed]

230. Fang, J.; Shi, F.; Bu, J.; Ding, J.; Xu, S.; Bao, J.; Ma, Y.; Jiang, Z.; Zhang, W.; Gao, C.; et al. One-step synthesis of bifunctional $\mathrm{TiO}_{2}$ catalysts and their photocatalytic activity. J. Phys. Chem. C 2010, 114, 7940-7948. [CrossRef]

231. Atabaev, T.S.; Hossain, M.A.; Lee, D.; Kim, H.-K.; Hwang, Y.-H. Pt-coated $\mathrm{TiO}_{2}$ nanorods for photoelectrochemical water splitting applications. Results Phys. 2016, 6, 373-376. [CrossRef]

232. Kondratenko, E.V.; Mul, G.; Baltrusaitis, J.; Larrazábal, G.O.; Pérez-Ramírez, J. Status and perspectives of $\mathrm{CO}_{2}$ conversion into fuels and chemicals by catalytic, photocatalytic and electrocatalytic processes. Energy Environ. Sci. 2013, 6, 3112. [CrossRef]

233. Dhakshinamoorthy, A.; Navalon, S.; Corma, A.; Garcia, H. Photocatalytic $\mathrm{CO}_{2}$ reduction by $\mathrm{TiO}_{2}$ and related titanium containing solids. Energy Environ. Sci. 2012, 5, 9217-9233. [CrossRef]

234. Inoue, T.; Fujishima, A.; Konishi, S.; Honda, K. Photoelectrocatalytic reduction of carbon-dioxide in aqueous suspensions of semiconductor powders. Nature 1979, 277, 637-638. [CrossRef] 
235. Gao, M.Y.; Jiang, D.; Sun, D.K.; Hou, B.; Li, D.B. Synthesis of Ag/N-TiO $2 / \mathrm{SBA}-15$ photocatalysts and photocatalytic reduction of $\mathrm{CO}_{2}$ under visible light irradiation. Acta Chim. Sin. 2014, 72, 1092-1098. [CrossRef]

236. Kim, S.; Hwang, S.-J.; Choi, W. Visible light active platinum-ion-doped $\mathrm{TiO}_{2}$ photocatalyst. J. Phys. Chem. $B$ 2005, 109, 24260-24267. [CrossRef] [PubMed]

237. You, X.; Chen, F.; Zhang, J.; Anpo, M. A novel deposition precipitation method for preparation of Ag-loaded titanium dioxide. Catal. Lett. 2005, 102, 247-250. [CrossRef]

238. Tian, B.; Zhang, J.; Tong, T.; Chen, F. Preparation of $\mathrm{Au} / \mathrm{TiO}_{2}$ catalysts from $\mathrm{Au}(\mathrm{I})$-thiosulfate complex and study of their photocatalytic activity for the degradation of methyl orange. Appl. Catal. B 2008, 79, 394-401. [CrossRef] article distributed under the terms and conditions of the Creative Commons Attribution (CC BY) license (http:/ / creativecommons.org/licenses/by/4.0/). 